Cochrane Database of Systematic Reviews

\title{
Venous cutdown versus the Seldinger technique for placement of totally implantable venous access ports (Review)
}

Hsu CCT, Kwan GNC, Evans-Barns H, Rophael JA, van Driel ML

Hsu CCT, Kwan GNC, Evans-Barns H, Rophael JA, van Driel ML.

Venous cutdown versus the Seldinger technique for placement of totally implantable venous access ports.

Cochrane Database of Systematic Reviews 2016, Issue 8. Art. No.: CD008942.

DOI: 10.1002/14651858.CD008942.pub2.

www.cochranelibrary.com 
TABLE OF CONTENTS

HEADER

ABSTRACT

PLAIN LANGUAGE SUMMARY

SUMMARY OF FINDINGS

2

BACKGROUND

OBJECTIVES

METHODS

RESULTS

Figure 1.

Figure 2.

Figure 3.

DISCUSSION

AUTHORS' CONCLUSIONS

ACKNOWLEDGEMENTS

REFERENCES

CHARACTERISTICS OF STUDIES

DATA AND ANALYSES

Analysis 1.1. Comparison 1 Success of primary implantation, Outcome 1 Seldinger (subclavian \& IJ) versus venous cutdown (cephalic vein) ITT.

Analysis 1.2. Comparison 1 Success of primary implantation, Outcome 2 Seldinger (subclavian vein) versus venous cutdown (cephalic vein) ITT.

Analysis 1.3. Comparison 1 Success of primary implantation, Outcome 3 Seldinger (IJ vein) versus venous cutdown (cephalic vein) ITT.

Analysis 1.4. Comparison 1 Success of primary implantation, Outcome 4 Seldinger (subclavian \& IJ) versus venous cutdown (cephalic vein). On-treatment analysis.

Analysis 1.5. Comparison 1 Success of primary implantation, Outcome 5 Seldinger (subclavian vein) versus venous cutdown (cephalic vein). On-treatment analysis.

Analysis 1.6. Comparison 1 Success of primary implantation, Outcome 6 Seldinger (IJ vein) versus venous cutdown (cephalic vein). On-treatment analysis.

Analysis 2.1. Comparison 2 Overall perioperative and postoperative complications, Outcome 1 Seldinger (subclavian \& IJ) versus venous cutdown (cephalic vein) ITT.

Analysis 2.2. Comparison 2 Overall perioperative and postoperative complications, Outcome 2 Seldinger (subclavian vein) versus venous cutdown (cephalic vein) ITT.

Analysis 2.3. Comparison 2 Overall perioperative and postoperative complications, Outcome 3 Seldinger (IJ vein) versus venous cutdown (cephalic vein) ITT.

Analysis 2.4. Comparison 2 Overall perioperative and postoperative complications, Outcome 4 Seldinger (subclavian \& IJ) versus venous cutdown (cephalic vein). On-treatment analysis.

Analysis 2.5. Comparison 2 Overall perioperative and postoperative complications, Outcome 5 Seldinger (subclavian vein) versus venous cutdown (cephalic vein). On-treatment analysis.

Analysis 2.6. Comparison 2 Overall perioperative and postoperative complications, Outcome 6 Seldinger (IJ vein) versus venous cutdown (cephalic vein). On-treatment analysis.

Analysis 3.1. Comparison 3 Pneumothorax, Outcome 1 Seldinger (subclavian \& IJ) versus venous cutdown (cephalic vein) ITT. Analysis 3.2. Comparison 3 Pneumothorax, Outcome 2 Seldinger (subclavian vein) versus venous cutdown (cephalic vein) ITT. Analysis 3.3. Comparison 3 Pneumothorax, Outcome 3 Seldinger (IJ vein) versus venous cutdown (cephalic vein) ITT. ............ Analysis 3.4. Comparison 3 Pneumothorax, Outcome 4 Seldinger (subclavian \& IJ) versus venous cutdown (cephalic vein). Ontreatment analysis.

Analysis 3.5. Comparison 3 Pneumothorax, Outcome 5 Seldinger (subclavian vein) versus venous cutdown (cephalic vein). Ontreatment analysis.

Analysis 3.6. Comparison 3 Pneumothorax, Outcome 6 Seldinger (IJ vein) versus venous cutdown (cephalic vein). On-treatment analysis.

Analysis 4.1. Comparison 4 Infections, Outcome 1 Seldinger (subclavian \& IJ) versus venous cutdown (cephalic vein) ITT. ...... Analysis 4.2. Comparison 4 Infections, Outcome 2 Seldinger (subclavian vein) versus venous cutdown (cephalic vein) ITT. ...... Analysis 4.3. Comparison 4 Infections, Outcome 3 Seldinger (IJ vein) versus venous cutdown (cephalic vein) ITT. 
Analysis 4.4. Comparison 4 Infections, Outcome 4 Seldinger (subclavian \& IJ) versus venous cutdown (cephalic vein). Ontreatment analysis.

Analysis 4.5. Comparison 4 Infections, Outcome 5 Seldinger (subclavian vein) versus venous cutdown (cephalic vein). Ontreatment analysis.

Analysis 4.6. Comparison 4 Infections, Outcome 6 Seldinger (IJ vein) versus venous cutdown (cephalic vein). On-treatment analysis.

Analysis 5.1. Comparison 5 Catheter/port-related complications, Outcome 1 Seldinger (subclavian \& IJ) versus venous cutdown (cephalic vein) ITT.

Analysis 5.2. Comparison 5 Catheter/port-related complications, Outcome 2 Seldinger (subclavian vein) versus venous cutdown (cephalic vein) ITT.

Analysis 5.3. Comparison 5 Catheter/port-related complications, Outcome 3 Seldinger (IJ vein) versus venous cutdown (cephalic vein) ITT.

Analysis 5.4. Comparison 5 Catheter/port-related complications, Outcome 4 Seldinger (subclavian \& IJ) versus venous cutdown (cephalic vein). On-treatment analysis.

Analysis 5.5. Comparison 5 Catheter/port-related complications, Outcome 5 Seldinger (subclavian vein) versus venous cutdown (cephalic vein). On-treatment analysis.

Analysis 5.6. Comparison 5 Catheter/port-related complications, Outcome 6 Seldinger (IJ vein) versus venous cutdown (cephalic vein). On-treatment analysis.

Analysis 6.1. Comparison 6 Other complications, Outcome 1 Seldinger (subclavian \& IJ) versus venous cutdown (cephalic vein) ITT.

Analysis 6.2. Comparison 6 Other complications, Outcome 2 Seldinger (subclavian vein) versus venous cutdown (cephalic vein) ITT.

Analysis 6.3. Comparison 6 Other complications, Outcome 3 Seldinger (IJ vein) versus venous cutdown (cephalic vein) ITT. ..... Analysis 6.4. Comparison 6 Other complications, Outcome 4 Seldinger (subclavian \& IJ) versus venous cutdown (cephalic vein). On-treatment analysis.

Analysis 6.5. Comparison 6 Other complications, Outcome 5 Seldinger (subclavian vein) versus venous cutdown (cephalic vein). On-treatment analysis.

Analysis 6.6. Comparison 6 Other complications, Outcome 6 Seldinger (IJ vein) versus venous cutdown (cephalic vein). Ontreatment analysis.

APPENDICES

CONTRIBUTIONS OF AUTHORS

DECLARATIONS OF INTEREST 
[Intervention Review]

\title{
Venous cutdown versus the Seldinger technique for placement of totally implantable venous access ports
}

\author{
Charlie C-T Hsu로 Gigi NC Kwan¹, Hannah Evans-Barns², John A Rophael ${ }^{3}$, Mieke L van Driel ${ }^{4}$
}

1Department of Medical Imaging, Princess Alexandra Hospital, Brisbane, Australia. 2Faculty of Medicine, Dentistry and Health Sciences, University of Melbourne, Melbourne, Australia. ${ }^{3}$ Department of Surgery - St Vincent's Hospital, University of Melbourne, Fitzroy, Australia.

${ }^{4}$ Discipline of General Practice, School of Medicine, The University of Queensland, Brisbane, Australia

Contact address: Charlie C-T Hsu, Department of Medical Imaging, Princess Alexandra Hospital, 199 Ipswich Road, Brisbane, Queensland, 4102, Australia. charlie.ct.hsu@gmail.com.

Editorial group: Cochrane Vascular Group.

Publication status and date: New, published in Issue 8, 2016.

Citation: Hsu CCT, Kwan GNC, Evans-Barns H, Rophael JA, van Driel ML. Venous cutdown versus the Seldinger technique for placement of totally implantable venous access ports. Cochrane Database of Systematic Reviews 2016, Issue 8. Art. No.: CD008942. DOI: 10.1002/14651858.CD008942.pub2.

Copyright ( 2016 The Cochrane Collaboration. Published by John Wiley \& Sons, Ltd.

\section{A B S T R A C T}

\section{Background}

Totally implantable venous access ports (TIVAPs) provide patients with a safe and permanent venous access, for instance in the administration of chemotherapy for oncology patients. There are several methods for TIVAP placement, and the optimal evidence-based method is unclear.

\section{Objectives}

To compare the efficacy and safety of three commonly used techniques for implanting TIVAPs: the venous cutdown technique, the Seldinger technique, and the modified Seldinger technique. This review includes studies that use Doppler or real-time two-dimensional ultrasonography for locating the vein in the Seldinger technique.

\section{Search methods}

The Cochrane Vascular Trials Search Co-ordinator searched the Cochrane Vascular Specialised Register (last searched August 2015) and the Cochrane Central Register of Controlled Trials (CENTRAL) (2015, Issue 7), as well as clinical trials registers.

\section{Selection criteria}

We included randomised or quasi-randomised controlled clinical trials that randomly allocated people requiring TIVAP to the venous cutdown, Seldinger, or modified Seldinger technique. Two review authors independently assessed studies for inclusion eligibility, with a third review author checking excluded studies.

\section{Data collection and analysis}

Two review authors independently extracted data. We assessed all studies for risk of bias. We assessed heterogeneity using Chi2 statistic and variance (12statistic) methods. Dichotomous outcomes, summarised as odds ratio (OR) with 95\% confidence interval (Cl), were: primary implantation success, complications (in particular infection), pneumothorax, and catheter complications. We conducted separate analyses to assess the two access veins, subclavian and internal jugular (IJ) vein, in the Seldinger technique versus the venous cutdown technique. We used both intention-to-treat (ITT) and on-treatment analyses and pooled data using a fixed-effect model. 


\section{Main results}

We included nine studies with a total of 1253 participants in the review. Five studies compared Seldinger technique (subclavian vein access) with venous cutdown technique (cephalic vein access). Two studies compared Seldinger (IJ vein) versus venous cutdown (cephalic vein). One study compared the modified Seldinger technique (cephalic vein) with the venous cutdown (cephalic vein), and one study compared the Seldinger (subclavian vein) versus the Seldinger (IJ vein) technique.

Seldinger technique (subclavian or IJ vein access) versus venous cutdown (cephalic vein): We included seven trials with 1006 participants for analysis. Both ITT (OR 0.40; $95 \% \mathrm{Cl} 0.25$ to 0.65 ) and on-treatment analysis (OR $0.59 ; 95 \% \mathrm{Cl} 0.36$ to 0.98 ) showed that the Seldinger technique for implantation of TIVAP had a higher success rate compared with the venous cutdown technique. We found no difference between overall peri- and postoperative complication rates: ITT (OR 1.16; 95\% Cl 0.76 to 1.75 ) and on-treatment analysis (OR 0.93 ; $95 \% \mathrm{Cl}$ 0.62 to 1.40 ). In the Seldinger group, the majority of the trials reported use of the subclavian vein for venous access, with only a limited number of trials utilising the IJ vein for access. When individual complication rates of infection, pneumothorax, and catheter complications were analysed, the Seldinger technique (subclavian vein access) was associated with a higher rate of catheter complications compared to the venous cutdown technique: ITT (OR 6.77; 95\% $\mathrm{Cl} 2.31$ to 19.79) and on-treatment analysis (OR 6.62; $95 \% \mathrm{Cl} 2.24$ to 19.58 ). There was no difference in incidence of infections, pneumothorax, and other complications between the groups.

Modified Seldinger technique (cephalic vein) versus venous cutdown (cephalic vein): We identified one trial with 164 participants. ITT analysis showed no difference in primary implantation success rate between the modified Seldinger technique (69/82, 84\%) and the venous cutdown technique $(66 / 82,80 \%), P=0.686$. We observed no differences in the peri- or postoperative complication rates.

Seldinger (subclavian vein access) versus Seldinger (IJ vein access): We identified one trial with 83 participants. The primary success rate was $84 \%$ (37/44) for Seldinger (subclavian vein) versus 74\% (29/39) for the Seldinger (IJ vein). There was a higher overall complication rate in the subclavian group (48\%) compared to the jugular group (23\%), $\mathrm{P}=0.02$. However, when specific complications were compared individually, we found no differences between the groups.

The overall quality of the trials included in this review was moderate. The methods used for randomisation were inadequate in four of the nine included studies, but sensitivity analysis excluding these trials did not alter the outcome. The nature of the interventions, either venous cutdown or Seldinger techniques, meant that it was not feasible to blind the participant or personnel, therefore we judged this to be at low risk of bias. The majority of participants in the included trials were oncology patients at tertiary centres, and the outcomes were applicable to the typical clinical scenario. For all outcomes, when comparing venous cutdown and Seldinger technique, serious imprecision was evident by wide confidence intervals in the included trials. The quality of the overall evidence was therefore downgraded from high to moderate. Due to the limited number of included studies we were unable to assess publication bias.

\section{Authors' conclusions}

Moderate-quality evidence showed that the Seldinger technique has a higher primary implantation success rate compared with the venous cutdown technique. The majority of trials using the Seldinger technique used the subclavian vein for venous access, and only a few trials reported the use of the internal jugular vein for venous access. Moderate-quality evidence showed no difference in the overall complication rate between the Seldinger and venous cutdown techniques. However, when the Seldinger technique with subclavian vein access was compared with the venous cutdown group, there was a higher reported incidence of catheter complications. The rates of pneumothorax and infection did not differ between the Seldinger and venous cutdown group. We identified only one trial for each of the comparisons modified Seldinger technique (cephalic vein) versus venous cutdown (cephalic vein) and Seldinger (subclavian vein access) versus Seldinger (IJ vein access), thus a definitive conclusion cannot be drawn for these comparisons and further research is recommended.

\section{PLAIN LANGUAGE SUMMARY}

\section{Venous cutdown versus the Seldinger technique for placement of totally implantable venous access ports}

\section{Background}

Totally implantable venous access ports (TIVAPs) provide patients with a safe and permanent access to a vein. They are often used in patients who need continuous administration of intravenous drugs, such as those receiving chemotherapy. TIVAPs are also used when regular intravenous medications, transfusion of blood products, or parenteral nutrition needs to be given, or if regular periodic blood sampling is required. There are two methods for the insertion or implantation of a TIVAP: the surgical venous cutdown technique is an open surgical procedure where the cephalic vein is opened and accessed, and the Seldinger technique uses a percutaneous access (through the skin without having to surgically prepare the vein) of either the subclavian or the internal jugular (IJ) vein. We examined the available evidence from randomised controlled trials for the effectiveness and safety of different TIVAP techniques, comparing them in terms of success rate and complications.

\section{Study characteristics and key results}

We included nine studies with a total of 1253 participants in the review (current until August 2015). Five studies compared the Seldinger technique (subclavian vein) with the venous cutdown technique (cephalic vein). Two studies compared the Seldinger (IJ vein) versus the venous cutdown (cephalic vein) technique. One study compared a modified Seldinger (cephalic vein) with the venous cutdown (cephalic 
vein) technique, and one study compared the Seldinger (subclavian vein) with the Seldinger (IJ vein) technique. The Seldinger technique had a higher success rate than the venous cutdown technique. For the Seldinger technique, the majority of trials used the subclavian vein for venous access, with only two trials reporting use of the IJ vein. In those trials using the Seldinger technique with subclavian access, more participants experienced catheter complications than those who had been exposed to the venous cutdown technique. However, there was no difference in overall complication rates between the Seldinger and venous cutdown techniques. Comparisons between a modified Seldinger technique (using the cephalic vein) and the venous cutdown technique (also using the cephalic vein) and between the Seldinger (subclavian vein access) and Seldinger (IJ vein access) techniques were limited by small sample sizes, therefore a definitive conclusion cannot be drawn for these comparisons and further studies are recommended.

\section{Quality of the evidence}

The overall quality of the included trials was moderate. The methods used for randomisation were inadequate in four of the nine included studies, but an analysis excluding these trials did not alter the outcome. The nature of the interventions, either venous cutdown or Seldinger techniques, meant that it was not feasible to blind the participant or personnel, therefore we judged this to be at low risk of bias. The great majority of participants in the included trials were cancer patients at tertiary centres, and the outcomes were applicable to the typical clinical scenario. For all outcomes, when comparing venous cutdown and Seldinger technique, serious imprecision was evident by wide confidence intervals in the included trials. The quality of the overall evidence was therefore downgraded from high to moderate. Due to the limited number of included studies we were unable to assess publication bias. 


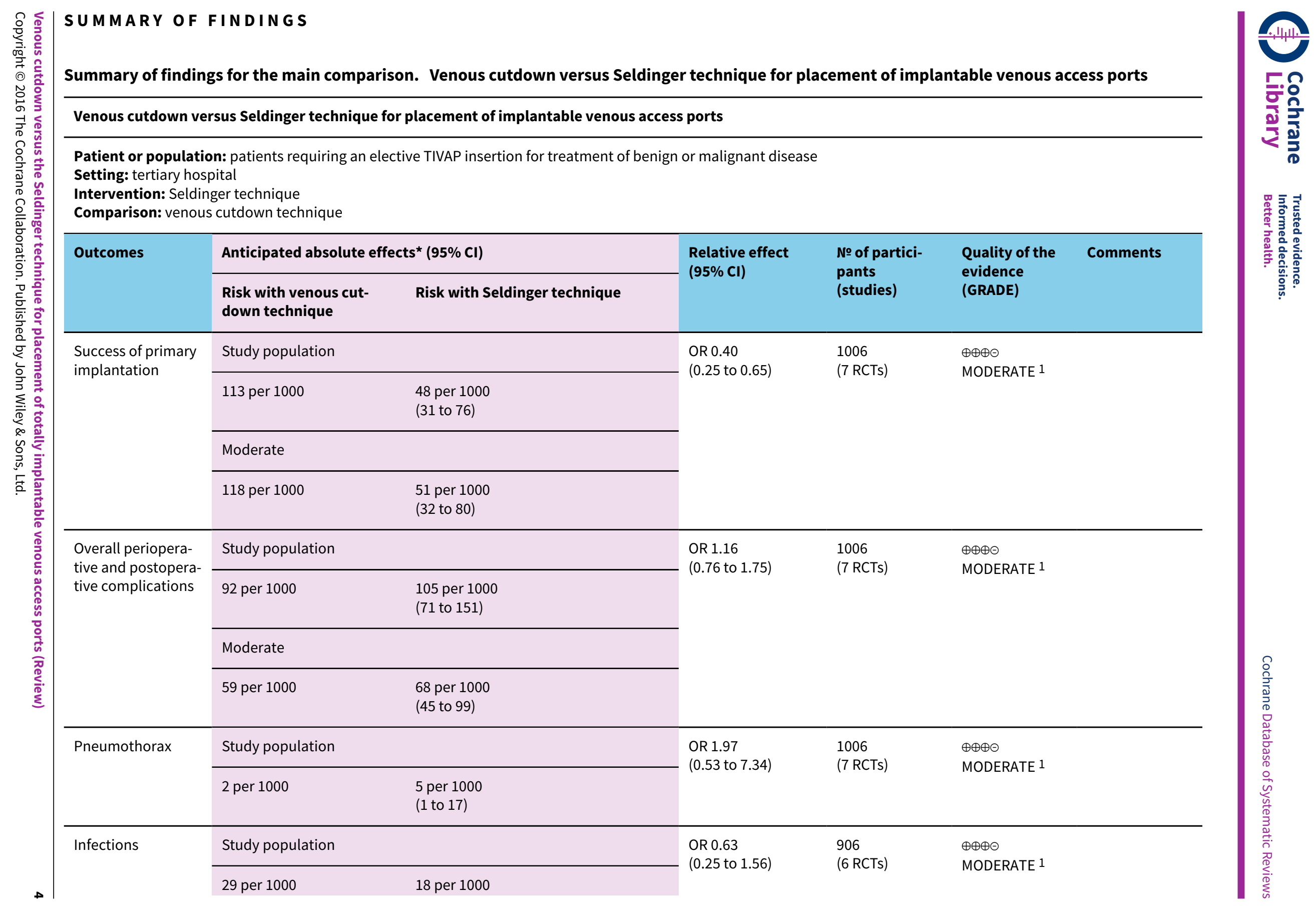




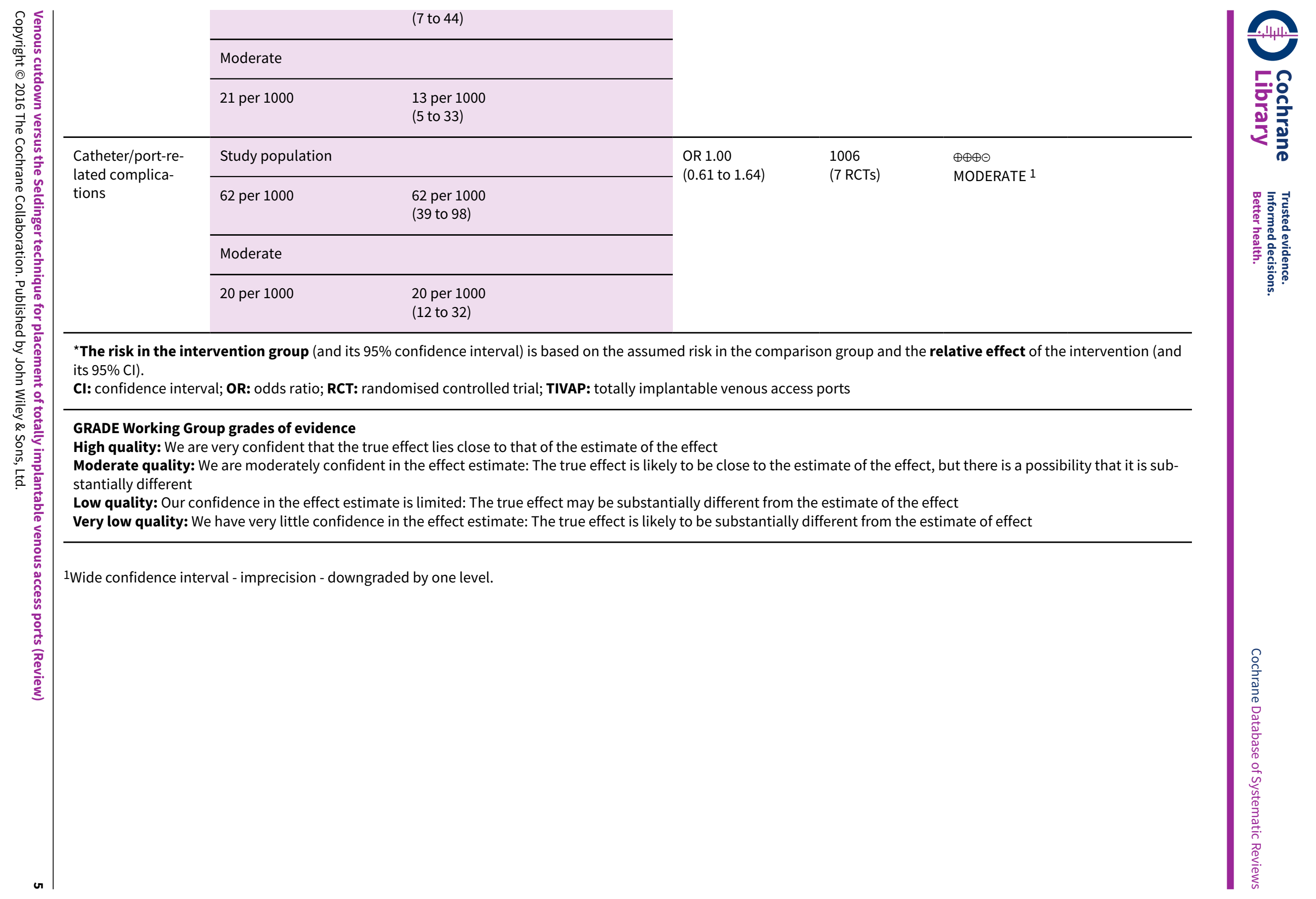




\section{B A C K G R O U N D}

Totally implantable venous access ports (TIVAPs) are subcutaneous reservoir ports with a catheter that reside in the superior vena cava or central veins. TIVAPs are commonly placed in patients prior to commencement of chemotherapy to provide central venous access and to reduce the risk of thrombosis, infection, and extravasation of chemotherapeutic agents ( $\mathrm{Ng} 2007$ ). Other applications of TIVAPs include administration of medications, parenteral nutrition, transfusion of blood products, and periodic blood sampling. The reservoir port is accessed by needle puncture through the patient's skin. TIVAP is positioned beneath the skin, thus providing several advantages over externalised indwelling catheter systems including reduced access-related anxiety, pain, and discomfort (Bow 1999).

\section{Description of the intervention}

The main approaches to placement of a TIVAP are the venous cutdown, the Seldinger, and a recently described modified Seldinger technique. The venous cutdown technique uses the cephalic vein and requires skin incision and surgical dissection of the cephalic vein. Venotomy is then performed to allow catheter insertion. The modified Seldinger technique is similar to the venous cutdown technique with the addition of a guidewire and peel-away vein dilator sheath featured to further assist in catheter insertion and placement.

The Seldinger technique involves percutaneous puncture of either the internal jugular vein or the subclavian vein. The right internal jugular vein is most commonly used because its leads directly to the superior vena cava, thus minimising catheter contact with the vessel wall. This unique anatomy may explain the lower risk of catheter malposition, thrombosis, and pneumothorax/ haemothorax. Although traditionally the Seldinger technique is based on anatomical landmarks, ultrasonography-guided venous access has become universal in obtaining vascular access. A metaanalysis by Hind et al found that real-time ultrasound for internal jugular vein procedures in adults resulted in fewer failed catheter placements, fewer complications with catheter placement, and a lower failure rate on first attempt (Hind 2003).

Potential complications of TIVAP placement techniques include stenosis, kinking, or dislodgement of the catheter, subcutaneous haematoma, and wound infection (Di Carlo 2001). The Seldinger technique, in particular the subclavian vein puncture, may be associated with complications such as pneumothorax, haemothorax, and injuries to the great vessels (Di Carlo 2010).

Over the past two decades, there has been a shift in practice towards the Seldinger technique over the venous cutdown technique due to the availability of operators, perceived costeffectiveness of the procedure, and probable shorter procedure time than the venous cutdown technique, which requires access to an operating theatre. This review investigated the success rates and complications of TIVAP placement comparing the three techniques.

\section{Why it is important to do this review}

Over the years placement of TIVAPs has increasingly been used as a method of delivering chemotherapeutic regimes and for other uses such as administration of medications, parenteral nutrition, transfusion of blood products, and periodic blood sampling. It is therefore important to identify the placement technique associated with the highest primary success rate and the lowest risk of complications, as well as the technique associated with the greatest patient satisfaction.

\section{O B J E C T IVES}

To compare the efficacy and safety of three commonly used techniques for implanting totally implantable venous access ports (TIVAPs): the venous cutdown technique, the Seldinger technique, and the modified Seldinger technique. The review includes studies that use Doppler or real-time two-dimensional ultrasonography for locating the vein in the Seldinger technique.

\section{METHODS}

\section{Criteria for considering studies for this review}

\section{Types of studies}

Randomised or quasi-randomised controlled clinical trials comparing the venous cutdown technique with the Seldinger technique and the modified Seldinger technique for implantation of TIVAPs. This review encompassed all potential venous access locations, involving both superficial and deep arm veins: cephalic vein, basilic vein, axillary vein, subclavian vein, and internal and external jugular veins. We included trials of the Seldinger technique with the use of ultrasound guidance. A distinction was made between real-time brightness mode ultrasound with/ without colour Doppler function and Doppler ultrasound which only provides auditory feedback.

\section{Types of participants}

People requiring an elective TIVAP insertion for treatment of benign or malignant disease. Indications for insertion of a TIVAP include safe administration of chemotherapy, parenteral nutrition, application of medications, transfusion of blood products, and recurrent periodic blood sampling.

Exclusion criteria: lack of compliance, impaired mental state, acquired or congenital coagulopathy, and perceived difficulties with venous access.

\section{Types of interventions}

- Seldinger group: a percutaneous technique with use of either the subclavian vein or internal jugular vein.

- Venous cutdown group: a surgical technique which uses the cephalic vein.

- Modified Seldinger group: a hybrid surgical technique which also uses the cephalic vein.

\section{Types of outcome measures}

\section{Primary outcomes}

1. The correct placement of a functional TIVAP (success of primary implantation). The position of the catheter tip was checked by fluoroscopy and the functionality assessed by aspiration of blood as well as injection of heparinised saline solution during the procedure. Initial procedural failure could include the following: vein not found, vein too small, venous occlusion, inability to advance catheter, failure of venepuncture. 


\section{Secondary outcomes}

1. Overall perioperative and postoperative complications: pneumothorax, infection, catheter/port-related complications, and others

a. Pneumothorax/haemothorax

b. Infections: localised infection: insertion site infection, reservoir infection, subcutaneous tunnel infection; or systemic infection such as sepsis, septic deep vein thrombosis, endocarditis, or septic emboli.

c. Catheter/port related-complications: thrombosis, fibrin sleeve, stenosis, kinking, extravasation, or migration of the catheter or dislodgement of the reservoir port.

d. Other complications: mortality, haematoma, seroma, nerve palsy, thoracic duct injury.

2. Patient outcomes
a. Duration of the procedure
b. Postoperative pain
c. Patient satisfaction

\section{Search methods for identification of studies}

There was no restriction on language.

\section{Electronic searches}

The Cochrane Vascular Trials Search Co-ordinator (TSC) searched the Cochrane Vascular Specialised Register (August 2015). In addition, the TSC searched the Cochrane Register of Studies (CRS) (www.metaxis.com/CRSWeb/Index.asp) (Cochrane Central Register of Controlled Trials (CENTRAL) (2015, Issue 7)). See Appendix 1 for details of the search strategy used to search the CRS. The Specialised Register is maintained by the TSC and is constructed from weekly electronic searches of MEDLINE, EMBASE, CINAHL, AMED, and through handsearching relevant journals. The full list of the databases, journals, and conference proceedings which have been searched, as well as the search strategies used, are described in the Specialised Register section of the Cochrane Vascular module in the Cochrane Library (www.cochranelibrary.com).

The TSC searched the following trial databases (August 2015) using the term 'Seldinger' for details of ongoing and unpublished studies:

- World Health Organization International Clinical Trials Registry Platform (apps.who.int/trialsearch/);

- ClinicalTrials.gov (clinicaltrials.gov/);

- Current Controlled Trials (www.controlled-trials.com/).

\section{Searching other resources}

We searched citations within identified studies and contacted authors of the identified studies to inquire about potential unpublished studies.

\section{Data collection and analysis}

All randomised or quasi-randomised trials that compared the success rate of the venous cutdown technique with the Seldinger or modified Seldinger techniques were eligible. Once the studies were selected, two review authors (CC-TH and GNCK) independently extracted data from the studies.

\section{Selection of studies}

Two review authors (CC-TH and GNCK) independently assessed the identified studies for inclusion in the review using the criteria stated above. The two review authors resolved disagreements by discussion or by consulting a third review author (MLVD). The third review authors (MLVD) also checked the excluded studies.

\section{Data extraction and management}

Two review authors (CC-TH and GNCK) independently extracted data from the included studies using a standard data extraction form created for the review. The two review authors resolved disagreements by discussion or by consulting a third review author (MLvD).

\section{Assessment of risk of bias in included studies}

Three review authors (CC-TH, GNCK, and MLVD) assessed the risk of bias for each study as described in the Cochrane Handbook for Systematic Reviews of Interventions 5.1 (Higgins 2011). We assessed the risk of bias for each of the following domains:

- randomisation;

- allocation concealment;

- blinding (of participants, personnel, and outcome assessors);

- completeness of data;

- selective outcome reporting;

- other sources of bias.

The review authors evaluated each criterion as 'low risk of bias', 'high risk of bias', or if these criteria were not discussed in the publication, as 'unclear'.

\section{Measures of treatment effect}

When dealing with dichotomous outcome measures, we calculated a pooled estimate of the treatment effect for each outcome across trials using the odds ratio (OR) (the odds of an outcome among treatment-allocated participants to the corresponding odds among participants in the control group) and the $95 \%$ confidence interval (Cl). For continuous outcomes, we recorded either mean change from baseline for each group or mean post-intervention values and standard deviation (SD) for each group. Then, where appropriate, we calculated a pooled estimate of treatment effect by calculating the mean difference and SD.

\section{Unit of analysis issues}

We did not include cross-over trials in the review because only a single treatment is designated to each group. We did not include cluster-randomised trials, where the unit of randomisation is not the same as the unit of analysis.

\section{Dealing with missing data}

In order to allow an intention-to-treat analysis, we sought data on the number of participants with each outcome event by allocated treatment group irrespective of compliance and whether or not the participant was later thought to be ineligible or otherwise excluded from the treatment or follow-up. We analysed the overall data using both intention-to-treat and on-treatment analysis. We scrutinised difference in both analyses for both confidence interval and statistical significance. 


\section{Assessment of heterogeneity}

We assessed heterogeneity using a two-stage approach. Firstly, we assessed face value heterogeneity (for example population, setting, risk of complications). Secondly, we assessed statistical heterogeneity in the meta-analysis using the $1^{2}$ statistic (Higgins 2011). A guide to interpretation is described in the Cochrane Handbook as (Higgins 2011):

- $0 \%$ to $40 \%$ might not be important;

- $30 \%$ to $60 \%$ may represent moderate heterogeneity;

- $50 \%$ to $90 \%$ may represent substantial heterogeneity;

- $75 \%$ to $100 \%$ represents considerable heterogeneity.

The observed importance of the 12 statistic depends on factors including: (i) magnitude and direction of effects, and (ii) strength of evidence for heterogeneity determined by the $\mathrm{P}$ value from the $\mathrm{Chi}^{2}$ test or a confidence interval for the $\mathrm{I}^{2}$ statistic (Higgins 2011).

We explored and discussed reasons for heterogeneity in the Discussion section of this review.

\section{Assessment of reporting biases}

We were unable to investigate publication bias as an insufficient number of studies were available for a funnel plot (at least 10 required), as recommended by the Cochrane Handbook 5.1 (Higgins 2011; Sterne 2001). If we suspected reporting bias, we contacted trial authors. We assessed outcome reporting bias by comparing the methods section of a published trial to the results section where the original protocol was not available.

\section{Data synthesis}

We used a fixed-effect model in our analysis. However, if moderate (or more) heterogeneity ( 12 greater than $30 \%$ ) was detected, we reassessed the significance of the treatment effect by using a random-effects model in the form a sensitivity analysis.

\section{Subgroup analysis and investigation of heterogeneity}

Where data were available, we planned to perform the following separate analyses for the potential percutaneous puncture sites.

\section{- Potential percutaneous puncture site}

* subclavian vein

* internal jugular vein
* cephalic vein

* basilic vein

* external jugular vein

* axillary vein

Where data were available, we planned to perform the following subgroup analyses.

- Reasons for implanting TIVAP

* malignancy: administration of chemotherapy

* other: parenteral nutrition, application of pharmaceutical drugs, transfusion of blood products, and recurrent periodic blood sampling

- Experience of the operator (surgeon or interventional radiologist): years, additional certifications

- Anatomical landmark technique versus the use of either Doppler or real-time two-dimensional ultrasonography in the Seldinger technique

\section{Sensitivity analysis}

If possible, we planned to perform a sensitivity analysis to assess the impact of trials with high risk of bias on the overall outcome of the pooling of data.

\section{Summary of findings}

We presented the main findings of the review results concerning the quality of evidence, the magnitude of effect of the interventions examined, and the sum of available data for the main outcomes of this review (success rate of implantation, overall perioperative and postoperative complications, pneumothorax, infections, catheter/ port-related complications) for the comparison venous cutdown versus Seldinger technique for placement of implantable venous access ports in a 'Summary of findings' table, according to the GRADE principles as described by Higgins 2011 and Atkins 2004. We used the GRADEprofiler (GRADEpro) software to assist in the preparation of the 'Summary of findings' table (www.guidelinedevelopment.org).

\section{RESULTS}

\section{Description of studies}

Results of the search

See Figure 1. 
Figure 1. Study flow diagram.

1906 records identified through searching CRS

ClinicalTrials.gov

31 studies found for Seldinger

WHO ICTRP

18 records for 18 trials found for

Seldinger

ISRCTN

5 records for 5 studies found for

Seldinger
35 records identified from Specialised Register

1934 records not relevant

3 reports of 3 studies excluded, with reasons

13 full-text reports of studies assessed for eligibility 1 report of 1 ongoing study 


\section{Included studies}

We included nine trials with a total of 1253 participants in the review. All nine trials were conducted in the 2000s (Biffi 2009; Boldó 2003; Chen 2007; D'Angelo 2002; Knebel 2009; Knebel 2011; Nocito 2009; Riapisarda 2006; Ribeiro 2012). Seven trials compared the Seldinger with the venous cutdown technique (Biffi 2009; Boldó 2003; Chen 2007; D'Angelo 2002; Knebel 2011; Nocito 2009; Riapisarda 2006), one trial compared the modified Seldinger technique with the venous cutdown technique (Knebel 2009), and one trial compared the Seldinger techniques subclavian vein versus internal jugular vein (Ribeiro 2012).

Four trials included only participants aged 18 years or older (Biffi 2009; Knebel 2009; Knebel 2011; Nocito 2009). Four trials did not specify the inclusion criteria for age (Boldó 2003; Chen 2007; D'Angelo 2002; Riapisarda 2006); in two of these trials the youngest participants were 17 and 19 years old, respectively (Boldó 2003; D'Angelo 2002). The remaining two trials did not specify age range (Chen 2007; Riapisarda 2006). Lastly, the trial by Ribeiro 2012 included paediatric and young people aged between 5 and 293 months ( 24 years) old.

Nearly all participants in the included trials were oncology patients, with the majority of oncology patients requiring TIVAP placement for chemotherapy. In eight trials all participants were oncology patients with known malignancy (Biffi 2009; Boldó 2003; Chen 2007; D'Angelo 2002; Knebel 2009; Knebel 2011; Riapisarda 2006; Ribeiro 2012).

In the trial by Nocito 2009 the major indication for TIVAP was administration of chemotherapy, and so we assumed that this trial also included oncology patients. In three other trials TIVAP placement was specified as to facilitate administration of chemotherapy (Biffi 2009; D'Angelo 2002; Riapisarda 2006).

Imaging was used consistently across all included studies to confirm final catheter position using either intraoperative fluoroscopy or postprocedural chest radiograph or both. Six trials utilised intraprocedural fluoroscopy in both Seldinger and venous cutdown groups (Boldó 2003; D'Angelo 2002; Knebel 2009; Knebel 2011; Nocito 2009; Riapisarda 2006). Two studies used only postprocedural radiograph to document final catheter position (Biffi 2009; Ribeiro 2012). In one study fluoroscopy was used to guide intraoperative venous cutdown technique, whilst the Seldinger group used electrocardiogram to confirm catheter tip position (Chen 2007). However, postprocedural chest radiographic was performed in both groups to confirm the final catheter position. Only one trial described ultrasound guidance (Biffi 2009). In this trial the Seldinger group venus access was obtained via either subclavian puncture guided by two-dimensional ultrasound or landmark technique for internal jugular vein puncture.

Seven trials compared the Seldinger technique and the venous cutdown technique (Biffi 2009; Boldó 2003; Chen 2007; D'Angelo 2002; Knebel 2011; Nocito 2009; Riapisarda 2006). Four trials used the subclavian vein as the access port for the Seldinger technique (D'Angelo 2002; Knebel 2011; Nocito 2009; Riapisarda 2006), and one trial used the right internal jugular vein (Chen 2007). In two trials both subclavian and jugular veins were used as the access vein for the Seldinger technique (Biffi 2009; Boldó 2003). One trial compared the Seldinger techniques subclavian vein versus internal jugular vein (Ribeiro 2012). The trial by Boldó 2003 did not specify the numbers of participants in whom access was obtained through either the subclavian or the jugular vein.

All nine trials reported complications, including pneumothorax, infection, and catheter complications. The study by Boldó 2003 did not specify infection as an outcome measure is therefore not included in the meta-analysis.

Additional outcome measures mentioned in the trials included periprocedural satisfaction and pain/comfort (Chen 2007; D'Angelo 2002), mean operation time (Chen 2007; D'Angelo 2002; Riapisarda 2006), experience of operator (Nocito 2009), and cost (D'Angelo 2002).

\section{Excluded studies}

We excluded two trials because they were not randomised controlled trials (D'Angelo 1997; Munro 1999). We excluded one trial because it was withdrawn prior to enrolment (NCT01584193).

\section{Risk of bias in included studies}

Four of the nine included studies had an acceptable risk of bias (Biffi 2009; Knebel 2009; Knebel 2011; Nocito 2009). The remaining five studies either poorly reported the methods that were used or used inadequate methods (see Figure 2; Figure 3). 
Figure 2. Risk of bias graph: review authors' judgements about each risk of bias item presented as percentages across all included studies.

Random sequence generation (selection bias)

Allocation concealment (selection bias)

Blinding of participants and personnel (performance bias)

Blinding of outcome assessment (detection bias)

Incomplete outcome data (attrition bias)

Selective reporting (reporting bias)

Other bias

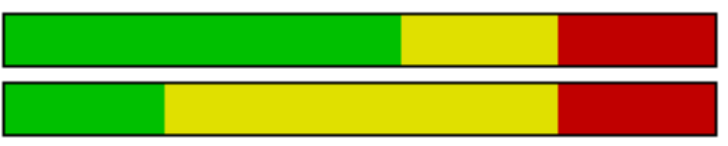

L

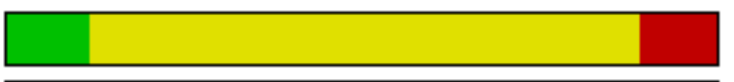

L
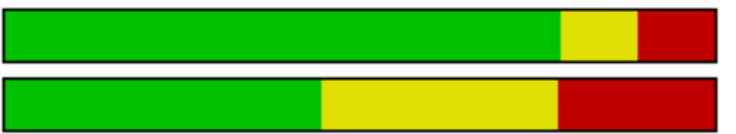

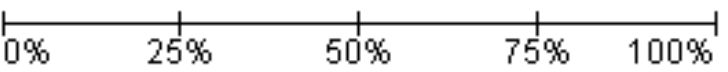

Low risk of bias

Unclear risk of bias

High risk of bias 
Figure 3. Risk of bias summary: review authors' judgements about each risk of bias item for each included study.

\begin{tabular}{|c|c|c|c|c|c|c|c|}
\hline & 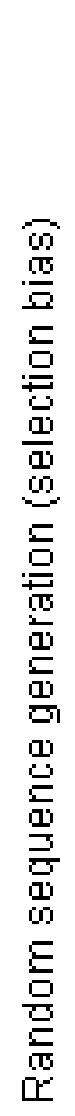 & 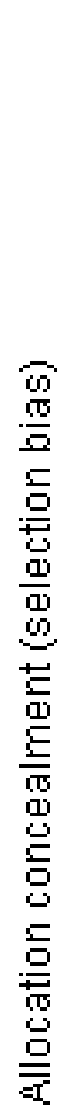 & 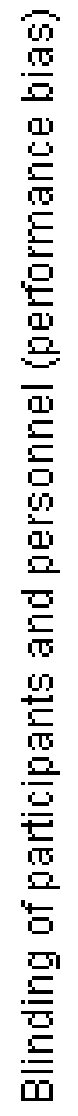 & 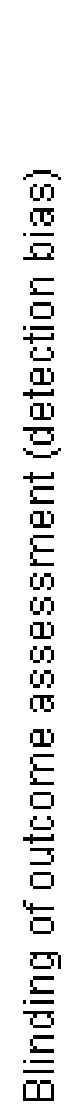 & 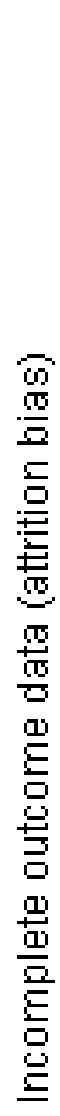 & 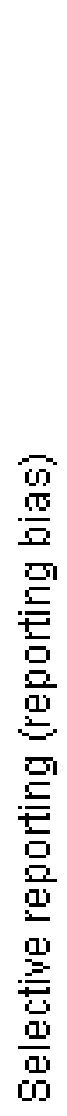 & 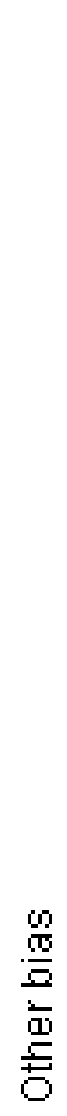 \\
\hline Biffi 2009 & 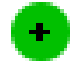 & $?$ & I & $?$ & & & \\
\hline Boldó 2003 & & & & & & & $?$ \\
\hline Chen 2007 & 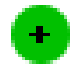 & $?$ & & $?$ & & & $?$ \\
\hline D'Angelo 2002 & 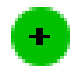 & $?$ & & $?$ & & & \\
\hline Knebel 2009 & . & + & & $?$ & & & \\
\hline Knebel 2011 & + & $?$ & + & + & & & \\
\hline Nocito 2009 & $?$ & + & + & $?$ & & & \\
\hline Riapisarda 2006 & $?$ & $?$ & + & $?$ & & & \\
\hline Ribeiro 2012 & & & & $?$ & & $?$ & $?$ \\
\hline
\end{tabular}

Venous cutdown versus the Seldinger technique for placement of totally implantable venous access ports (Review) 


\section{Allocation}

The generation of random numbers was adequate in most trials (Biffi 2009; Chen 2007; D'Angelo 2002; Knebel 2009; Knebel 2011), unclear in two studies (Nocito 2009; Riapisarda 2006), and inadequate in two trials (Boldó 2003; Ribeiro 2012). Boldó 2003 described the method as "randomized" but did not mention the method used, and the authors acknowledged this weakness in their discussion. In the Ribeiro 2012 trial the surgeons tossed a coin to decide who was allocated to which group.

Allocation concealment was adequately described and performed in Knebel 2009 and Nocito 2009, but unclear (inadequately described) in Biffi 2009, Chen 2007, D'Angelo 2002, Knebel 2011 and Riapisarda 2006. Two studies used high-risk methods (Boldó 2003; Ribeiro 2012), such as envelopes, in Boldó 2003, or by tossing a coin at the moment of surgery (Ribeiro 2012).

\section{Blinding}

Only one trial described the method for blinding of outcome assessors, which we assessed as at low risk of performance bias (Knebel 2011). The study by Boldó 2003 was not blinded (high risk of bias), and in the study by Nocito 2009 a study nurse was tasked with outcome assessment, but blinding was not described. In the other studies blinding of outcome assessors was not mentioned, and they were therefore judged to be at unclear risk of bias (Biffi 2009; Chen 2007; D'Angelo 2002; Knebel 2009; Riapisarda 2006; Ribeiro 2012).

All of the included studies made no specific mention of blinding of either personnel or participants, and we assessed this as low risk of bias. Given that the implementation of the procedure requires technical knowledge by the personnel to undertake the randomised tasks, blinding of personnel carrying out the procedure was not feasible. Blinding of participants, however, is practically feasible, but as this was not specifically mentioned in the included studies, it is unlikely it was undertaken.

\section{Incomplete outcome data}

Dropouts were accounted for in all except for four studies (Boldó 2003; Chen 2007; Riapisarda 2006; Ribeiro 2012).

\section{Selective reporting}

All included trials reported the outcomes prespecified in their methods section except the study by Riapisarda 2006, and it was not clearly described in the trial by Ribeiro 2012.

\section{Other potential sources of bias}

Only two studies mention that they have received funding from an external source (Biffi 2009; Knebel 2009), and one reports that they have not received any external funding (Nocito 2009). The remaining studies do not mention external funding at all.

Three studies declared that the authors do not have a conflict of interest (Knebel 2009; Knebel 2011; Nocito 2009); the other studies do not address conflict of interest.

In D'Angelo 2002 and Riapisarda 2006 patients were excluded post randomisation without explanation, therefore we assessed these studies as at high risk of bias in this category.

\section{Effects of interventions}

See: Summary of findings for the main comparison Venous cutdown versus Seldinger technique for placement of implantable venous access ports

\section{Comparison 1: Seldinger versus venous cutdown}

\section{Success of primary implantation}

Data presented in the analysis tables and forest plots represent the numbers of primary implantation failures in each group (Analysis 1.1; Analysis 1.2; Analysis 1.3; Analysis 1.4; Analysis 1.5; Analysis 1.6). This means that the number of events in the table for a $100 \%$ success rate of primary implantation would be 0 . An effect estimate on the left side of the equipose (effect estimate of 1 ) therefore indicates an effect in favour of the Seldinger group, whereas an effect estimate on the right side indicates an effect in favour of the venous cutdown group. Hence, odds ratios less than 1 favour the Seldinger group, and odds ratios greater than 1 favour the venous cutdown group.

\section{Intention-to-treat analysis (ITT)}

ITT analysis of the Seldinger technique versus the venous cutdown technique included seven trials (Biffi 2009; Boldó 2003; Chen 2007; D'Angelo 2002; Knebel 2011; Nocito 2009; Riapisarda 2006), with a total of 1006 participants. The analysis showed that the Seldinger technique had a greater primary success rate than the venous cutdown technique for TIVAP implantation (odds ratio (OR) 0.40 ; $95 \%$ confidence interval $(\mathrm{Cl}) 0.25$ to 0.65 ; moderate quality evidence; Analysis 1.1).

We performed a separate analysis to assess the different access veins used in the Seldinger technique with the venous cutdown technique. In four trials the subclavian vein was the only venous access point used in the Seldinger group (D'Angelo 2002; Knebel 2011; Nocito 2009; Riapisarda 2006). In two trials both subclavian and internal jugular veins were used (Biffi 2009; Boldó 2003). The trial by Boldó 2003 did not specify the numbers of participants in the Seldinger group with access through either the subclavian or the internal jugular vein and thus could not be included in the analysis.

Analysis of five trials included 672 participants in whom the subclavian vein was used as access point in the Seldinger group (Biffi 2009; D'Angelo 2002; Knebel 2011; Nocito 2009; Riapisarda 2006). The ITT analysis showed Seldinger to be the more successful implantation technique of TIVAP (OR $0.23 ; 95 \% \mathrm{Cl} 0.13$ to 0.41 ; Analysis 1.2).

Two trials with 367 participants reported internal jugular vein access in the Seldinger technique (Biffi 2009; Chen 2007). When compared to the venous cutdown group, there was no difference in success rate (OR $0.62 ; 95 \% \mathrm{Cl} 0.3$ to 1.28 ; Analysis 1.3 ).

Sensitivity analysis excluding three studies at high risk of bias did not lead to any material differences in the result (Boldó 2003; D'Angelo 2002; Riapisarda 2006).

\section{On-treatment analysis}

The on-treatment analysis of Seldinger versus venous cutdown technique included 972 participants and showed differences between the Seldinger technique and the venous cutdown technique for implantation of TIVAP (OR $0.59 ; 95 \% \mathrm{Cl} 0.36$ to 0.98 ; 
Analysis 1.4). Sensitivity analysis using a random-effects model, as the $1^{2}$ statistic was larger than $30 \%(76 \%)$, showed that although the estimate of effect remained in favour of the Seldinger technique, the confidence intervals widened and crossed the line of equipoise.

The on-treatment analysis of the subclavian vein access Seldinger group versus the venous cutdown group included 640 participants and showed subclavian vein access Seldinger technique to be more successful than the venous cutdown technique for implantation of TIVAP (OR 0.27; 95\% Cl 0.15 to 0.49; Analysis 1.5).

Two trials with 332 participants used the internal jugular vein as the access vein for the Seldinger technique, and analysis showed no difference in comparison with the venous cutdown technique (OR 0.48; 95\% Cl 0.22 to 1.03; Analysis 1.6) (Biffi 2009; Chen 2007).

Sensitivity analysis excluding three studies at high risk of bias did not lead to a any material differences in the result (Boldó 2003; D'Angelo 2002; Riapisarda 2006).

\section{Overall perioperative and postoperative complications}

\section{Intention-to-treat analysis (ITT)}

ITT analysis of the Seldinger technique versus the venous cutdown technique included seven trials with a total of 1006 participants (Biffi 2009; Boldó 2003; Chen 2007; D'Angelo 2002; Knebel 2011; Nocito 2009; Riapisarda 2006). The analysis showed no difference in overall complication rate between the Seldinger technique and the venous cutdown technique (OR $1.16 ; 95 \% \mathrm{Cl} 0.76$ to 1.75 ; moderate quality evidence; Analysis 2.1). Sensitivity analysis using a randomeffects model, as the $1^{2}$ statistic was larger than $30 \%(60 \%)$, also showed no difference in overall complication rate between the Seldinger technique and the venous cutdown technique.

Further analyses were performed comparing different access veins used in the Seldinger technique versus the venous cutdown technique. In four trials, the subclavian vein was the only venous access point used in the Seldinger group (D'Angelo 2002; Knebel 2011; Nocito 2009; Riapisarda 2006). In two trials both subclavian and internal jugular veins were used (Biffi 2009; Boldó 2003). The trial by Boldó 2003 did not specify the numbers of participants in the Seldinger group with access through either the subclavian or the internal jugular vein and thus could not be included in the analysis.

Five trials with 672 participants reported outcomes for the Seldinger technique using the subclavian vein access versus the venous cutdown technique (Biffi 2009; D'Angelo 2002; Knebel 2011; Nocito 2009; Riapisarda 2006). The ITT analysis showed no difference in overall complication rate between the two groups (OR $1.28 ; 95 \% \mathrm{Cl} 0.78$ to 2.1 ; Analysis 2.2).

In two trials with 367 participants the internal jugular vein was used as the access vein for the Seldinger technique (Biffi 2009; Chen 2007). In these two trials there was no difference in perioperative and postoperative complications between the Seldinger technique and the venous cutdown technique $(\mathrm{OR} 0.72 ; 95 \% \mathrm{Cl} 0.4$ to 1.31 ; Analysis 2.3).

Sensitivity analysis excluding three studies at high risk of bias did not lead to any material differences in the result (Boldó 2003; D'Angelo 2002; Riapisarda 2006).

\section{On-treatment analysis}

The on-treatment analysis of the Seldinger versus the venous cutdown technique included 938 participants. We observed no difference in overall complication rate between the Seldinger technique and the venous cutdown technique (OR 0.93; 95\% Cl 0.62 to 1.40; Analysis 2.4). Sensitivity analysis using a random-effects model, as the $I^{2}$ statistic was larger than $30 \%$ (45\%), also showed no difference in overall complication rate between the Seldinger technique and the venous cutdown technique.

The on-treatment analysis of the Seldinger group with subclavian vein access versus the venous cutdown group included 618 participants and showed no difference between subclavian vein Seldinger technique and venous cutdown technique (OR 1.06; 95\% $\mathrm{Cl} 0.66$ to 1.72 ; Analysis 2.5 ).

Two trials with 332 participants used the internal jugular vein as the access vein for the Seldinger technique, and analysis showed no difference in comparison with the venous cutdown technique (OR 0.67 ; 95\% Cl 0.37 to 1.23; Analysis 2.6) (Biffi 2009; Chen 2007).

Sensitivity analysis excluding three studies at high risk of bias did not lead to any material differences in the result (Boldó 2003; D'Angelo 2002; Riapisarda 2006).

\section{Specific perioperative and postoperative complications}

We performed ITT and on-treatment analyses to assess the effects of Seldinger and venous cutdown techniques with regards to specific complications such as pneumothorax, infection, and catheter complications. This analysis followed the format of the overall perioperative and postoperative complications above.

\section{Pneumothorax/haemothorax}

The ITT analysis showed no difference in pneumothorax between the Seldinger and venous cutdown techniques (OR 1.97; $95 \% \mathrm{Cl}$ 0.53 to 7.34 ; moderate quality evidence; Analysis 3.1). Separate analysis of the Seldinger technique using subclavian vein and internal jugular vein access versus the venous cutdown technique also showed no difference between the two techniques: OR 4.49; $95 \% \mathrm{Cl} 0.75$ to 26.82 (Analysis 3.2) and OR $0.33 ; 95 \% \mathrm{Cl} 0.01$ to 8.13 (Analysis 3.3), respectively.

The on-treatment analysis showed no difference in pneumothorax between the Seldinger and venous cutdown techniques (OR 2.06; $95 \% \mathrm{Cl} 0.56$ to 7.57 ; Analysis 3.4). Separate analysis of the Seldinger technique using subclavian vein and internal jugular vein access versus the venous cutdown technique also showed no difference between the two comparator groups: OR 4.96; $95 \% \mathrm{Cl} 0.83$ to 29.56 (Analysis 3.5) and OR 0.31; 95\% Cl 0.01 to 7.65 (Analysis 3.6), respectively.

Sensitivity analysis excluding three studies at high risk of bias did not lead to any material differences in the result (Boldó 2003; D'Angelo 2002; Riapisarda 2006).

\section{Infections}

The ITT analysis showed no difference in infection rate between the Seldinger and venous cutdown techniques (OR 0.63; $95 \% \mathrm{Cl} 0.25$ to 1.56; moderate quality evidence; Analysis 4.1). Separate analysis of the Seldinger technique using subclavian vein and internal jugular vein access versus the venous cutdown technique also showed no difference between the two techniques: OR $0.85 ; 95 \% \mathrm{Cl} 0.28$ to 
2.58 (Analysis 4.2) and OR 0.27; 95\% Cl 0.06 to 1.34 (Analysis 4.3), respectively.

The on-treatment analysis showed no difference in infection rate between the Seldinger and venous cutdown techniques (OR 0.61; $95 \% \mathrm{Cl} 0.24$ to 1.51; Analysis 4.4). Separate analysis of the Seldinger technique using subclavian vein and internal jugular vein access versus the venous cutdown technique also showed no difference between the two comparator groups: OR $0.79 ; 95 \% \mathrm{Cl} 0.26$ to 2.40 (Analysis 4.5) and OR 0.27; 95\% Cl 0.05 to 1.30 (Analysis 4.6), respectively.

Sensitivity analysis excluding three studies at high risk of bias did not lead to any material differences in the result (Boldó 2003; D'Angelo 2002; Riapisarda 2006).

\section{Catheter/port-related complications}

The ITT analysis showed no difference in catheter-related complication rate between the Seldinger and venous cutdown techniques (OR 1; 95\% Cl 0.61 to 1.64; moderate quality evidence; Analysis 5.1). Sensitivity analysis using a random-effects model, as the $1^{2}$ statistic was larger than $30 \%(33 \%)$, also showed no difference in catheter-related complication rate between the Seldinger technique and the venous cutdown technique.

Separate analysis of the Seldinger technique using subclavian vein versus the venous cutdown technique showed a greater rate of catheter complications in the subclavian Seldinger group (OR 6.77; $95 \% \mathrm{Cl} 2.31$ to 19.79 ; Analysis 5.2). Analysis of the internal jugular vein Seldinger group versus the venous cutdown group showed no difference in catheter-related complication rate (OR $0.81 ; 95 \% \mathrm{Cl}$ 0.43 to 1.52 ; Analysis 5.3).

The on-treatment analysis showed no difference in catheter-related complication rate between the Seldinger and venous cutdown techniques (OR 0.93; $95 \% \mathrm{Cl} 0.57$ to 1.53 ; Analysis 5.4). Sensitivity analysis using a random-effects model, as the $\mathrm{I}^{2}$ statistic was larger than $30 \%(42 \%)$, also showed no difference in catheter-related complication rate between the Seldinger technique and the venous cutdown technique.

Separate analysis of the Seldinger technique using subclavian vein versus the venous cutdown technique showed a greater rate of catheter complications in the subclavian Seldinger group (OR 6.62; $95 \% \mathrm{Cl} 2.24$ to 19.58 ; Analysis 5.5). Analysis of the internal jugular vein Seldinger group versus the venous cutdown group showed no difference in catheter-related complication rate (OR 0.75; 95\% $\mathrm{Cl} 0.4$ to 1.43; Analysis 5.6).

Sensitivity analysis excluding three studies at high risk of bias did not lead to any material differences in the result (Boldó 2003; D'Angelo 2002; Riapisarda 2006).

\section{Other complications}

The ITT analysis showed no difference in the rate of other complications between the Seldinger and venous cutdown techniques (OR $0.59 ; 95 \% \mathrm{Cl} 0.18$ to 1.96 ; Analysis 6.1 ). Analysis of the Seldinger technique using the subclavian vein versus the venous cutdown technique also showed no difference between the two techniques (OR 0.59; $95 \% \mathrm{Cl} 0.18$ to 1.96; Analysis 6.2). No other complications were reported in the Seldinger group using the internal jugular vein for venous access and the venous cutdown group.

The on-treatment analysis showed no difference in the rate of other complications between the Seldinger and venous cutdown techniques (OR $0.64 ; 95 \% \mathrm{Cl} 0.19$ to 2.14 ; Analysis 6.4). Analysis of the Seldinger technique using the subclavian vein versus the venous cutdown technique also showed no difference between the two techniques (OR $0.64 ; 95 \% \mathrm{Cl} 0.19$ to 2.14; Analysis 6.5). No other complications were reported in the Seldinger group using the internal jugular vein for venous access and the venous cutdown group.

Sensitivity analysis excluding three studies at high risk of bias did not lead to any material differences in the result (Boldó 2003; D'Angelo 2002; Riapisarda 2006).

\section{Patient outcomes}

\section{Duration of the procedure}

Three trials reported the duration of the procedure in minutes (Chen 2007; D'Angelo 2002; Riapisarda 2006). The trial by Chen 2007 reported a mean operation time of 28 minutes for the internal jugular vein access Seldinger technique and 35 minutes for the venous cutdown technique. The trial by Riapisarda 2006 reported a mean operation time of 35 minutes for the subclavian access Seldinger technique and 48 minutes for the venous cutdown technique. The trial by D'Angelo 2002 reported a mean operation time of 40 minutes for the subclavian Seldinger technique and 50 minutes for the venous cutdown technique $(P=0.108)$. Overall, the Seldinger technique appears to be the shorter procedure, however the three studies did not specify how the procedure was timed.

\section{Postoperative pain}

Two trials reported postoperative pain (Chen 2007; D'Angelo 2002).

In the study by Chen 2007 periprocedure satisfaction and comfort scores were defined as follows: 1 , comfortable and in no pain; 2 , comfortable but with a slight sensation of pain; 3 , tolerable pain; and 4, intolerable pain. The result did not specify participant numbers in each category but rather a generalised approximation, with the Seldinger group reporting a comfort and satisfaction score of between 1 and 2 and the venous cutdown group reporting a score of 2 to 3 .

In the study by D'Angelo 2002 postoperative pain was defined as mild, moderate, or severe. No difference in postoperative pain was found between the Seldinger and venous cutdown groups. In the Seldinger group $(23 / 25,95 \%)$ complained of mild to moderate pain, and $(2 / 25,5 \%)$ complained of severe pain. The same figures were reported for the venous cutdown group.

\section{Patient satisfaction}

None of the trials in this comparison reported patient satisfaction.

\section{Comparison 2: Modified Seldinger versus venous cutdown}

We identified only one trial using the modified Seldinger technique (Knebel 2009). ITT analysis of 164 participants showed no difference in primary implantation success rate between the modified Seldinger technique $(69 / 82,84 \%)$ and venous cutdown technique (66/82, 80\%), $P=0.686$. No difference in infection rate between the modified Seldinger technique (1/82) and venous cutdown 
technique (3/82) was reported. No cases of pneumothorax were reported. Catheter-related complications and thrombosis rates were similar in the modified Seldinger technique $(2 / 82)$ and the venous cutdown technique (3/82).

The remaining prespecified primary and secondary outcomes of this review were not assessed by Knebel 2009.

\section{Comparison 3: Seldinger technique (subclavian vein) versus Seldinger technique (internal jugular vein)}

One study in children and adolescents compared the effectiveness and safety of using a Seldinger technique in the subclavian versus the internal jugular vein (Ribeiro 2012). The primary success rate for the initial attempt at implantation was $84 \%$ (37/44) for puncture in the subclavian vein and $74 \%(29 / 39)$ for the internal jugular vein. Six participants $(7 \%)$ were excluded from the study because of procedure failure at both sites. Alternative techniques were used, which included catheter implanted by dissection (four participants), femoral vein by puncture (one participant), and one did not have any implantation. Among the excluded participants, three cases (3.6\%) presented with early complications: one case with haemothorax, one with pneumothorax, and one with cervical haematoma. The authors made no mention of complications in participants with successful initial implantation. There was a difference in overall complication rate in the subclavian group $(48 \%)$ versus the jugular group (23\%), $P=0.02$. However, when specific complications were compared individually, no differences were found between the groups.

The remaining prespecified primary and secondary outcomes of this review were not assessed by Ribeiro 2012.

\section{DISCUSSION}

\section{Summary of main results}

The primary success rate for TIVAP placement is higher with the Seldinger technique than with the venous cutdown technique. The majority of included trials reporting on the Seldinger technique used the subclavian vein for access, while the internal jugular vein was used less frequently. Additional analyses showed that the Seldinger group using subclavian vein access was more successful in TIVAP insertion than the venous cutdown technique, while no difference was found between the Seldinger group using the internal jugular vein access and the venous cutdown technique. However, this can be attributed to the small number of participants in the internal jugular vein access group.

There was no difference in overall complication rates between the two techniques. Analysis per access vein used in the Seldinger technique versus the venous cutdown technique showed that the Seldinger technique using the subclavian vein has a greater rate of catheter-related complications compared to the venous cutdown group. The remaining outcomes, infections, pneumothorax, and other complications, did not show differences between the groups.

We identified only one trial for each of the comparisons modified Seldinger technique (cephalic vein) versus venous cutdown (cephalic vein), and Seldinger (subclavian vein access) versus Seldinger (internal jugular vein access), thus a definitive conclusion cannot be drawn for these comparisons and further research is recommended.

\section{Overall completeness and applicability of evidence}

The Cochrane Vascular Group Trials Search Co-ordinator searched multiple databases to identify trials for this review. The review authors scrutinised all trials. A sufficient number of trials was available to conduct a meaningful comparison between the subclavian vein Seldinger technique and the venous cutdown technique. However, there was paucity of data on the internal jugular vein Seldinger technique, since only three of the identified trials used internal jugular vein access for the Seldinger technique (Biffi 2009; Chen 2007; Ribeiro 2012). Only one trial compared the two different access sites for the Seldinger technique (Ribeiro 2012); this was also the only study including children and adolescents.

Fundamentally, the techniques for implantation of venous access ports are dependent on the choice of vein with venous cutdown technique limited to the cephalic vein and Seldinger technique utilising either subclavian or internal jugular vein. Both trials by Biffi 2009 and Nocito 2009 reported numbers of failed primary insertion via the venous cutdown technique, which were shifted to another group. Pre-randomisation visualisation of cephalic vein via imaging was not an inclusion criteria and would certainly go against the concept of randomisation as it would introduce bias.

\section{Quality of the evidence}

The overall quality of the trials included in this review was moderate, although the methods used for randomisation (a key to avoiding selection bias) were inadequate in four of the nine included studies (Boldó 2003; D'Angelo 2002; Riapisarda 2006; Ribeiro 2012). However, sensitivity analysis excluding these trials did not alter the outcome of the analyses. We reported a fixedeffect model for all the outcomes, and in the presence of statistical heterogeneity ( $I^{2}$ greater than $30 \%$ ) used a random-effects model to assess the robustness of the outcome estimates. However, all effect estimates remained unchanged. The nature of the interventions, either venous cutdown or Seldinger techniques, meant that it was not feasible to blind the participant or personnel, therefore we judged this to be at low risk of bias. The great majority of participants in the included trials were oncology patients at tertiary centres, and the outcomes were applicable to the usual clinical setting. The venous access for Seldinger technique can utilise either subclavian or internal jugular veins, whereas the venous cutdown technique consistently uses the cephalic vein, as it is superficial and surgically more accessible. Only one trial described ultrasound guidance (Biffi 2009). In this trial the venous access in the Seldinger group was obtained via either subclavian vein puncture guided by two-dimensional ultrasound or landmark technique for the internal jugular vein puncture. No serious inconsistencies were evident. For all outcomes, when comparing venous cutdown and Seldinger technique, serious imprecision was evident from wide confidence intervals in the included trials. Due to the limited number of included studies, we were unable assess publication bias. Two trials received research grants and funding (Biffi 2009; Knebel 2009), but we determined that these were at low risk of bias. We therefore judged the overall quality of the evidence to be moderate.

\section{See Summary of findings for the main comparison.}

\section{Potential biases in the review process}

We followed Cochrane guidance to assess the results of the searches and select the included studies (Higgins 2011). Each step was carried out independently by two review authors and 
discussed with a third review author who does not professionally perform the interventions investigated in this review and thus does not have professional interest in either of the procedures investigated in this review. This was intended to reduce the risk of selection bias in the review process. Contacting authors did not result in the identification of additional studies, therefore we believe it is unlikely that we have missed eligible studies.

In the secondary outcome we categorise complications into periprocedural complication, mechanical failure of catheter/port, and infection without a specifying a time frame. It is an assumption that periprocedural complications (pneumothorax, haemothorax, haematoma, seroma, nerve palsy, thoracic duct injury) occur early, whereas mechanical failure (fibrin sleeve, stenosis, kinking, extravasation, or migration of the catheter or dislodgement of the reservoir port) are likely long term. Infection of the port/catheter can occur as an early or late complication.

\section{Agreements and disagreements with other studies or reviews}

We have identified no other reviews comparing the Seldinger and venous cutdown techniques.

\section{AUTHORS' CONCLUSIONS}

\section{Implications for practice}

Moderate-quality evidence shows that the Seldinger technique has a greater primary success rate for TIVAP placement than the venous cutdown technique, mainly in adult oncology patients. Moderatequality evidence also shows no difference in overall perioperative and postoperative complication rates. Additional analysis found that when using the subclavian vein in the Seldinger technique there is a higher risk of catheter-related complications compared to the venous cutdown group. The rates of pneumothorax and infection did not differ between the Seldinger and venous cutdown groups. This review has not been able to determine which vein would be the optimal access vein for the Seldinger technique.

\section{Implications for research}

In current clinical practice the internal jugular vein is most commonly chosen for venous access. However, the majority of trials included in our review used the subclavian vein for venous access in the Seldinger technique. More studies are needed to determine the optimal route of venous access in the Seldinger technique, internal jugular vein or subclavian vein. The use of ultrasound has become universal to guide venous access, and its efficacy should also be assessed in future studies.

\section{ACKNOWLEDGEMENTS}

We would like to thank Marlene Stewart, Managing Editor of Cochrane Vascular, for her support in preparing this manuscript. 


\section{R E F E R E N C E S}

\section{References to studies included in this review}

Biffi 2009 \{published data only\}

Biffi R, Orsi F, Pozzi S, Pace U, Bonomo G, Monfardini L, et al. Best choice of central venous insertion site for the prevention of catheter-related complications in adult patients who need cancer therapy: a randomized trial. Annals of Oncology 2009;20(5):935-40.

\section{Boldó 2003 \{published data only\}}

Boldó E, Armelles A, Martín F, Aracil JP, Peñas RD, Busquier I, et al. Subcutaneous venous reservoirs: dissection versus puncture [Reservorios venosos subcutáneos: disección versus punción]. Oncología 2003;26(8):52-5.

\section{Chen 2007 \{published data only\}}

Chen PT, Sung CS, Wang CC, Chan KH, Chang WK, Hsu WH. Experience of anesthesiologists with percutaneous nonangiographic venous access. Journal of Clinical Anesthesia 2007;19(8):609-15.

\section{D'Angelo 2002 \{published data only\}}

D'Angelo FA, Ramacciato G, Aurello P, De Angelis R, Amodio P, Magri M, et al. Prospective randomised study of cephalic vein cut-down versus subclavian vein puncture technique in the implantation of subcutaneous venous access devices. Chirurgia Italiana 2002;54(4):495-500.

\section{Knebel 2009 \{published data only\}}

Knebel P, Fischer L, Huesing J, Hennes R, Büchler MW, Seiler CM. Randomized clinical trial of a modified Seldinger technique for open central venous cannulation for implantable access devices. The British Journal of Surgery 2009;96(2):159-65.

\section{Knebel 2011 \{published data only\}}

Knebel P, Lopez-Benitez R, Fischer L, Radeleff BA, Stampfl U, Bruckner $T$, et al. Insertion of totally implantable venous access devices: an expertise-based, randomized, controlled trial. Annals of Surgery 2011;253(6):1111-7. [NCT00600444]

\section{Nocito 2009 \{published data only\}}

Nocito A, Wildi S, Rufibach K, Clavien PA, Weber M. Randomized clinical trial comparing venous cutdown with the Seldinger technique for placement of implantable venous access ports. British Journal of Surgery 2009;96(10):1129-34. [NCT00272623]

\section{Riapisarda 2006 \{published data only\}}

Riapisarda C, Lanteri R, Santangelo M, Li Destri G, Di Cataldo A Licata A. Totally implantable venous access ports: a clinical trial comparing percutaneous versus surgical technique. Chirurgia Italiana 2006;58(3):305-8.

\section{Ribeiro 2012 \{published data only\}}

Ribeiro RC, Abib SC, Aguiar AS, Schettini ST. Long-term complications in totally implantable venous access devices: randomized study comparing subclavian and internal jugular vein puncture. Pediatric Blood and Cancer 2012;58(2):274-7.

\section{References to studies excluded from this review}

D'Angelo 1997 \{published data only\}

D'Angelo FA, Ramacciato G, Aurello P, Lauro S, Caramitti A, Lalle $M$, et al. Alternative insertion sites for permanent central venous access devices. European Journal of Surgical Oncology 1997;23(6):547-9.

\section{Munro 1999 \{published data only\}}

Munro WS, Fletcher JP, Avramovic J, Richardson AJ. Long-term central venous access catheters: A prospective randomized trial comparing percutaneous and cut-down methods of insertion. International Journal of Angiology 1999;8(2):109-11.

\section{NCT01584193 \{published data only\}}

NCT01584193. Ultrasound-guided subclavian vein puncture versus cephalic vein dissection for venous access port implantation. http://clinicaltrials.gov/ct2/show/NCT01584193 (accessed August 2015).

\section{References to ongoing studies}

\section{Huttner 2015 \{published data only\}}

Huttner FJ, Bruckner T, Alldinger I, Hennes R, Ulrich A, Buchler MW, et al. Frequency of pneumothorax and haemothorax after primary open versus closed implantation strategies for insertion of a totally implantable venous access port in oncological patients: Study protocol for a randomised controlled trial. Trials 2015;16:128.

\section{Additional references}

\section{Atkins 2004}

Atkins D, Best D, Briss PA, Eccles M, Falck-Ytter Y, Flottorp S, et al. GRADE Working Group. Grading quality of evidence and strength of recommendations. BMJ 2004;328(7454):1490-4.

\section{Bow 1999}

Bow EJ, Kilpatrick MG, Clinch JJ. Totally implantable venous access ports systems for patients receiving chemotherapy for solid tissue malignancies: a randomized controlled clinical tria examining the safety, efficacy, costs, and impact on quality of life. Journal of Clinical Oncology 1999;17(4):1267.

\section{Di Carlo 2001}

Di Carlo I, Cordio S, La Greca G, Privitera G, Russello D, Puleo S, et al. Totally implantable venous access devices implanted surgically: a retrospective study on early and late complications. Archives of Surgery 2001;136(9):1050-3.

\section{Di Carlo 2010}

Di Carlo I, Pulvirenti E, Mannino M, Toro A. Increased use of percutaneous technique for totally implantable venous access devices. Is it real progress? A 27-year comprehensive review on early complications. Annals of Surgical Oncology 2010;17(6):1649-56. 


\section{Higgins 2011}

Higgins JPT, Green S (editors). Cochrane Handbook for Systematic Reviews of Interventions Version 5.1.0 [updated March 2011]. The Cochrane Collaboration, 2011. Available from www.cochrane-handbook.org.

\section{Hind 2003}

Hind D, Calvert N, McWilliams R, Davidson A, Paisley S, Beverley $C$, et al. Ultrasonic locating devices for central venous cannulation: meta-analysis. BMJ 2003;327(7411):361.

\section{Ng 2007}

Ng F, Mastoroudes H, Paul E, Davies N, Tibballs J, Hochhauser D, et al. A comparison of Hickman line- and Port-a-Cath-associated complications in patients with solid tumours undergoing

CHARACTERISTICS OF STUDIES

Characteristics of included studies [ordered by study ID] chemotherapy. Clinical Oncology (Royal College of Radiologist (Great Britain)) 2007;19(7):551-6.

\section{Sterne 2001}

Sterne JA, Egger M. Funnel plots for detecting bias in metaanalysis: guidelines on choice of axis. Journal of Clinical Epidemiology 2001;54(10):1046-55.

\section{References to other published versions of this review Hsu 2011}

Hsu CCT, Kwan GNC, van Driel ML, Rophael JA. Venous cutdown versus the Seldinger technique for placement of totally implantable venous access ports. Cochrane Database of Systematic Reviews 2011, Issue 1. [DOI: 10.1002/14651858.CD008942]

Biffi 2009

$\begin{array}{ll}\text { Methods } & \text {-Country: Italy } \\ & \text {-Setting: European Institute of Oncology in Milan (operating room or angiographic suite) }\end{array}$

-Study design: RCT

\section{Participants}

-No. of participants randomised: 403

-Exclusions post randomisation: 2 cancelled operations in the internal jugular catheter group

-Shifted to another arm: 12 in the internal jugular catheter group, 1 in the subclavian catheter group, and 21 in the cephalic catheter group

-Number of participants evaluated: data for late complications evaluated for 360 participants

-Age (mean): 52 years

-Gender: 90 males, 313 females

-Inclusion criteria: Hospitalised adults (aged 18 to 75), with an Eastern Cooperative Oncology Group performance status of 0 to 2, bearing solid tumours and candidate for intravenous chemotherapy

-Exclusion criteria: Active infections, coagulopathy (defined as platelet count $<50,000 / \mu \mathrm{L}$ and/or prothrombin time $>18 \mathrm{~s}$ ), life expectancy $<6$ months, or inability to give written informed consent

Interventions

-A total of 403 participants were randomly assigned to undergo implantation of TIVAP through a percutaneous landmark access to internal jugular vein $(n=134)$, US-guided infraclavicular access to subclavian vein $(n=136)$, or a surgical cutdown access through the cephalic vein $(n=133)$

-No mention of procedure fluoroscopy, however chest radiograph was obtained after each procedure

- - Oailure of catheter placement
-Duration of TIVAP
-Early complication (intraoperative and post implantation period to first use)
-Late complications (occurring after first chemotherapy course given through the device)

Notes

TIVAP: single type of port, constructed of titanium and silicone rubber, with a attached 6-F polyurethane catheter tubing (BardPort; Bard Access Systems Inc, Salt Lake City, UT, USA)

Only oncology patients 
Biffi 2009 (Continued)

Risk of bias

\begin{tabular}{|c|c|c|}
\hline Bias & Authors' judgement & Support for judgement \\
\hline $\begin{array}{l}\text { Random sequence genera- } \\
\text { tion (selection bias) }\end{array}$ & Low risk & "computer-assisted procedure" \\
\hline $\begin{array}{l}\text { Allocation concealment } \\
\text { (selection bias) }\end{array}$ & Unclear risk & $\begin{array}{l}\text { "Randomization was intraoperatively carried out by the data manager of the } \\
\text { trial using a computer-assisted procedure and communicated to the opera- } \\
\text { tors." It is unclear if the data manager was blinded }\end{array}$ \\
\hline $\begin{array}{l}\text { Blinding of participants } \\
\text { and personnel (perfor- } \\
\text { mance bias) } \\
\text { All outcomes }\end{array}$ & Low risk & $\begin{array}{l}\text { No blinding of either participants or personnel mentioned in the methodology. } \\
\text { Comment: Blinding of personnel carrying out the procedure is not feasible for } \\
\text { this procedure. Blinding of participants, however, is practically feasible. Never- } \\
\text { theless, it is unlikely the blinding of the personnel and participants would have } \\
\text { affected the outcomes of the study. We judged performance bias as low risk of } \\
\text { bias }\end{array}$ \\
\hline $\begin{array}{l}\text { Blinding of outcome as- } \\
\text { sessment (detection bias) } \\
\text { All outcomes }\end{array}$ & Unclear risk & Not mentioned \\
\hline $\begin{array}{l}\text { Incomplete outcome data } \\
\text { (attrition bias) } \\
\text { All outcomes }\end{array}$ & Low risk & $\begin{array}{l}\text { Losses to follow-up: } 2 \text { withdrew informed consent and } 13 \text { had no data avail- } \\
\text { able in the internal jugular vein group; } 1 \text { withdrew informed consent and } 12 \\
\text { had no data available in the subclavian catheter group; } 2 \text { withdrew informed } \\
\text { consent and } 11 \text { had no data available in the cephalic catheter group. } \\
\text { Data on late complication only reported in the on-treatment group. No ITT } \\
\text { analysis }\end{array}$ \\
\hline $\begin{array}{l}\text { Selective reporting (re- } \\
\text { porting bias) }\end{array}$ & Low risk & All outcomes reported; flowchart provided \\
\hline Other bias & Low risk & $\begin{array}{l}\text { Funding from Italian Association for Cancer Research } \\
\text { No mention of author conflict of interest }\end{array}$ \\
\hline
\end{tabular}

Boldó 2003

\begin{tabular}{ll}
\hline Methods & - Country: Spain \\
-Setting: Hospital Provincial de Castellón \\
-Study design: RCT \\
\hline Participants & -No. of participants randomised: 100 consecutive patients \\
& -Exclusions post randomisation: not specified \\
& -Shifted to another arm: not specified \\
& -Age (median): 58.6 years cutdown group, 58.2 years percutaneous group \\
& -Gender: 43 males, 57 females \\
& -Inclusion criteria: not specified \\
& -Exclusion criteria: not specified \\
-A total of 100 participants were randomised to the venous cutdown technique which was performed & by vertical or horizontal incision on the path of the chosen vein (did not specify which vein)
\end{tabular}


Boldó 2003 (Continued)

-The Seldinger technique was performed by puncture of the internal jugular or subclavian vein using the anatomical landmark for reference ( $n=50$ for each group)

-In the Seldinger group catheter was introduced under fluoroscopy guidance

\begin{tabular}{ll}
\hline Outcomes & -Duration of TIVAP in days \\
& -Complications \\
\hline Notes & $\begin{array}{l}\text { If a participant randomised to the venous cutdown underwent an unsuccessful procedure, it was ex- } \\
\text { cluded and the randomisation on the cutdown group was kept until the next successful participant. } \\
\text { Only oncology patients }\end{array}$ \\
\hline
\end{tabular}

\section{Risk of bias}

\begin{tabular}{|c|c|c|}
\hline Bias & Authors' judgement & Support for judgement \\
\hline $\begin{array}{l}\text { Random sequence genera- } \\
\text { tion (selection bias) }\end{array}$ & High risk & $\begin{array}{l}\text { Described as "Randomized", but method not mentioned and authors acknowl- } \\
\text { edge the weakness in their discussion }\end{array}$ \\
\hline $\begin{array}{l}\text { Allocation concealment } \\
\text { (selection bias) }\end{array}$ & High risk & Envelope method \\
\hline $\begin{array}{l}\text { Blinding of participants } \\
\text { and personnel (perfor- } \\
\text { mance bias) } \\
\text { All outcomes }\end{array}$ & Low risk & $\begin{array}{l}\text { No blinding of either participants or personnel mentioned in the methodology. } \\
\text { Comment: Blinding of personnel carrying out the procedure is not feasible for } \\
\text { this procedure. Blinding of participants, however, is practically feasible. Never- } \\
\text { theless, it is unlikely the blinding of the personnel and participants would have } \\
\text { affected the outcomes of the study. We judged performance bias as low risk of } \\
\text { bias }\end{array}$ \\
\hline $\begin{array}{l}\text { Blinding of outcome as- } \\
\text { sessment (detection bias) } \\
\text { All outcomes }\end{array}$ & High risk & $\begin{array}{l}\text { No blinding of outcome assessment (as mentioned in the discussion of Boldó } \\
\text { 2003) }\end{array}$ \\
\hline $\begin{array}{l}\text { Incomplete outcome data } \\
\text { (attrition bias) } \\
\text { All outcomes }\end{array}$ & High risk & $\begin{array}{l}\text { Losses to follow-up: not specified. No ITT analysis, although numbers recruit- } \\
\text { ed and numbers analysed are the same. No mention if any patients were ineli- } \\
\text { gible or withdrew consent }\end{array}$ \\
\hline $\begin{array}{l}\text { Selective reporting (re- } \\
\text { porting bias) }\end{array}$ & Low risk & All outcomes reported. No flowchart provided \\
\hline Other bias & Unclear risk & $\begin{array}{l}\text { No mention of funding. } \\
\text { No mention of conflict of interest of authors }\end{array}$ \\
\hline
\end{tabular}

\begin{tabular}{ll} 
Chen 2007 & \\
\hline Methods & - Country: Taiwan \\
& -Setting: Taipei-Veterans General Hospital (operating room and anaesthesia induction room of a uni- \\
& versity hospital) \\
& -Study design: RCT
\end{tabular}


Chen 2007 (Continued)

-Age (mean): percutaneous group (56.5) and surgical group (62.5)

-Gender: 43 males, 57 females

-Exclusions post randomisation: none

-Shifted to another arm: None, the success rate for both insertion techniques was $100 \%$

-Losses to follow-up: none

-Inclusion criteria: 100 consecutive oncology patients scheduled for intravenous chemotherapy

-Exclusion criteria: Patients with local infection or pathology over the venipuncture or incision site, previous long-term central venous catheterisation over the neck, previous history of difficulty in central venous catheterisation, potential risk of compromised airway, or abnormalities in image studies (e.g. a huge mediastinal tumour from chest radiography or compression of the superior vena cava by tumour mass as seen on chest computed tomography)

Interventions

A total of 100 participants were randomised to the percutaneous group who received implantation through the internal jugular vein by experienced anaesthesiologists or the surgical group who received venous cutdown insertion through the cephalic or subclavian vein by surgeons ( $n=50$ for each group)

-In the percutaneous group, ECG was used to confirm catheter position. Fluoroscopy was used to confirmed catheter tip position in the surgical group. Both groups received postprocedural chest radiographic to confirm the location of the catheter tip and to rule out pneumothorax

All participants received long-term empirical antibiotic treatment and device care according to standard practice

\begin{tabular}{ll}
\hline Outcomes & -Procedure failure rate \\
& -Duration of procedure \\
& -Long-term device function \\
& -Patients' satisfaction with the placement: Comfort and satisfaction score: 1 = best score (least pain); 4 \\
& - worst score (intolerable pain) \\
& -Procedural complication \\
-Late complication (follow-up) \\
TIVAP: Arrow Implantable Vascular Access System (Arrow International Inc) \\
All participants received long-term empirical antibiotic treatment and device care according to stan- \\
dard practice. \\
Only oncology patients
\end{tabular}

\section{Risk of bias}

\begin{tabular}{lll}
\hline Bias & Authors' judgement & Support for judgement \\
\hline $\begin{array}{l}\text { Random sequence genera- } \\
\text { tion (selection bias) }\end{array}$ & Low risk & "Computer generated table of random numbers." \\
\hline $\begin{array}{l}\text { Allocation concealment } \\
\text { (selection bias) }\end{array}$ & Unclear risk & Not mentioned \\
\hline $\begin{array}{l}\text { Blinding of participants } \\
\text { and personnel (perfor- } \\
\text { mance bias) } \\
\begin{array}{l}\text { All outcomes } \\
\text { L }\end{array}\end{array}$ & Low risk & No blinding of either participants or personnel mentioned in the methodology. \\
& $\begin{array}{l}\text { Comment: Blinding of personnel carrying out the procedure is not feasible for } \\
\text { this procedure. Blinding of participants, however, is practically feasible. Never- } \\
\text { theless, it is unlikely the blinding of the personnel and participants would have }\end{array}$
\end{tabular}


Chen 2007 (Continued)

affected the outcomes of the study. We judged performance bias as low risk of bias

Blinding of outcome as- $\quad$ Unclear risk $\quad$ Not mentioned
sessment (detection bias)
All outcomes

\begin{tabular}{ll}
\hline $\begin{array}{l}\text { Incomplete outcome data } \\
\text { (attrition bias) }\end{array}$ & $\begin{array}{l}\text { No dropouts reported. Study reports } 100 \text { consecutive patients were recruited } \\
\text { into the study, however they do not mention if any were ineligible }\end{array}$ \\
All outcomes &
\end{tabular}

\begin{tabular}{lll}
\hline $\begin{array}{l}\text { Selective reporting (re- } \\
\text { porting bias) }\end{array}$ & Low risk & All outcomes reported \\
\hline Other bias & Unclear risk & No mention of funding. \\
& \\
\hline
\end{tabular}

D'Angelo 2002

\begin{tabular}{ll}
\hline Methods & - Country: Italy \\
& -Setting: hospital \\
& -Study design: RCT \\
\hline
\end{tabular}

Participants

-No. of participants randomised: 50

-Exclusions post randomisation: not specified

-Shifted to another arm: Technical failure occurred in 2 participants in the subclavian vein puncture which resulted in cephalic vein cutdown. 4 participants with failed cephalic vein cutdown received subclavian vein puncture

-Age (mean): 61.5 years

-Gender: 34 males, 16 females

-Inclusion criteria: All patients presented with solid tumour, and TIVAP was performed for systemic chemotherapy. None of the patients had undergone a previous access procedure

-Exclusion criteria: Study paper refers to tables 1 and 2, but these are missing from the publication

$\begin{array}{ll}\text { Interventions } & \text { A total of } 50 \text { participants were randomised to the cephalic vein cutdown technique or the Seldinger } \\ \text { technique using the subclavian vein ( } n=25 \text { for each group). Intraoperative fluoroscopy was used to as- } \\ \text { sess correct catheter placement in all cases }\end{array}$

Outcomes
-Procedure time for successful TIVAP placement
-Technical failure was defined as the impossibility of positioning the catheter or more than 4 attempts at percutaneous puncture on the same side in the Seldinger group
-Perioperative complications within 30 days of TIVAP implantation
-Late complications: Follow-up was conducted up to the end of the oncological treatment
-Patient acceptance: Verbal report of pain as mild, moderate, or severe, according to a 10-point scoring scale: mild 0 to 3 , moderate 4 to 7 , and severe pain 8 to 10
-Procedural cost: Comprehensive of operative room, device, and intraoperative fluoroscopy control. In case of Seldinger technique there is an additional cost of chest X-ray


D'Angelo 2002 (Continued)

Notes
-The TIVAP were inserted by general surgery residents under the direct supervision of a staff surgeon

-All participants presented solid tumour, and the TIVAP was performed for systemic chemotherapy. Device (Celsite ST201, B. Braun, Chasseneuil, France). A preoperative third-generation cephalosporin was given in all cases

Only oncology patients with solid tumours

\section{Risk of bias}

\begin{tabular}{|c|c|c|}
\hline Bias & Authors' judgement & Support for judgement \\
\hline $\begin{array}{l}\text { Random sequence genera- } \\
\text { tion (selection bias) }\end{array}$ & Low risk & "Randomisation table" \\
\hline $\begin{array}{l}\text { Allocation concealment } \\
\text { (selection bias) }\end{array}$ & Unclear risk & Not mentioned \\
\hline $\begin{array}{l}\text { Blinding of participants } \\
\text { and personnel (perfor- } \\
\text { mance bias) } \\
\text { All outcomes }\end{array}$ & Low risk & $\begin{array}{l}\text { No blinding of either participants or personnel mentioned in the methodology. } \\
\text { Comment: Blinding of personnel carrying out the procedure is not feasible for } \\
\text { this procedure. Blinding of participants, however, is practically feasible. Never- } \\
\text { theless, it is unlikely the blinding of the personnel and participants would have } \\
\text { affected the outcomes of the study. We judged performance bias as low risk of } \\
\text { bias }\end{array}$ \\
\hline
\end{tabular}

Blinding of outcome as- Unclear risk Not mentioned

sessment (detection bias)

All outcomes

$\begin{array}{ll}\begin{array}{l}\text { Incomplete outcome data } \\ \text { (attrition bias) }\end{array} & \text { Low risk } \\ \text { All outcomes } & \begin{array}{l}\text { Losses to follow-up: } 5 \text { participants in the Seldinger group and } 9 \text { participants in } \\ \text { the cephalic vein cutdown group died before the end of the } 6 \text { month oncolog- } \\ \text { ical treatment (follow-up) periods. One participant was lost to follow-up after } \\ \text { the first month }\end{array}\end{array}$

Selective reporting (re- Low risk $\quad$ All outcomes reported
porting bias)

porting bias)

Other bias High risk

No mention of funding.

No mention of conflict of interest of authors.

Exclusions post randomisation: not specified

Knebel 2009

\begin{tabular}{ll}
\hline Methods & - Country: Germany \\
& -Setting: university hospital (University of Heidelberg) \\
& -Study design: RCT \\
\hline Participants & -No. of participants randomised: 164 \\
& -Exclusions post randomisation: None \\
& -Shifted to another arm: When the primary approach failed, conversion to the other technique was nec- \\
essary. In the modified Seldinger group 5 participants subsequently received stand open insertion, \\
and 8 participants received puncture of subclavian vein. In the cephalic vein cutdown group 11 partici-
\end{tabular}


Knebel 2009 (Continued)

pants received the modified Seldinger technique, 4 participants received puncture of subclavian vein, and in 1 participant no implantation possible

-Age (mean): 56 years

-Gender: 90 males, 74 females

-Inclusion criteria: Patients were included who needed an elective primary TIVAP insertion for either benign or malignant disease under local anaesthesia. Informed consent was obtained; all participants were at least 18 years old

-Exclusion criteria: Refusal to participate and other reasons such as lack of compliance, participation in another intervention trial, impaired mental state, or language problems

Interventions

-A total of 164 participants were randomised into either the modified Seldinger technique group or the cephalic vein cutdown group ( $n=82$ for each group). Intraoperative fluoroscopy was used in both groups to confirm final catheter position

Outcomes
-The primary success rate of TIVAP implantation
-Procedure time for successful TIVAP placement
-Primary implantation failure and reasons
-Success rate in conversion to alternative technique
-Perioperative complications

Notes All surgeons were briefed and trained in both techniques, using detailed surgical manuals and photographs of the single steps. Antibiotic prophylaxis was given only to participants at risk of endocarditis, or if the TIVAP was to be used for chemotherapy within 3 days of implantation

Mix of oncology and non-oncology patients

\section{Risk of bias}

\begin{tabular}{lll}
\hline Bias & Authors' judgement & Support for judgement \\
\hline $\begin{array}{l}\text { Random sequence genera- } \\
\text { tion (selection bias) }\end{array}$ & Low risk & "computer-generated system" \\
\hline $\begin{array}{l}\text { Allocation concealment } \\
\text { (selection bias) }\end{array}$ & Low risk & $\begin{array}{l}\text { "After visualization of the distal cephalic vein, randomization was performed } \\
\text { using a computer-generated system (Randomization In Treatment Arms (RI- } \\
\text { TA); StatSol, Lübeck, Germany). If no cephalic vein was visible after surgical ex- } \\
\text { ploration, patients were excluded." }\end{array}$
\end{tabular}

$\begin{array}{ll}\begin{array}{l}\text { Blinding of participants } \\ \text { and personnel (perfor- }\end{array} & \text { Low risk } \\ \begin{array}{l}\text { mance bias) } \\ \text { All outcomes }\end{array} & \begin{array}{l}\text { No blinding of either participants or personnel mentioned in the methodology. } \\ \text { this procedure. Blinding of participants, however, is practically feasible. Never- } \\ \text { theless, it is unlikely the blinding of the personnel and participants would have } \\ \text { affected the outcomes of the study. We judged performance bias as low risk of } \\ \text { bias }\end{array}\end{array}$

\begin{tabular}{lll}
\hline $\begin{array}{l}\text { Blinding of outcome as- } \\
\text { sessment (detection bias) }\end{array}$ & Unclear risk & $\begin{array}{l}\text { Outcome assessment by study nurse, but no mention if study nurse was blind- } \\
\text { ed }\end{array}$ \\
\hline $\begin{array}{l}\text { Incomplete outcome data } \\
\text { (attrition bias) }\end{array}$ & Low risk & $\begin{array}{l}\text { Losses to follow-up: total } n=5,1 \text { death in the modified Seldinger technique } \\
\text { gll outcomes }\end{array}$ \\
& $\begin{array}{l}\text { tempts). ITT for primary endpoints. Secondary endpoints both ITT and per- } \\
\text { protocol analysis }\end{array}$ \\
\hline
\end{tabular}


Knebel 2009 (Continued)

Selective reporting (re- Low risk $\quad$ All outcomes reported
porting bias)

Other bias

Low risk

Supported by grants from Heidelberg Surgical Foundation and Fresenius Kabi.

The authors declare no other conflict of interest

Knebel 2011

\begin{tabular}{ll}
\hline Methods & -Country: Germany \\
-Setting: university hospital (University of Heidelberg) \\
-Study design: RCT
\end{tabular}

Participants

-No. of participants randomised: 110

-Exclusions post randomisation: 3 patients died before the intervention and 5 patients cancelled their appointment

-Shifted to another arm: In 8 participants of the cephalic cutdown technique group the procedure was unsuccessful; the TIVAP was implanted with the modified Seldinger technique in 5 participants and by puncture of the subclavian vein in 3 participants. Two participants who were randomised to the subclavian vein puncture group erroneously received a venous cutdown for TIVAP implantation by a surgeon

-Age (mean): 60.5 in the venous cutdown group and 57.3 in the subclavian puncture group

-Gender: 46 males, 56 females

-Inclusion criteria: Patients aged at least 18 years, who were scheduled for elective primary TIVAP insertion under local anaesthesia, presenting to both participating institutions, and who gave informed consent were eligible

-Exclusion criteria: Refusal to participate, allergy to contrast agents, expected lack of compliance, impaired mental state, language problem, or participation in another interventional trial that might have interfered with the outcome of this trial

Interventions

-110 participants were randomly assigned to either open insertion technique performed by surgeons or puncture of the subclavian vein under fluoroscopic guidance by radiologists ( $n=51$ for each group). Both groups utilised intraoperative fluoroscopy guidance to confirm final catheter position

\title{
Outcomes
}

\author{
-Primary success rate of the cannulation strategy \\ -Duration of the procedure \\ -The dose of radiation in $\mathrm{cGy} / \mathrm{cm}^{2}$ \\ -Perioperative complications \\ -Postoperative complications
}

-Safety was defined as mortality or hospital admission for any cause up to 90 days after the intervention

Notes

-TIVAP device (Ambix Intraport C, Fresenius Kabi, Germany)

-Implantations were performed by 12 ( 6 board-certified) surgeons and 3 ( 2 board-certified) radiologists 
Knebel 2011 (Continued)

-8 participants received an antibiotic treatment at the time of implantation ( 5 participants with gastroenterological neoplasm and 3 participants with gynaecological neoplasm). However, an antibiotic prophylaxis during or after TIVAP was not used

\title{
Risk of bias
}

\begin{tabular}{lll}
\hline Bias & Authors' judgement & Support for judgement \\
\hline $\begin{array}{l}\text { Random sequence genera- } \\
\text { tion (selection bias) }\end{array}$ & Low risk & $\begin{array}{l}\text { Unstratified block randomisation ratio 1:1 } \\
\text { Computer software: Randomization in Treatment Arms (RITA) }\end{array}$ \\
\hline $\begin{array}{l}\text { Allocation concealment } \\
\text { (selection bias) }\end{array}$ & Unclear risk & Not mentioned \\
\hline $\begin{array}{l}\text { Blinding of participants } \\
\text { and personnel (perfor- } \\
\text { mance bias) } \\
\begin{array}{l}\text { All outcomes } \\
\text { Low risk }\end{array}\end{array}$ & $\begin{array}{l}\text { No blinding of either participants or personnel mentioned in the methodology. } \\
\text { Comment: Blinding of personnel carrying out the procedure is not feasible for } \\
\text { this procedure. Blinding of participants, however, is practically feasible. Never- } \\
\text { theless, it is unlikely the blinding of the personnel and participants would have } \\
\text { affected the outcomes of the study. We judged performance bias as low risk of } \\
\text { bias }\end{array}$ \\
\hline
\end{tabular}

Blinding of outcome as- Low risk Outcomes assessed by "independent study nurse"

sessment (detection bias)

All outcomes

Incomplete outcome data Low risk

(attrition bias)

All outcomes
Losses to follow-up: In the Seldinger group 4 participants were lost to follow-up: 2 could not be contacted via telephone and 2 died. In the venous cutdown group 7 participants were lost to follow-up: 2 could not be contacted via telephone and 5 died.

ITT analysis for all outcomes with all participants randomised minus the ones that died prior to the intervention

\begin{tabular}{lll}
\hline $\begin{array}{l}\text { Selective reporting (re- } \\
\text { porting bias) }\end{array}$ & Low risk & All outcomes reported \\
\hline Other bias & Low risk & No mention of funding. \\
& The authors declare no other conflict of interest \\
\hline
\end{tabular}

\section{Nocito 2009}

\begin{tabular}{ll}
\hline Methods & -Country: Switzerland \\
& -Setting: hospital (University Hospital Zurich) \\
& -Study design: RCT \\
\hline
\end{tabular}

\section{Participants}

\author{
-No. of participants randomised: 152 \\ -Exclusions post randomisation: None
}

-Shifted to another arm: When the primary approach failed, conversion to the other technique was necessary. In the venous cutdown group 22 participants required conversion to the Seldinger technique and 3 participants had failed implantation. In the Seldinger group 8 participants required conversion to the venous cutdown technique and 1 participant had failed implantation

-Age (mean): 54.2 in the venous cutdown group and 56.0 in the Seldinger group 
Nocito 2009 (Continued)

-Gender ratio (M:F): 25:51

-Inclusion criteria: Patients who needed a permanent central venous access were randomised to undergo TIVAP placement by either the Seldinger or venous cutdown technique. Eligible patients had to be at least 18 years of age

-Exclusion criteria: These included inability to obtain informed consent owing to language restriction, anticoagulation therapy, acquired or congenital coagulopathy, and previous bilateral interventions (including irradiation) on shoulder or breast

$\begin{array}{ll}\text { Interventions } & \begin{array}{l}\text { A total of } 152 \text { participants were randomised to the cephalic vein cutdown group or the subclavian vein } \\ \text { puncture/Seldinger technique for implantation of TIVAP ( } \mathrm{n}=76 \text { for each group). Both groups utilised in- } \\ \text { traoperative fluoroscopy guidance to confirm final catheter position }\end{array}\end{array}$

Outcomes -The primary success rate of TIVAP implantation. If primary success could not be achieved, the other method was employed

-Overall implantation success rate (including successful placement after conversion)

-Procedure time

-Perioperative complication

-The median number of needle passes for attempted venepuncture in the Seldinger group was assessed (defined as separate skin punctures)

-The influence of variables such as sex, BMI, implantation side, and surgeon experience on the rate of primary success was analysed

\section{Notes}

All surgeons were trained in both techniques. TIVAP implantation (BardPort; Bard Access Systems Inc, Salt Lake City, UT, USA) was done on an outpatient basis, under sterile conditions in the operating room, and under local anaesthesia. Participants who needed a concomitant surgical procedure had the TIVAP placed under general anaesthesia. Antibiotic prophylaxis was given to all participants.

Mixed group of oncology and non-oncology patients

\section{Risk of bias}

\begin{tabular}{|c|c|c|}
\hline Bias & Authors' judgement & Support for judgement \\
\hline $\begin{array}{l}\text { Random sequence genera- } \\
\text { tion (selection bias) }\end{array}$ & Unclear risk & Not mentioned \\
\hline $\begin{array}{l}\text { Allocation concealment } \\
\text { (selection bias) }\end{array}$ & Low risk & $\begin{array}{l}\text { "Randomization was done by a clinical nurse not otherwise involved in the } \\
\text { study, using opaque, sealed envelopes that were opened by the surgeon in the } \\
\text { operating room immediately before the procedure." }\end{array}$ \\
\hline $\begin{array}{l}\text { Blinding of participants } \\
\text { and personnel (perfor- } \\
\text { mance bias) } \\
\text { All outcomes }\end{array}$ & Low risk & $\begin{array}{l}\text { No blinding of either participants or personnel mentioned in the methodology. } \\
\text { Comment: Blinding of personnel carrying out the procedure is not feasible for } \\
\text { this procedure. Blinding of participants, however, is practically feasible. Never- } \\
\text { theless, it is unlikely the blinding of the personnel and participants would have } \\
\text { affected the outcomes of the study. We judged performance bias as low risk of } \\
\text { bias }\end{array}$ \\
\hline $\begin{array}{l}\text { Blinding of outcome as- } \\
\text { sessment (detection bias) } \\
\text { All outcomes }\end{array}$ & Unclear risk & $\begin{array}{l}\text { All data entered by nurse in confidential database, but unclear if the nurse was } \\
\text { aware of the allocated group }\end{array}$ \\
\hline $\begin{array}{l}\text { Incomplete outcome data } \\
\text { (attrition bias) } \\
\text { All outcomes }\end{array}$ & Low risk & Losses to follow-up: None \\
\hline
\end{tabular}


Nocito 2009 (Continued)

Selective reporting (re- Low risk $\quad$ All outcomes reported
porting bias)

Other bias Low risk There was no specific funding for this study.

The authors declare no conflict of interest

Riapisarda 2006

\begin{tabular}{ll}
\hline Methods & - Country: Italy \\
- Setting: university hospital \\
-Study design: RCT \\
\hline Participants & - No. of participants randomised: 99 \\
& - -Ge (mean): 67.1 years \\
& -Exclusions post randomisation: not specified \\
& -Shifted to another arm: In the Seldinger group conversion to the venous cutdown technique occurred \\
& in 3 participants. In the venous cutdown group conversion to the Seldinger technique occurred in 1 \\
& participant \\
-Inclusion criteria: TIVAP implantation for administration of systemic chemotherapy for the treatment \\
of neoplastic \\
-Exclusion criteria: not specified
\end{tabular}

Interventions A total of 99 participants were randomly assigned to the cephalic vein cutdown group or the Seldinger group with percutaneous puncture of the subclavian vein. $(n=49$ in the cutdown group and $n=50$ in the Seldinger group). Intraoperative fluoroscopy was used and final postprocedural chest radiograph to confirm final catheter position

\begin{tabular}{ll}
\hline Outcomes & -Technical failure requiring conversion to alternative technique \\
& -Mortality or associated morbidity \\
& -Early complications (within 30 days after implantation) \\
& -Late complications \\
& -Mean operation time \\
& -Operative cost \\
& -Patient acceptance \\
\hline Notes & All participants underwent local anaesthetics with antibiotic prophylaxis with ceftriaxone. \\
\hline Risk of bias & Only oncology patients \\
\hline Bias & Authors' judgement Support for judgement \\
\hline $\begin{array}{l}\text { Random sequence genera- } \\
\text { tion (selection bias) }\end{array}$ & Unclear risk Described as "randomized", but method not specified in the manuscript \\
\hline
\end{tabular}


Riapisarda 2006 (Continued)

\begin{tabular}{l}
$\begin{array}{l}\text { Allocation concealment } \\
\text { (selection bias) }\end{array}$ Unclear risk Not specified in the manuscript \\
\hline
\end{tabular}

$\begin{array}{ll}\begin{array}{l}\text { Blinding of participants } \\ \text { and personnel (perfor- }\end{array} & \text { Low risk } \\ \begin{array}{l}\text { mance bias) } \\ \text { All outcomes }\end{array} & \begin{array}{l}\text { No blinding of either participants or personnel mentioned in the methodology. } \\ \text { this procedure. Blinding of participants, however, is practically feasible. Never- } \\ \text { theless, it is unlikely the blinding of the personnel and participants would have } \\ \text { affected the outcomes of the study. We judged performance bias as low risk of } \\ \text { bias }\end{array}\end{array}$

\begin{tabular}{ll}
\hline Blinding of outcome as- & Unclear risk $\quad$ Not mentioned \\
sessment (detection bias) & \\
All outcomes &
\end{tabular}

\begin{tabular}{lll}
\hline $\begin{array}{l}\text { Incomplete outcome data } \\
\text { (attrition bias) } \\
\text { All outcomes }\end{array}$ & High risk & Losses to follow-up: not specified \\
\hline $\begin{array}{l}\text { Selective reporting (re- } \\
\text { porting bias) }\end{array}$ & High risk & Outcomes not reported in methods section \\
\hline Other bias & High risk & No mention of funding. \\
& No mention of conflict of interest of authors. \\
\hline
\end{tabular}

Ribeiro 2012

\begin{tabular}{ll}
\hline Methods & - Country: Brazil \\
-Setting: university hospital \\
-Study design: RCT \\
\hline Participants & -No. of participants randomised: 83 \\
- Age (mean): 6 years (72 months) in the subclavian Seldinger group and 7 years ( 82 months) in the in- \\
ternal jugular Seldinger group \\
-Gender: $58 \%$ males, $42 \%$ females \\
-Exclusions post randomisation: If the initial attempt in the randomised site was unsuccessful, the sur- \\
geon would proceed to a new attempt at the other puncture site. In cases where this second route was \\
also unsuccessful, children were excluded from the long-term analysis \\
-Inclusion criteria: Paediatric oncology patients \\
-Exclusion criteria: Patients weighing less than 6 kg had their catheters preferentially implanted by the \\
venous dissection technique and were excluded from the study \\
A total of 83 children were included in the study; 44 were initially randomised to TIVAP implantation in \\
the subclavian vein and 39 to the internal jugular vein. Six children were excluded from the study be- \\
cause implantation by puncture failed in both sites. Patients for TIVAP implantation were under general \\
anaesthesia. Routine antibiotic prophylaxis was administered. The Seldinger technique internal jugular \\
vein and subclavian vein punctures were performed without use of ultrasound. In all cases, implanta- \\
tion was preferentially performed on the child's right side. Chest radiograph was performed to confirm \\
catheter position
\end{tabular}


Ribeiro 2012 (Continued)

Notes

\section{Risk of bias}

\begin{tabular}{|c|c|c|}
\hline Bias & Authors' judgement & Support for judgement \\
\hline $\begin{array}{l}\text { Random sequence genera- } \\
\text { tion (selection bias) }\end{array}$ & High risk & Randomisation (using a coin; heads or tails) was employed \\
\hline $\begin{array}{l}\text { Allocation concealment } \\
\text { (selection bias) }\end{array}$ & High risk & $\begin{array}{l}\text { Not specified, but it seems likely that the coin tossing happened immediately } \\
\text { before surgery, which implies that there was no allocation concealment }\end{array}$ \\
\hline $\begin{array}{l}\text { Blinding of participants } \\
\text { and personnel (perfor- } \\
\text { mance bias) } \\
\text { All outcomes }\end{array}$ & Low risk & $\begin{array}{l}\text { No blinding of either participants or personnel mentioned in the methodology. } \\
\text { Comment: Blinding of personnel carrying out the procedure is not feasible for } \\
\text { this procedure. Blinding of participants, however, is practically feasible. Never- } \\
\text { theless, it is unlikely the blinding of the personnel and participants would have } \\
\text { affected the outcomes of the study. We judged performance bias as low risk of } \\
\text { bias }\end{array}$ \\
\hline $\begin{array}{l}\text { Blinding of outcome as- } \\
\text { sessment (detection bias) } \\
\text { All outcomes }\end{array}$ & Unclear risk & Not specified \\
\hline $\begin{array}{l}\text { Incomplete outcome data } \\
\text { (attrition bias) } \\
\text { All outcomes }\end{array}$ & High risk & $\begin{array}{l}\text { If the initial attempt in the randomised site was unsuccessful, the surgeon } \\
\text { would proceed to a new attempt at the other puncture site. In cases where this } \\
\text { second route was also unsuccessful, children were excluded from the long- } \\
\text { term analysis }\end{array}$ \\
\hline $\begin{array}{l}\text { Selective reporting (re- } \\
\text { porting bias) }\end{array}$ & Unclear risk & All endpoints mentioned in methods section are reported \\
\hline Other bias & Unclear risk & $\begin{array}{l}\text { Conflict of interest: nothing to declare } \\
\text { Funding source not reported }\end{array}$ \\
\hline
\end{tabular}

BMI: body mass index

ECG: electrocardiogram

ITT: intention to treat

$\mathrm{RCT}$ : randomised controlled trial

TIVAP: totally implantable venous access ports

US: ultrasound

Characteristics of excluded studies [ordered by study ID]

\begin{tabular}{ll}
\hline Study & Reason for exclusion \\
\hline D'Angelo 1997 & A retrospective study of 158 TIVAP implantations; 12 cases required a different insertion site \\
\hline Munro 1999 & $\begin{array}{l}\text { RCT comparing venous cutdown (cephalic vein or external jugular vein) versus percutaneous sub- } \\
\text { clavian puncture for insertion of Hickman catheters }\end{array}$ \\
\hline NCT01584193 & This study was withdrawn prior to enrolment \\
\hline
\end{tabular}

RCT: randomised controlled trial

TIVAP: totally implantable venous access ports 
Characteristics of ongoing studies [ordered by study ID]

Huttner 2015

\begin{tabular}{ll}
\hline Trial name or title & PORTAS-3 trial \\
\hline Methods & - Country: Germany \\
& -Setting: multicentre \\
& -Study design: RCT \\
\hline Participants & -Inclusion criteria: Consented oncology adult patients (> 18 years) designated for primary elective \\
& TIVAP implantation \\
& -Exclusion criteria: Patients participating in another interventional trial which could interfere with \\
the primary endpoint
\end{tabular}

\begin{tabular}{ll}
\hline Outcomes & -Primary success rate \\
-Complications: post interventional pneumothorax and haemothorax & -Duration of port implantation procedure \\
& -Subjective tolerability of intervention \\
-30-day mortality \\
-30-day morbidity
\end{tabular}

Starting date

The PORTAS-3 trial started recruitment of participants in November 2014. Recruitment is currently ongoing and is expected to be complete in the first quarter of 2016

Contact information_ phillip.knebel@med.uni-heidelberg.de

Notes

$\mathrm{RCT}$ : randomised controlled trial

TIVAP: totally implantable venous access ports

DATA AND ANALYSES

\section{Comparison 1. Success of primary implantation}

\begin{tabular}{lllll}
\hline Outcome or subgroup title & No. of studies & $\begin{array}{l}\text { No. of partici- } \\
\text { pants }\end{array}$ & Statistical method & Effect size \\
\hline $\begin{array}{l}1 \text { Seldinger (subclavian \& IJ) versus venous } \\
\text { cutdown (cephalic vein) ITT }\end{array}$ & 7 & 1006 & $\begin{array}{l}\text { Odds Ratio (M-H, } \\
\text { Fixed, 95\% Cl) }\end{array}$ & $0.40[0.25,0.65]$ \\
\hline
\end{tabular}




\begin{tabular}{lllll}
\hline Outcome or subgroup title & No. of studies & $\begin{array}{l}\text { No. of partici- } \\
\text { pants }\end{array}$ & Statistical method & Effect size \\
\hline $\begin{array}{l}\text { 2 Seldinger (subclavian vein) versus venous } \\
\text { cutdown (cephalic vein) ITT }\end{array}$ & 5 & 672 & $\begin{array}{l}\text { Odds Ratio (M-H, } \\
\text { Fixed, 95\% Cl) }\end{array}$ & $0.23[0.13,0.41]$ \\
\hline $\begin{array}{l}\text { 3 Seldinger (IJ vein) versus venous cutdown } \\
\text { (cephalic vein) ITT }\end{array}$ & 2 & 367 & $\begin{array}{l}\text { Odds Ratio (M-H, } \\
\text { Fixed, 95\% Cl) }\end{array}$ & $0.62[0.30,1.28]$ \\
\hline $\begin{array}{l}\text { 4 Seldinger (subclavian \& IJ) versus venous } \\
\text { cutdown (cephalic vein). On-treatment analy- } \\
\text { sis }\end{array}$ & 7 & 972 & $\begin{array}{l}\text { Odds Ratio (M-H, } \\
\text { Fixed, 95\% Cl) }\end{array}$ & $0.59[0.36,0.98]$ \\
\hline $\begin{array}{l}5 \text { Seldinger (subclavian vein) versus venous } \\
\text { cutdown (cephalic vein). On-treatment analy- } \\
\text { sis }\end{array}$ & 5 & 640 & Odds Ratio (M-H, \\
\hline $\begin{array}{l}\text { 6 Seldinger (IJ vein) versus venous cutdown } \\
\text { (cephalic vein). On-treatment analysis }\end{array}$ & 2 & Fixed, 95\% Cl) & $0.27[0.15,0.49]$ \\
\hline
\end{tabular}

Analysis 1.1. Comparison 1 Success of primary implantation, Outcome 1 Seldinger (subclavian \& IJ) versus venous cutdown (cephalic vein) ITT.

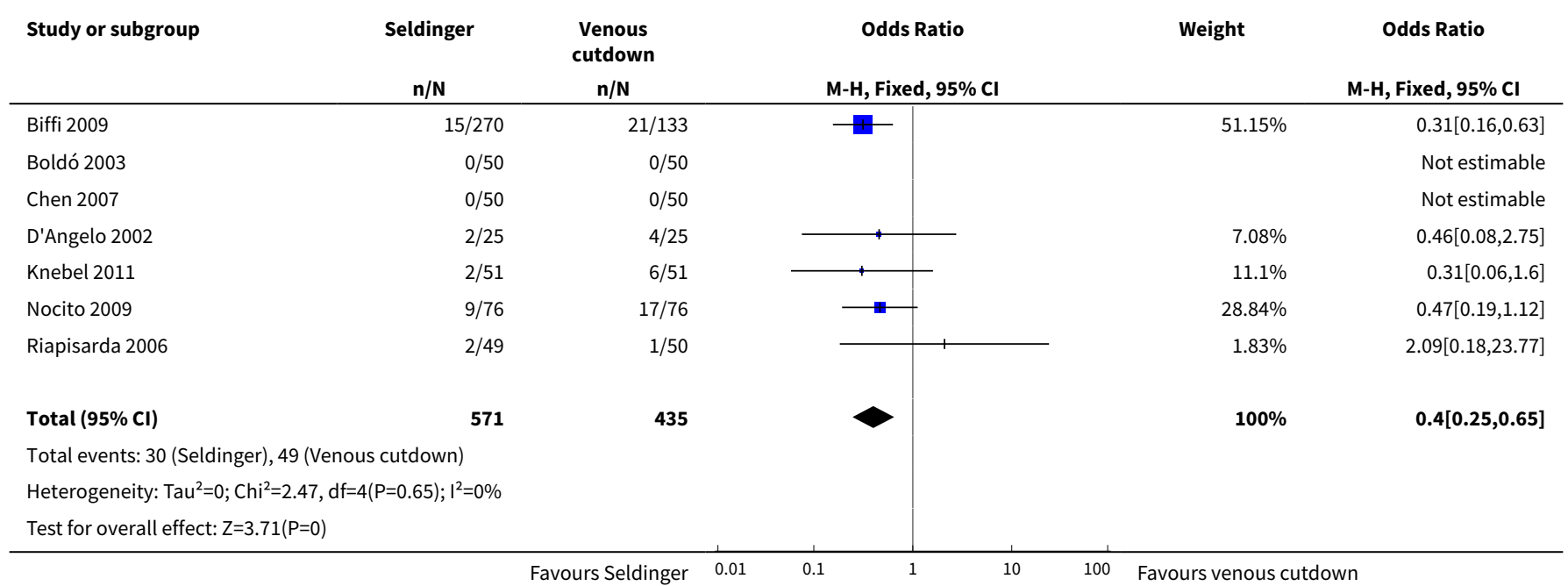

Analysis 1.2. Comparison 1 Success of primary implantation, Outcome 2 Seldinger (subclavian vein) versus venous cutdown (cephalic vein) ITT.

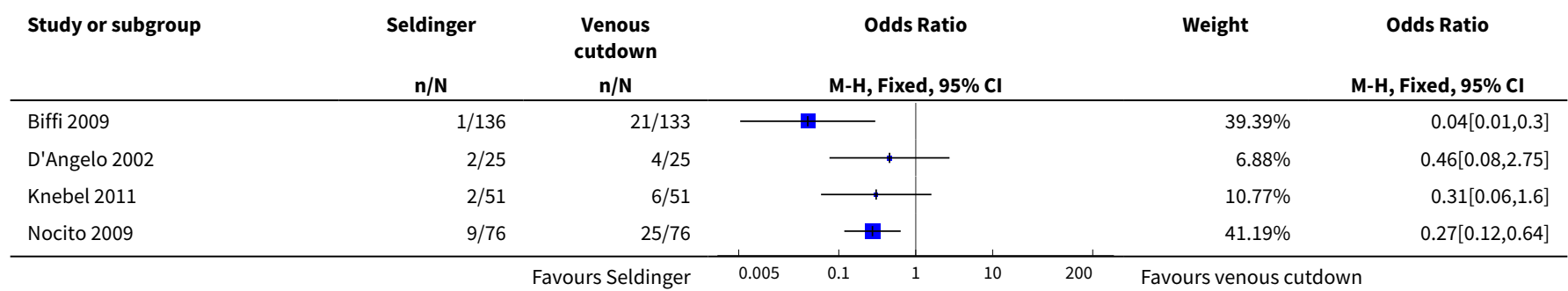




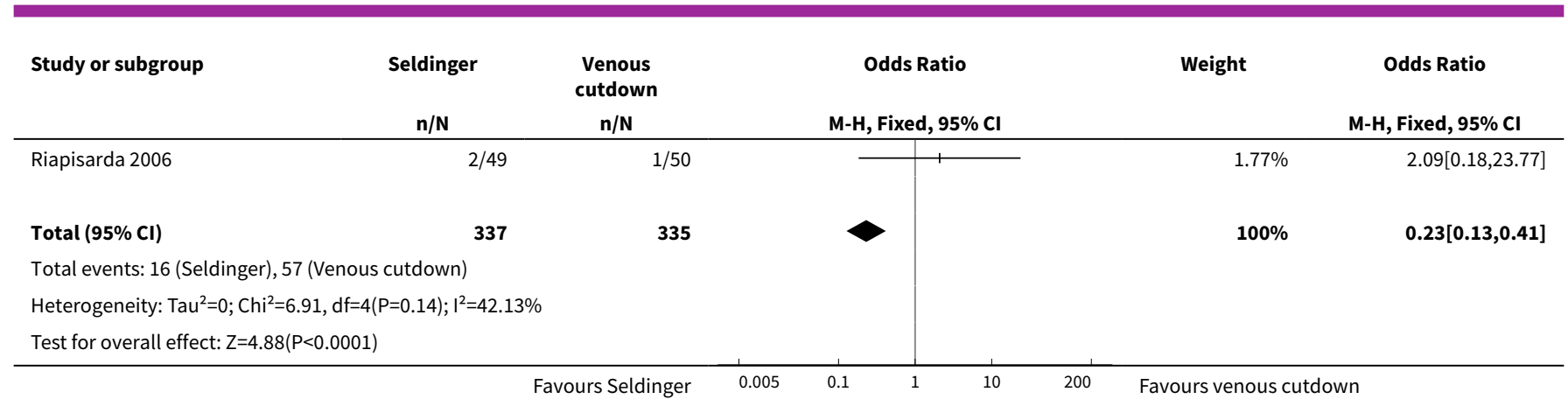

Analysis 1.3. Comparison 1 Success of primary implantation, Outcome 3 Seldinger (IJ vein) versus venous cutdown (cephalic vein) ITT.

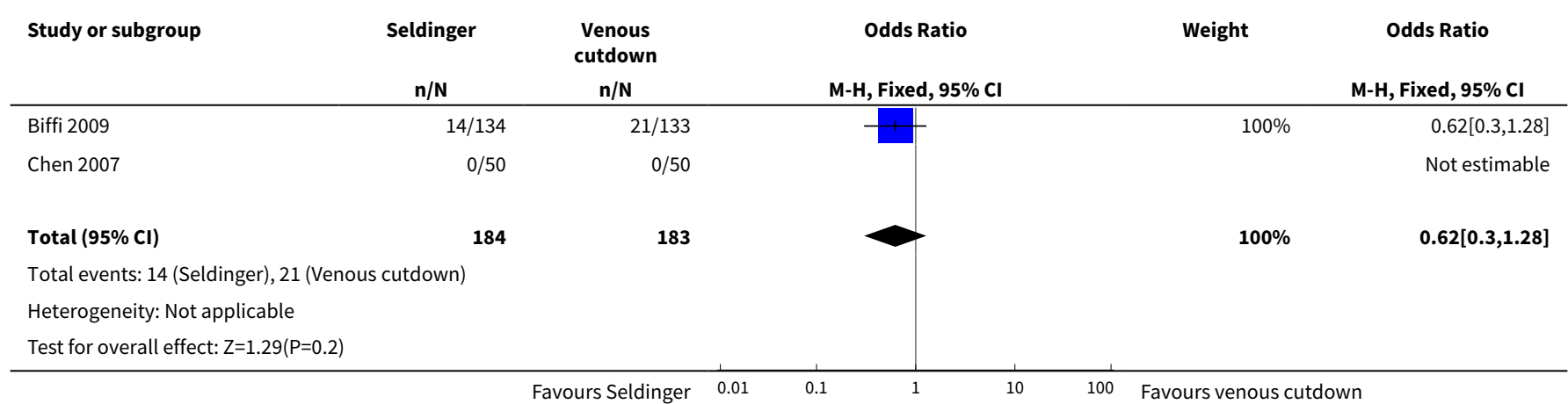

Analysis 1.4. Comparison 1 Success of primary implantation, Outcome 4 Seldinger (subclavian \& IJ) versus venous cutdown (cephalic vein). On-treatment analysis.

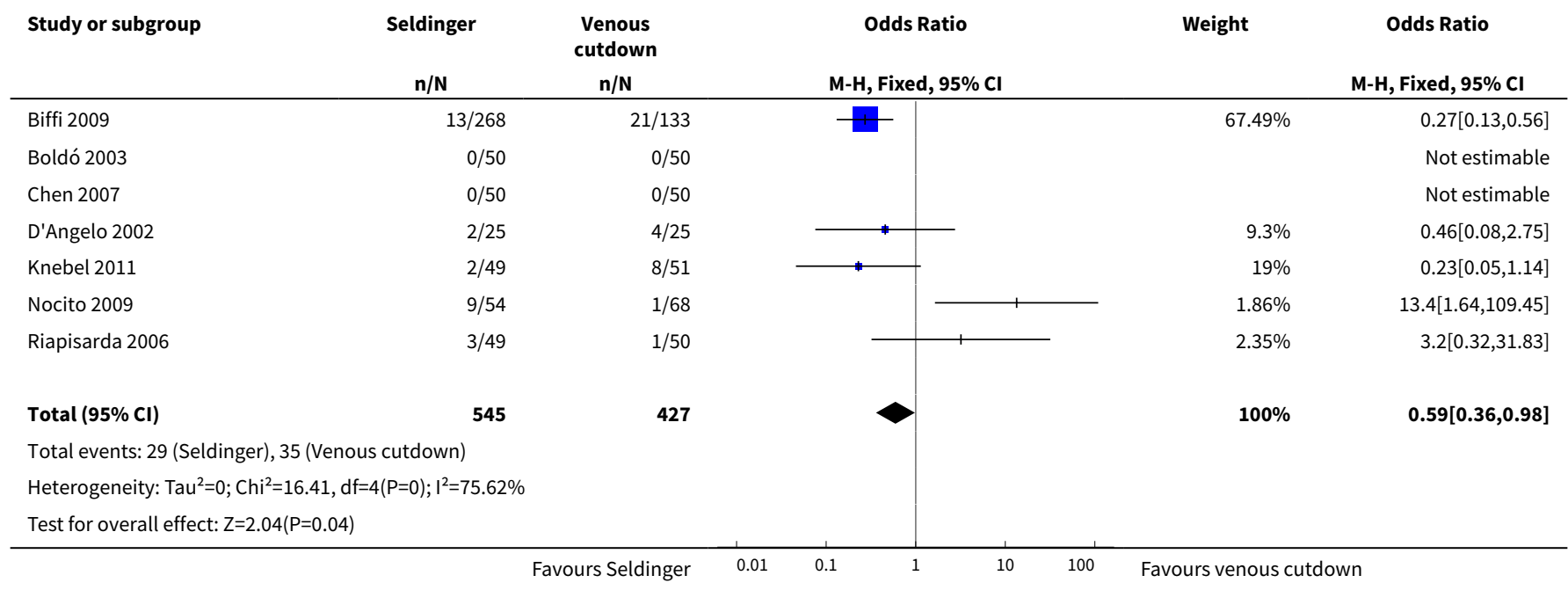


Analysis 1.5. Comparison 1 Success of primary implantation, Outcome 5 Seldinger (subclavian vein) versus venous cutdown (cephalic vein). On-treatment analysis.

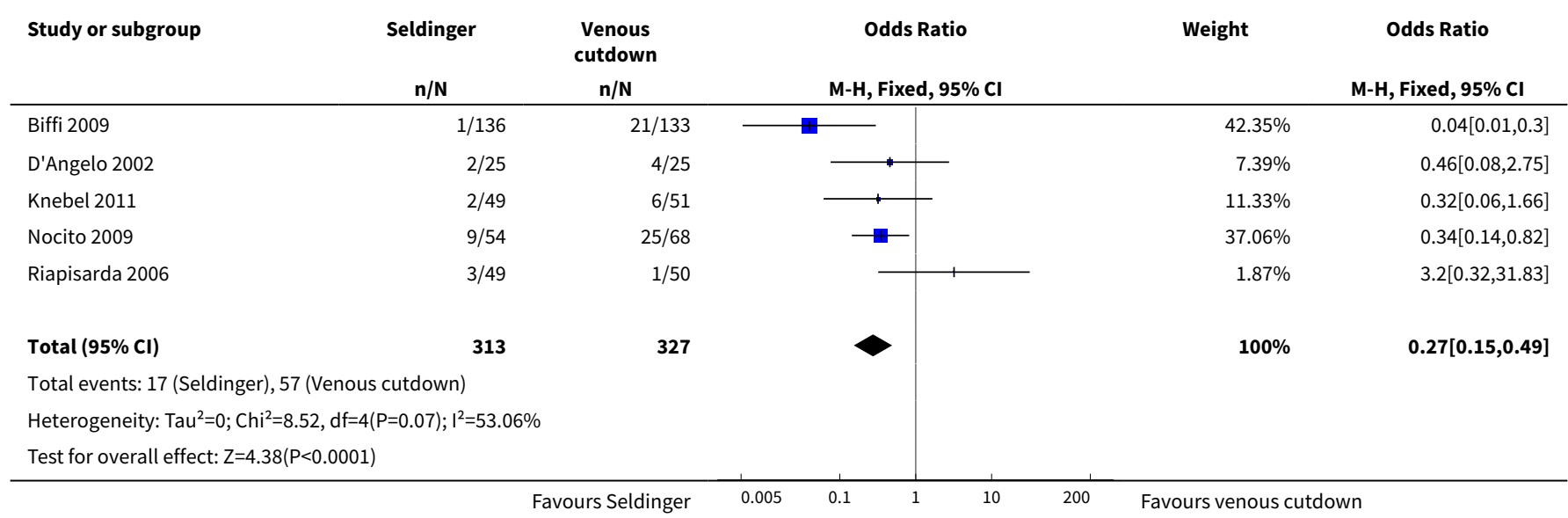

Analysis 1.6. Comparison 1 Success of primary implantation, Outcome 6 Seldinger (IJ vein) versus venous cutdown (cephalic vein). On-treatment analysis.

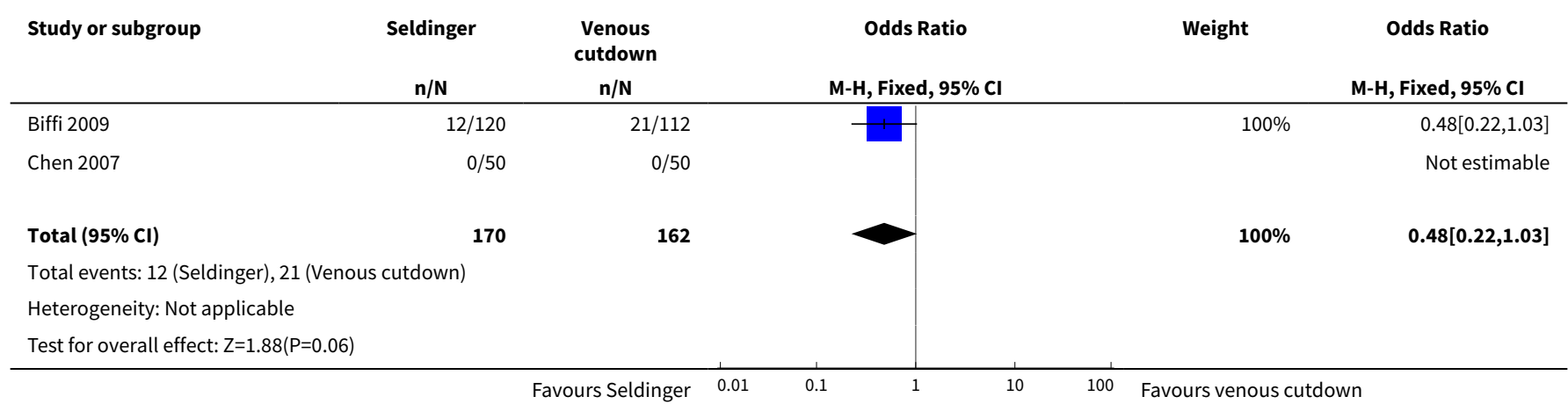

\section{Comparison 2. Overall perioperative and postoperative complications}

\begin{tabular}{lllll}
\hline Outcome or subgroup title & No. of studies & $\begin{array}{l}\text { No. of partici- } \\
\text { pants }\end{array}$ & Statistical method & Effect size \\
\hline $\begin{array}{l}\text { 1 Seldinger (subclavian \& IJ) versus venous } \\
\text { cutdown (cephalic vein) ITT }\end{array}$ & 7 & 1006 & $\begin{array}{l}\text { Odds Ratio (M-H, } \\
\text { Fixed, 95\% Cl) }\end{array}$ & $1.16[0.76,1.75]$ \\
\hline $\begin{array}{l}\text { 2 Seldinger (subclavian vein) versus venous } \\
\text { cutdown (cephalic vein) ITT }\end{array}$ & 5 & 672 & $\begin{array}{l}\text { Odds Ratio (M-H, } \\
\text { Fixed, 95\% Cl) }\end{array}$ & $1.28[0.78,2.10]$ \\
\hline $\begin{array}{l}\text { 3 Seldinger (IJ vein) versus venous cutdown } \\
\text { (cephalic vein) ITT }\end{array}$ & 2 & 367 & Odds Ratio (M-H, & $0.72[0.40,1.31]$ \\
\hline $\begin{array}{l}\text { 4 Seldinger (subclavian \& IJ) versus venous } \\
\text { cutdown (cephalic vein). On-treatment analy- } \\
\text { sis }\end{array}$ & 7 & & Fixed, 95\% Cl) & Odds Ratio (M-H, \\
\hline
\end{tabular}




\begin{tabular}{lllll}
\hline Outcome or subgroup title & No. of studies & $\begin{array}{l}\text { No. of partici- } \\
\text { pants }\end{array}$ & Statistical method & Effect size \\
\hline $\begin{array}{l}\text { 5 Seldinger (subclavian vein) versus venous } \\
\text { cutdown (cephalic vein). On-treatment analy- } \\
\text { sis }\end{array}$ & 5 & 618 & $\begin{array}{l}\text { Odds Ratio (M-H, } \\
\text { Fixed, 95\% Cl) }\end{array}$ & $1.06[0.66,1.72]$ \\
\hline $\begin{array}{l}\text { 6 Seldinger (IJ vein) versus venous cutdown } \\
\text { (cephalic vein). On-treatment analysis }\end{array}$ & 2 & 332 & Odds Ratio (M-H, & $0.67[0.37,1.23]$ \\
\hline
\end{tabular}

Analysis 2.1. Comparison 2 Overall perioperative and postoperative complications, Outcome 1 Seldinger (subclavian \& IJ) versus venous cutdown (cephalic vein) ITT.

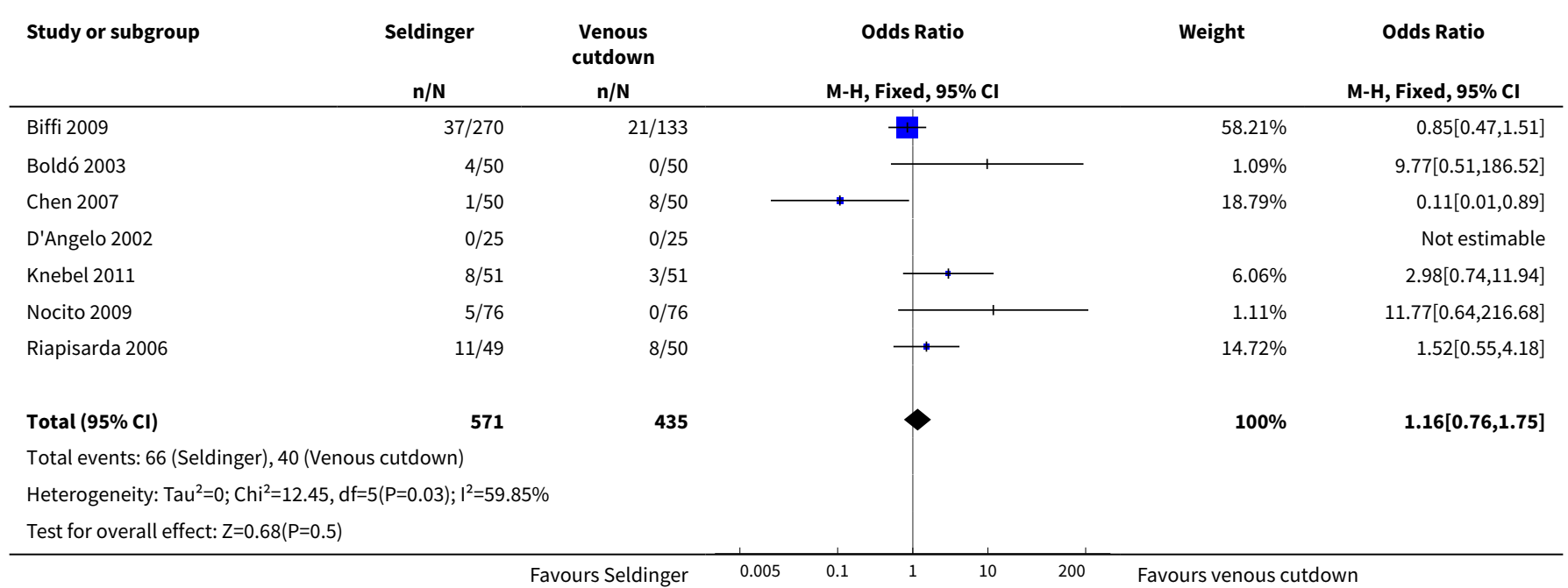

Analysis 2.2. Comparison 2 Overall perioperative and postoperative complications, Outcome 2 Seldinger (subclavian vein) versus venous cutdown (cephalic vein) ITT.

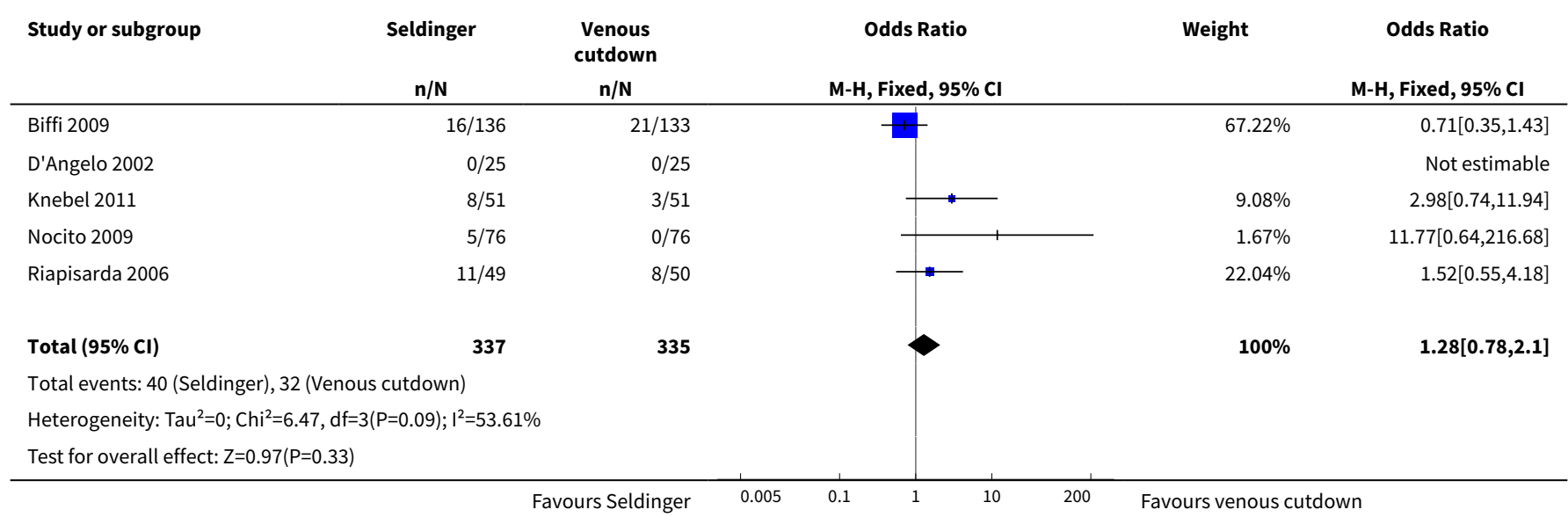


Analysis 2.3. Comparison 2 Overall perioperative and postoperative complications, Outcome 3 Seldinger (IJ vein) versus venous cutdown (cephalic vein) ITT.

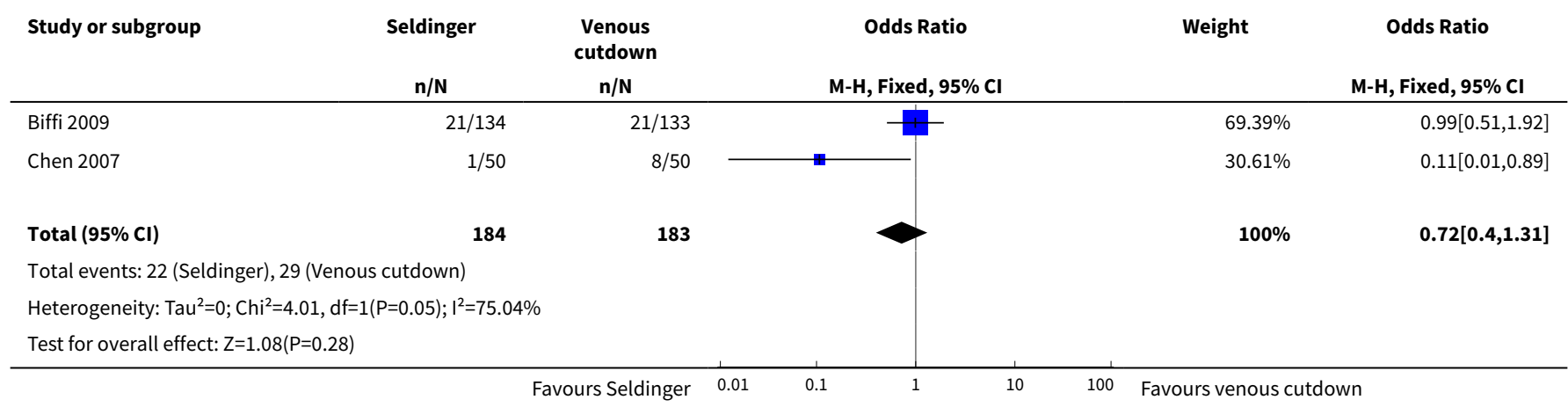

Analysis 2.4. Comparison 2 Overall perioperative and postoperative complications, Outcome 4 Seldinger (subclavian \& IJ) versus venous cutdown (cephalic vein). On-treatment analysis.

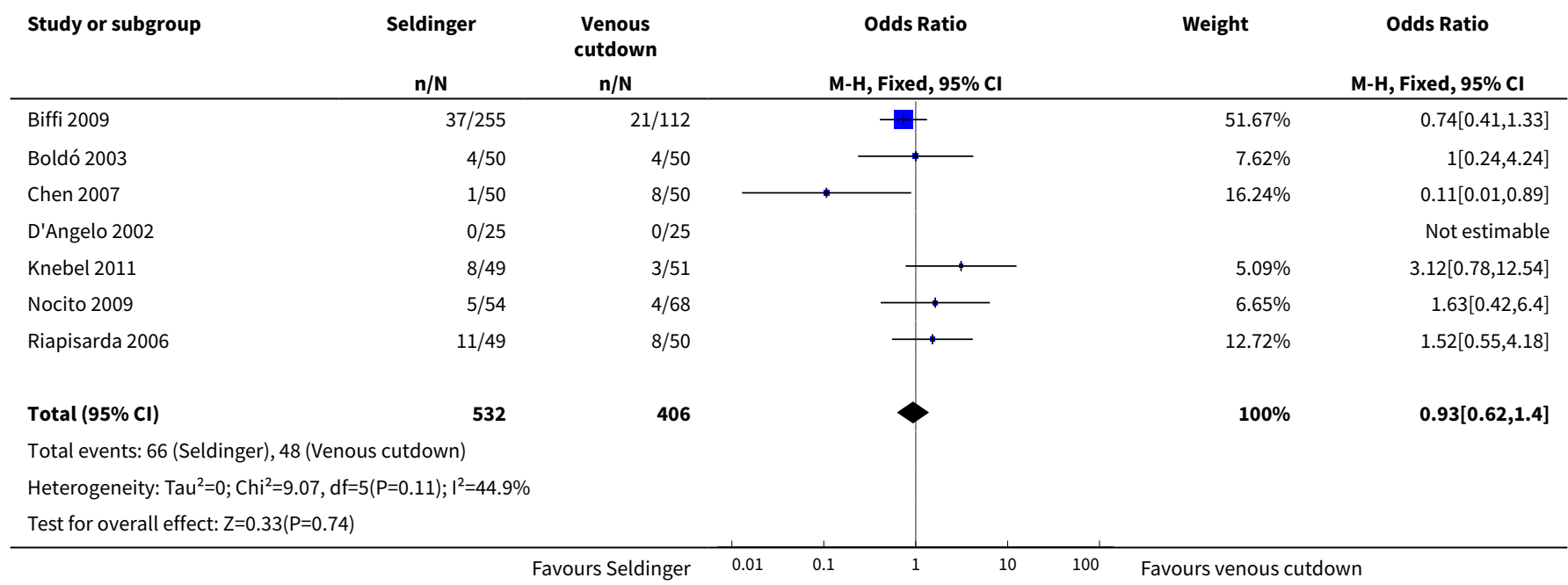

Analysis 2.5. Comparison 2 Overall perioperative and postoperative complications, Outcome 5 Seldinger (subclavian vein) versus venous cutdown (cephalic vein). On-treatment analysis.

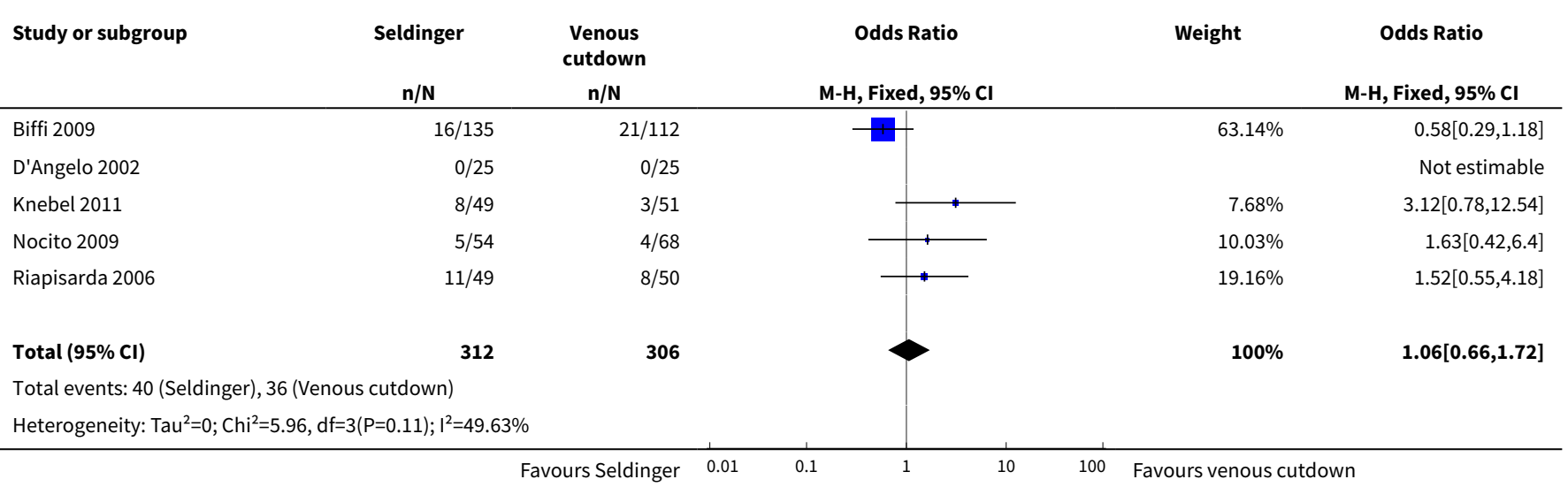




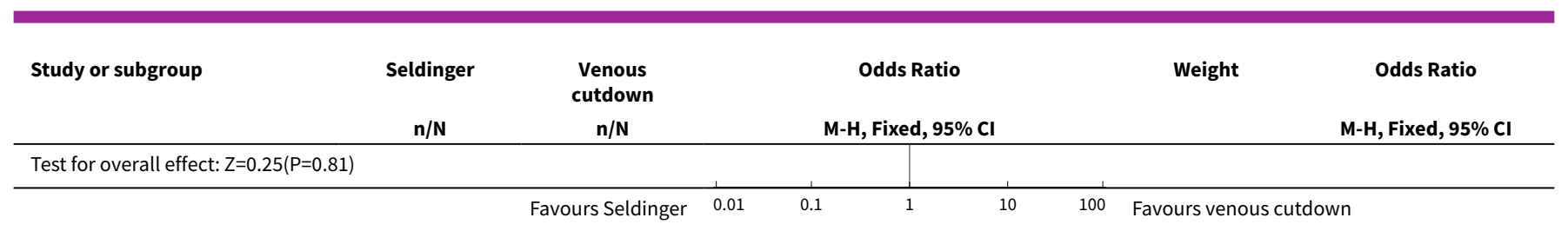

Analysis 2.6. Comparison 2 Overall perioperative and postoperative complications, Outcome 6 Seldinger (IJ vein) versus venous cutdown (cephalic vein). On-treatment analysis.

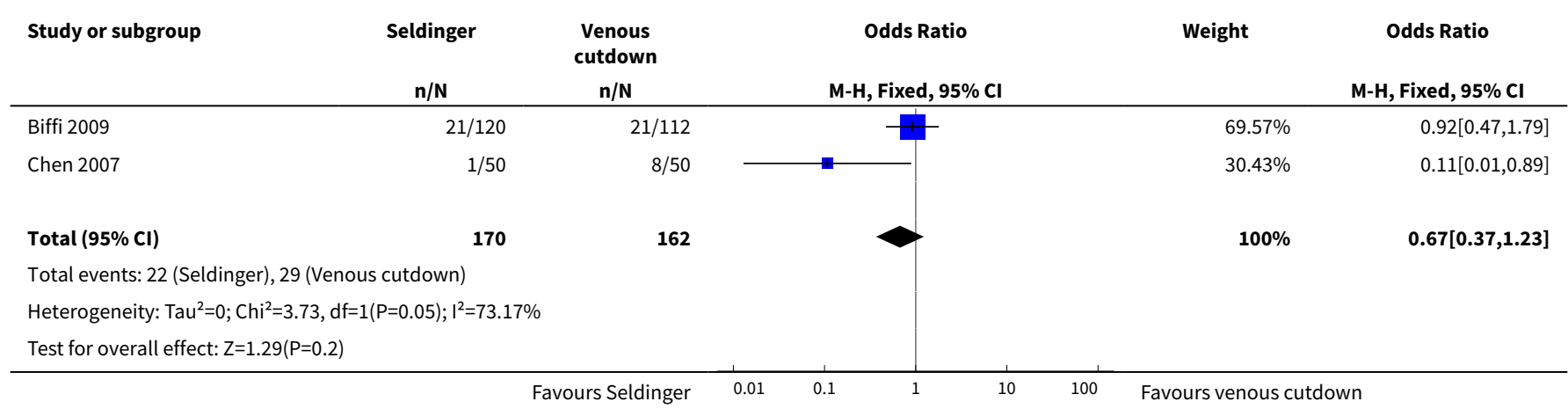

\section{Comparison 3. Pneumothorax}

\begin{tabular}{|c|c|c|c|c|}
\hline Outcome or subgroup title & No. of studies & $\begin{array}{l}\text { No. of partici- } \\
\text { pants }\end{array}$ & Statistical method & Effect size \\
\hline $\begin{array}{l}1 \text { Seldinger (subclavian \& IJ) versus venous } \\
\text { cutdown (cephalic vein) ITT }\end{array}$ & 7 & 1006 & $\begin{array}{l}\text { Odds Ratio }(\mathrm{M}-\mathrm{H} \text {, } \\
\text { Fixed, } 95 \% \mathrm{Cl})\end{array}$ & $1.97[0.53,7.34]$ \\
\hline $\begin{array}{l}2 \text { Seldinger (subclavian vein) versus venous } \\
\text { cutdown (cephalic vein) ITT }\end{array}$ & 5 & 672 & $\begin{array}{l}\text { Odds Ratio }(\mathrm{M}-\mathrm{H} \text {, } \\
\text { Fixed, } 95 \% \mathrm{Cl})\end{array}$ & $4.49[0.75,26.82]$ \\
\hline $\begin{array}{l}3 \text { Seldinger (IJ vein) versus venous cutdown } \\
\text { (cephalic vein) ITT }\end{array}$ & 2 & 367 & $\begin{array}{l}\text { Odds Ratio }(\mathrm{M}-\mathrm{H} \text {, } \\
\text { Fixed, } 95 \% \mathrm{Cl})\end{array}$ & $0.33[0.01,8.13]$ \\
\hline $\begin{array}{l}4 \text { Seldinger (subclavian \& IJ) versus venous } \\
\text { cutdown (cephalic vein). On-treatment analy- } \\
\text { sis }\end{array}$ & 7 & 938 & $\begin{array}{l}\text { Odds Ratio }(\mathrm{M}-\mathrm{H} \text {, } \\
\text { Fixed, } 95 \% \mathrm{Cl})\end{array}$ & $2.06[0.56,7.57]$ \\
\hline $\begin{array}{l}5 \text { Seldinger (subclavian vein) versus venous } \\
\text { cutdown (cephalic vein). On-treatment analy- } \\
\text { sis }\end{array}$ & 6 & 718 & $\begin{array}{l}\text { Odds Ratio (M-H, } \\
\text { Fixed, } 95 \% \mathrm{Cl})\end{array}$ & $4.96[0.83,29.56]$ \\
\hline $\begin{array}{l}6 \text { Seldinger (IJ vein) versus venous cutdown } \\
\text { (cephalic vein). On-treatment analysis }\end{array}$ & 2 & 332 & $\begin{array}{l}\text { Odds Ratio }(\mathrm{M}-\mathrm{H} \text {, } \\
\text { Fixed, } 95 \% \mathrm{Cl})\end{array}$ & $0.31[0.01,7.65]$ \\
\hline
\end{tabular}


Analysis 3.1. Comparison 3 Pneumothorax, Outcome 1 Seldinger (subclavian \& IJ) versus venous cutdown (cephalic vein) ITT.

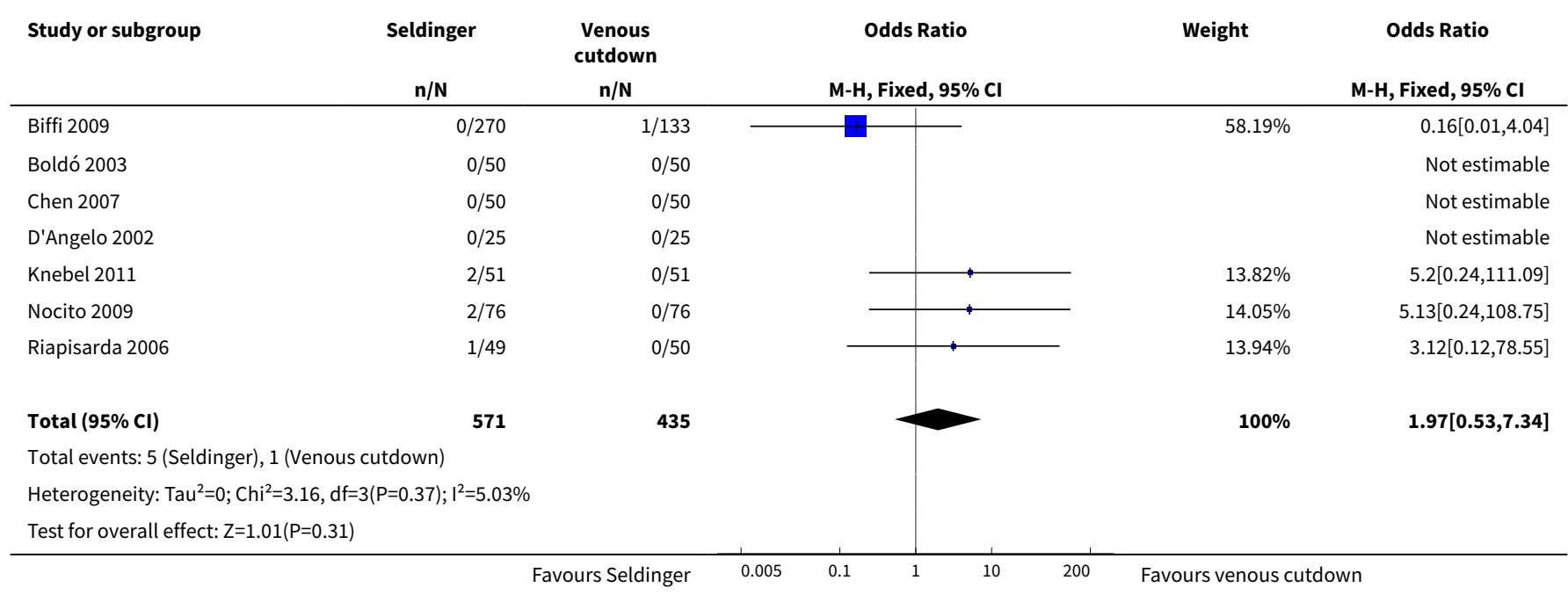

Analysis 3.2. Comparison 3 Pneumothorax, Outcome 2 Seldinger (subclavian vein) versus venous cutdown (cephalic vein) ITT.

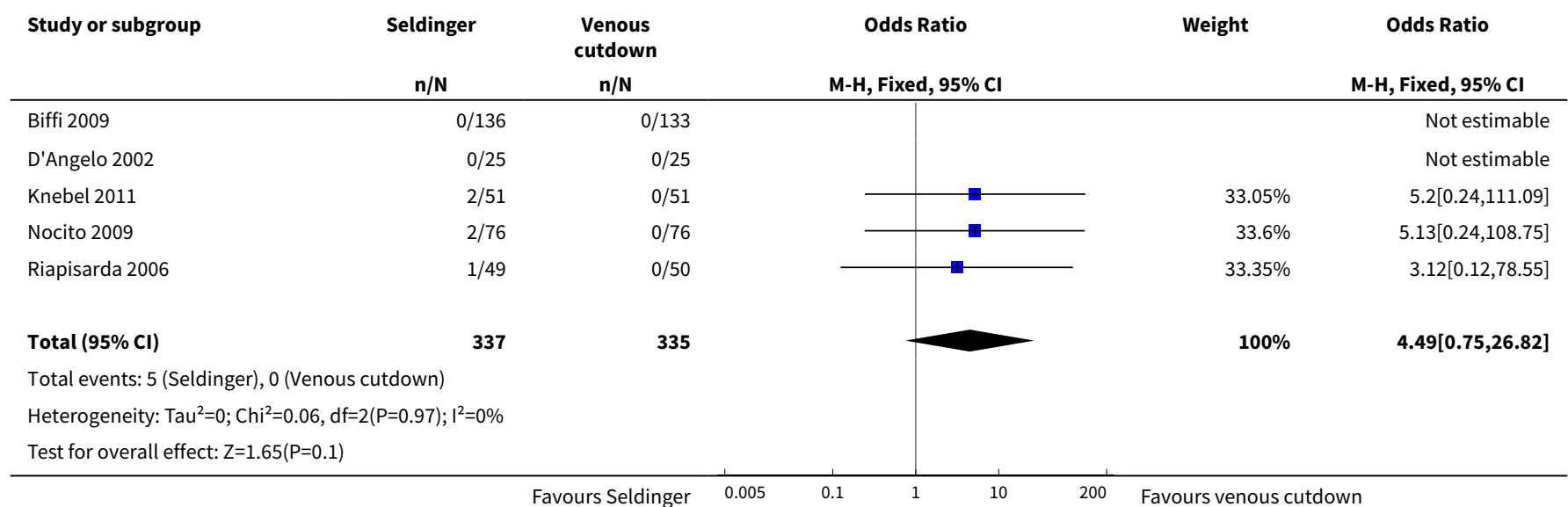

Analysis 3.3. Comparison 3 Pneumothorax, Outcome 3 Seldinger (IJ vein) versus venous cutdown (cephalic vein) ITT.

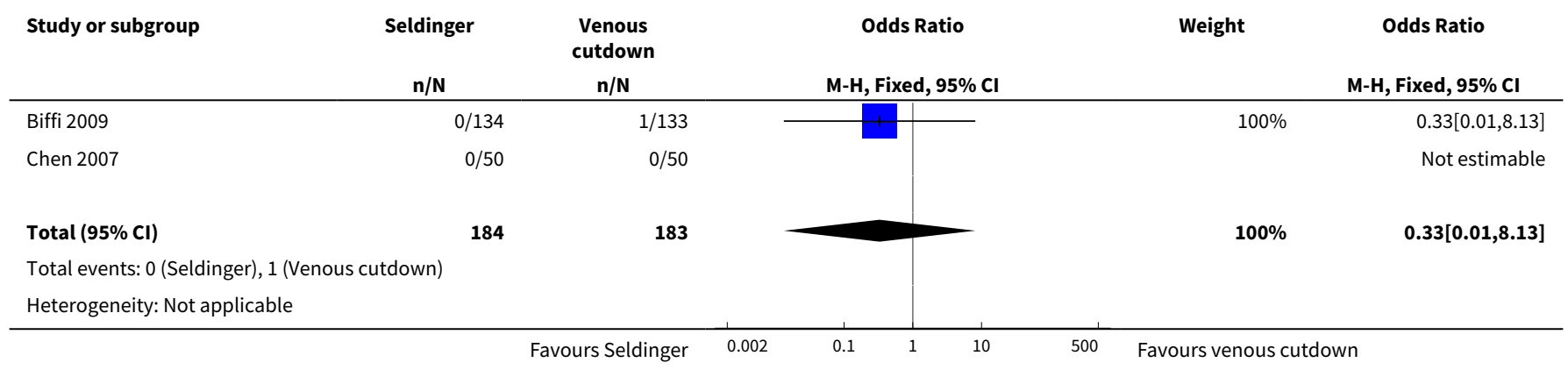




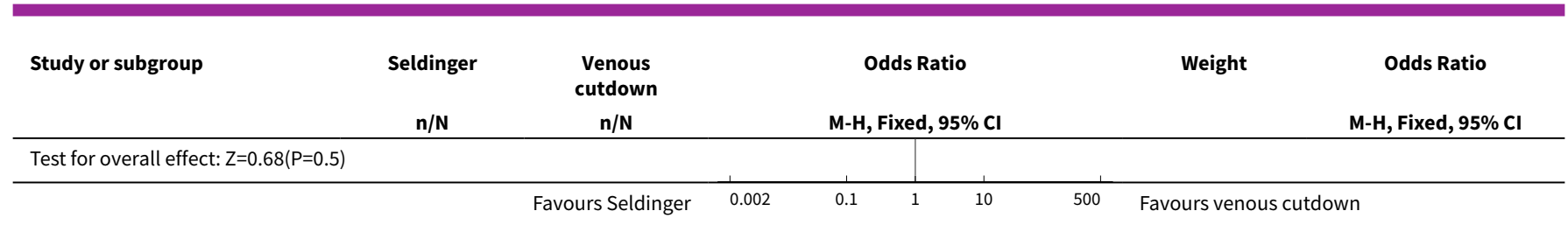

Analysis 3.4. Comparison 3 Pneumothorax, Outcome 4 Seldinger (subclavian \& IJ) versus venous cutdown (cephalic vein). On-treatment analysis.

\begin{tabular}{|c|c|c|c|c|c|}
\hline \multirow[t]{2}{*}{ Study or subgroup } & Seldinger & $\begin{array}{l}\text { Venous } \\
\text { cutdown }\end{array}$ & Odds Ratio & \multirow[t]{2}{*}{ Weight } & Odds Ratio \\
\hline & $n / N$ & $n / N$ & M-H, Fixed, 95\% Cl & & M-H, Fixed, $95 \% \mathrm{Cl}$ \\
\hline Biffi 2009 & $0 / 255$ & $1 / 112$ & -1 & $60.27 \%$ & $0.15[0.01,3.6]$ \\
\hline Boldó 2003 & $0 / 50$ & $0 / 50$ & & & Not estimable \\
\hline Chen 2007 & $0 / 50$ & $0 / 50$ & & & Not estimable \\
\hline D'Angelo 2002 & $0 / 25$ & $0 / 25$ & & & Not estimable \\
\hline Knebel 2011 & $2 / 49$ & $0 / 51$ & & $13.51 \%$ & $5.42[0.25,115.83]$ \\
\hline Nocito 2009 & $2 / 54$ & $0 / 68$ & & $12.28 \%$ & $6.52[0.31,138.8]$ \\
\hline Riapisarda 2006 & $1 / 49$ & $0 / 50$ & . & $13.93 \%$ & $3.12[0.12,78.55]$ \\
\hline Total $(95 \% \mathrm{Cl})$ & 532 & 406 & & $100 \%$ & $2.06[0.56,7.57]$ \\
\hline \multicolumn{6}{|c|}{ Total events: 5 (Seldinger), 1 (Venous cutdown) } \\
\hline \multicolumn{6}{|c|}{ Heterogeneity: $\mathrm{Tau}^{2}=0 ; \mathrm{Chi}^{2}=3.62, \mathrm{df}=3(\mathrm{P}=0.31) ; \mathrm{I}^{2}=17.03 \%$} \\
\hline Test for overall effec & & & & & \\
\hline
\end{tabular}

Analysis 3.5. Comparison 3 Pneumothorax, Outcome 5 Seldinger (subclavian vein) versus venous cutdown (cephalic vein). On-treatment analysis.

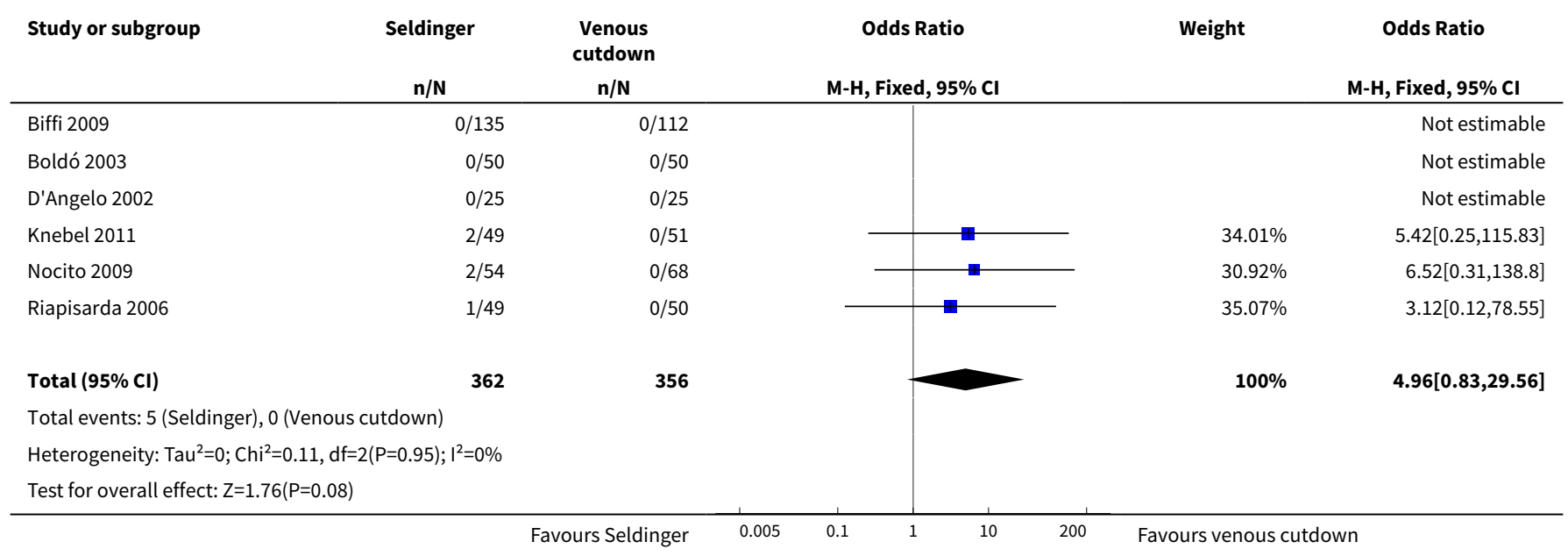


Analysis 3.6. Comparison 3 Pneumothorax, Outcome 6 Seldinger (IJ vein) versus venous cutdown (cephalic vein). On-treatment analysis.

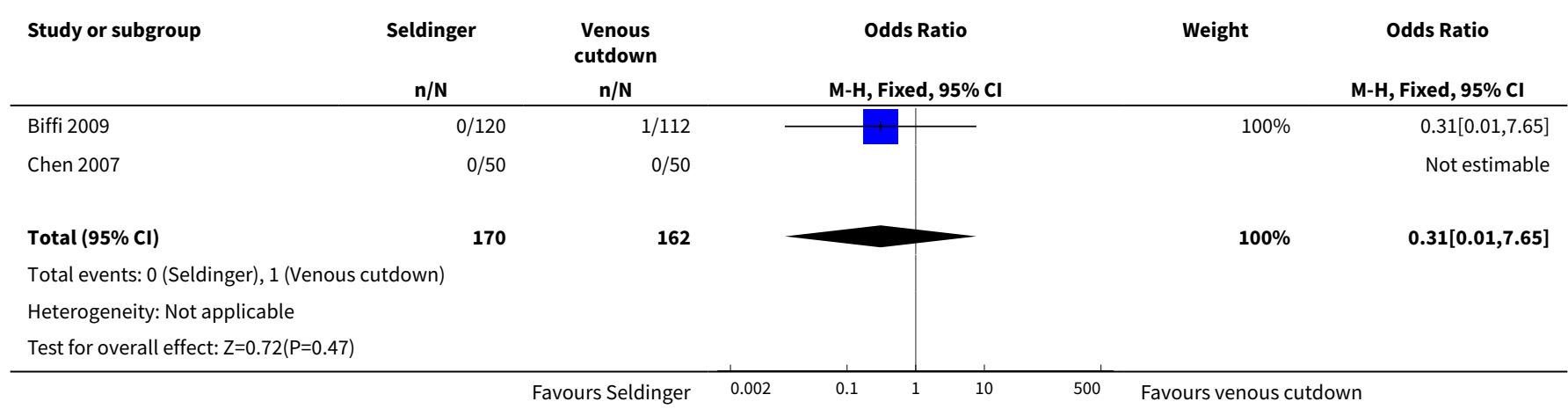

\section{Comparison 4. Infections}

\begin{tabular}{|c|c|c|c|c|}
\hline Outcome or subgroup title & No. of studies & $\begin{array}{l}\text { No. of partici- } \\
\text { pants }\end{array}$ & Statistical method & Effect size \\
\hline $\begin{array}{l}1 \text { Seldinger (subclavian \& IJ) versus venous } \\
\text { cutdown (cephalic vein) ITT }\end{array}$ & 6 & 906 & $\begin{array}{l}\text { Odds Ratio }(\mathrm{M}-\mathrm{H} \text {, } \\
\text { Fixed, } 95 \% \mathrm{Cl})\end{array}$ & $0.63[0.25,1.56]$ \\
\hline $\begin{array}{l}2 \text { Seldinger (subclavian vein) versus venous } \\
\text { cutdown (cephalic vein) ITT }\end{array}$ & 5 & 672 & $\begin{array}{l}\text { Odds Ratio }(\mathrm{M}-\mathrm{H} \text {, } \\
\text { Fixed, } 95 \% \mathrm{Cl})\end{array}$ & $0.85[0.28,2.58]$ \\
\hline $\begin{array}{l}3 \text { Seldinger (IJ vein) versus venous cutdown } \\
\text { (cephalic vein) ITT }\end{array}$ & 2 & 367 & $\begin{array}{l}\text { Odds Ratio }(\mathrm{M}-\mathrm{H} \text {, } \\
\text { Fixed, } 95 \% \mathrm{Cl})\end{array}$ & $0.27[0.06,1.34]$ \\
\hline $\begin{array}{l}4 \text { Seldinger (subclavian \& IJ) versus venous } \\
\text { cutdown (cephalic vein). On-treatment analy- } \\
\text { sis }\end{array}$ & 6 & 838 & $\begin{array}{l}\text { Odds Ratio }(\mathrm{M}-\mathrm{H} \text {, } \\
\text { Fixed, } 95 \% \mathrm{Cl})\end{array}$ & $0.61[0.24,1.51]$ \\
\hline $\begin{array}{l}5 \text { Seldinger (subclavian vein) versus venous } \\
\text { cutdown (cephalic vein). On-treatment analy- } \\
\text { sis }\end{array}$ & 5 & 618 & $\begin{array}{l}\text { Odds Ratio }(\mathrm{M}-\mathrm{H} \text {, } \\
\text { Fixed, } 95 \% \mathrm{Cl})\end{array}$ & $0.79[0.26,2.40]$ \\
\hline $\begin{array}{l}6 \text { Seldinger (IJ vein) versus venous cutdown } \\
\text { (cephalic vein). On-treatment analysis }\end{array}$ & 2 & 332 & $\begin{array}{l}\text { Odds Ratio }(\mathrm{M}-\mathrm{H} \text {, } \\
\text { Fixed, } 95 \% \mathrm{Cl})\end{array}$ & $0.27[0.05,1.30]$ \\
\hline
\end{tabular}

Analysis 4.1. Comparison 4 Infections, Outcome 1 Seldinger (subclavian \& IJ) versus venous cutdown (cephalic vein) ITT.

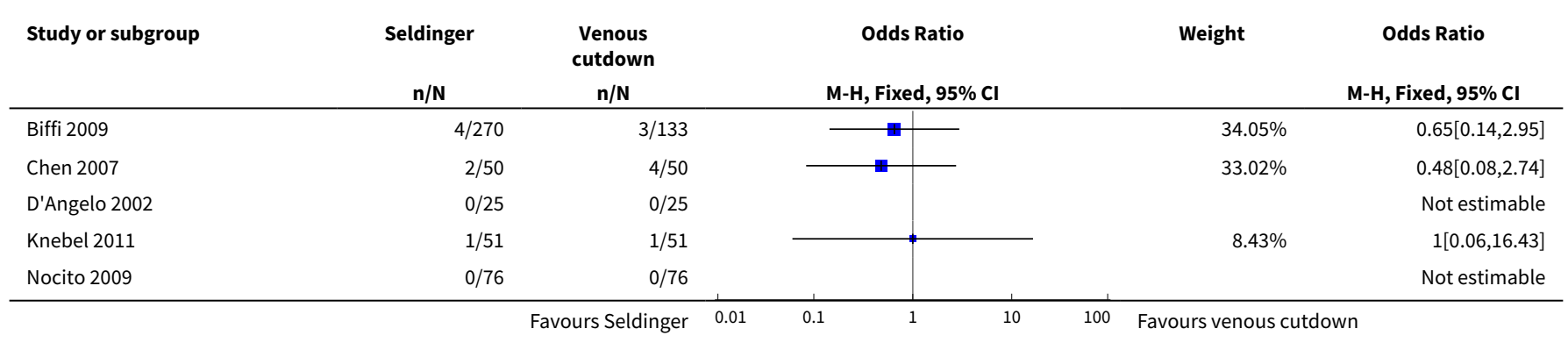




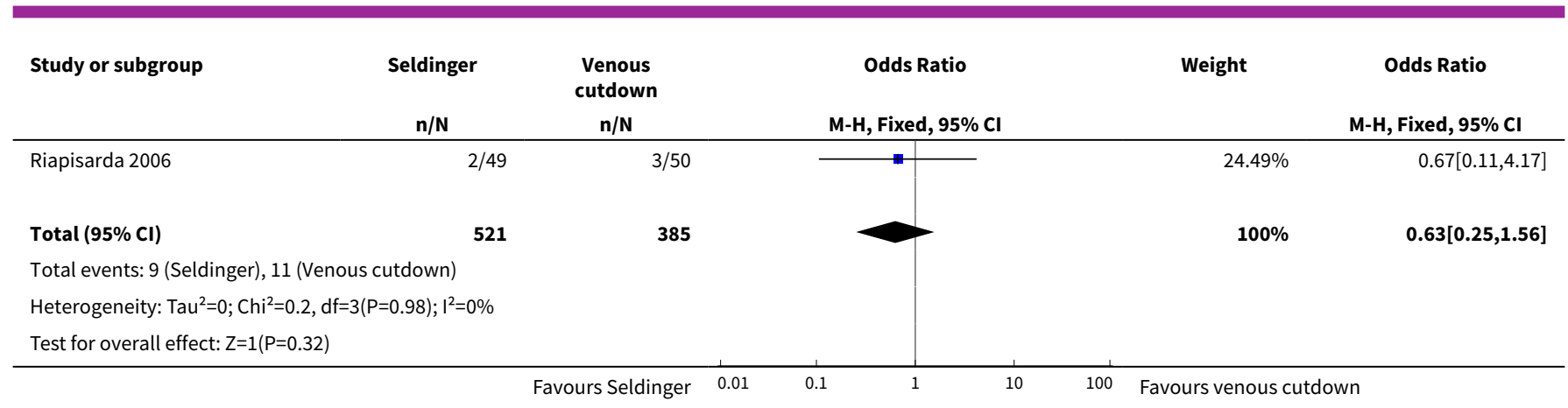

Analysis 4.2. Comparison 4 Infections, Outcome 2 Seldinger (subclavian vein) versus venous cutdown (cephalic vein) ITT.

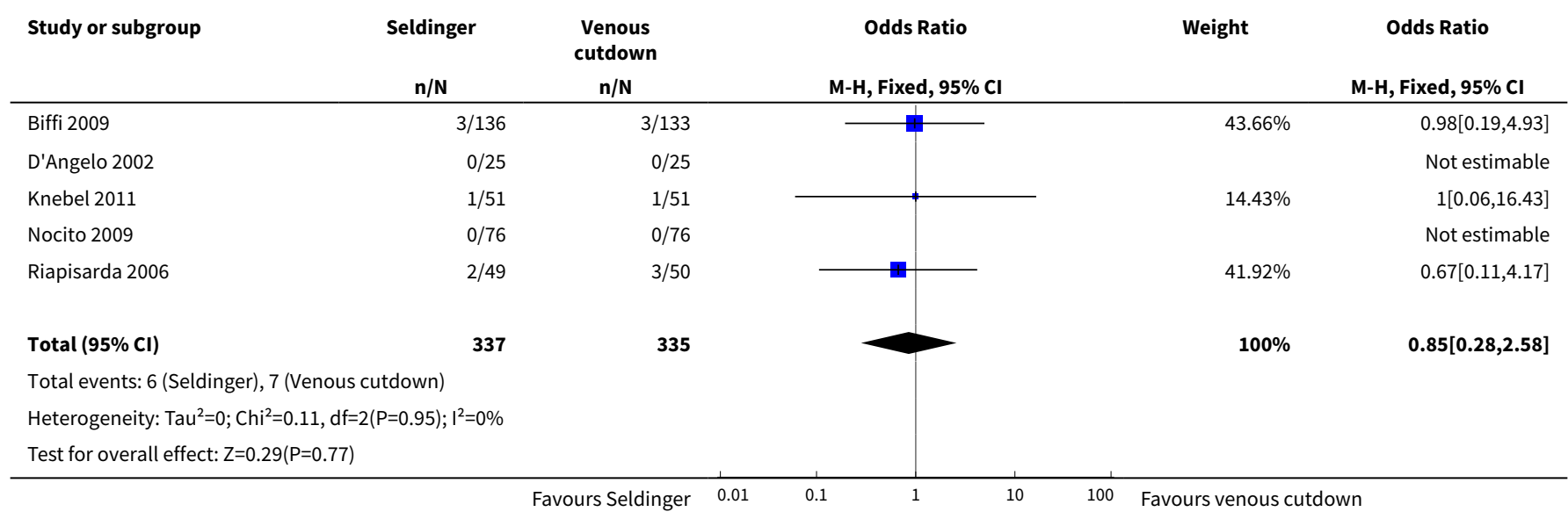

Analysis 4.3. Comparison 4 Infections, Outcome 3 Seldinger (IJ vein) versus venous cutdown (cephalic vein) ITT.

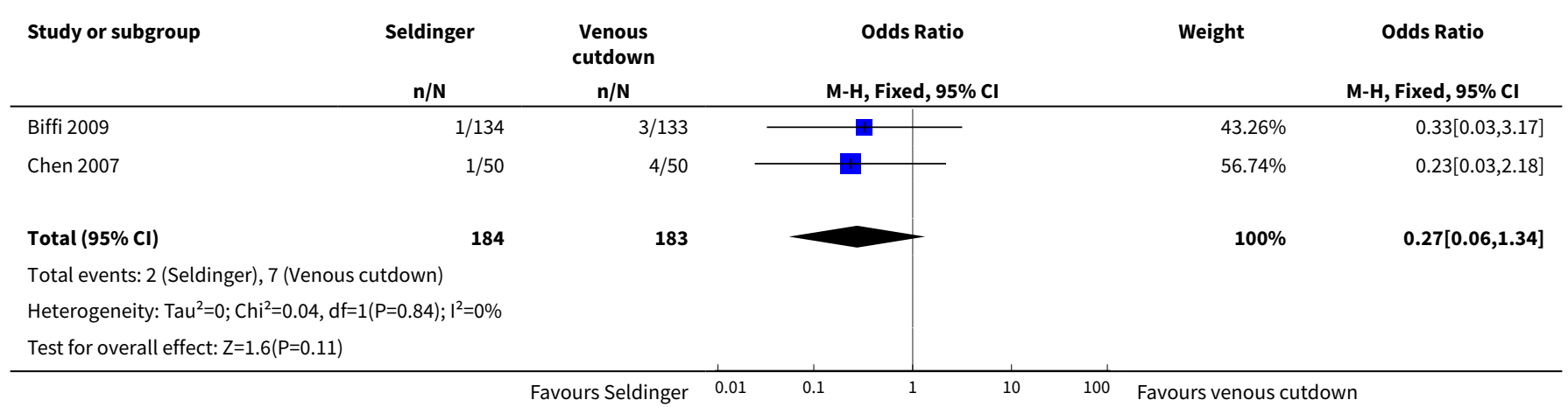


Analysis 4.4. Comparison 4 Infections, Outcome 4 Seldinger (subclavian

\& IJ) versus venous cutdown (cephalic vein). On-treatment analysis.

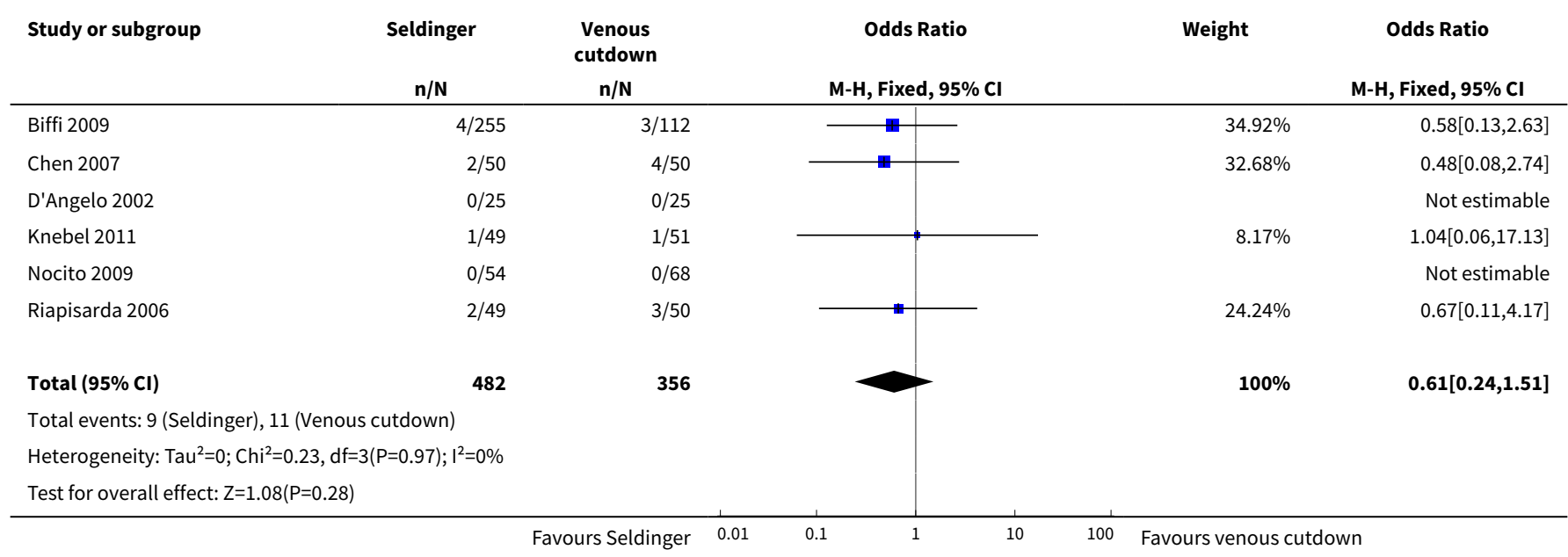

Analysis 4.5. Comparison 4 Infections, Outcome 5 Seldinger (subclavian vein) versus venous cutdown (cephalic vein). On-treatment analysis.

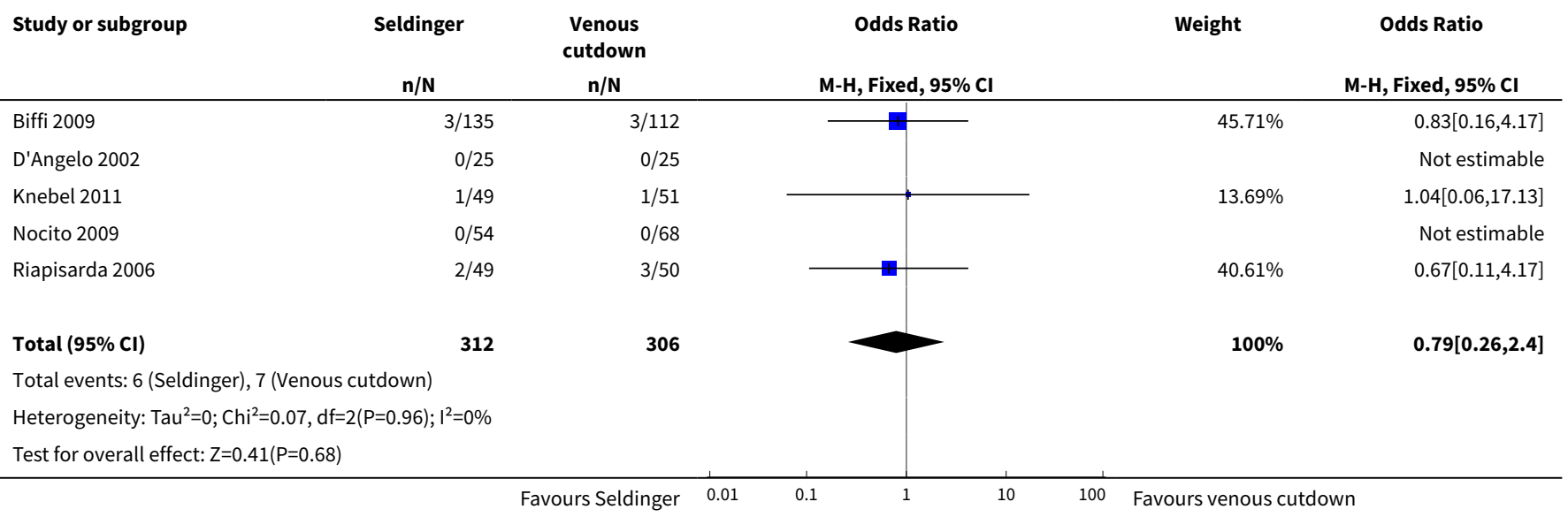

Analysis 4.6. Comparison 4 Infections, Outcome 6 Seldinger (IJ vein) versus venous cutdown (cephalic vein). On-treatment analysis.

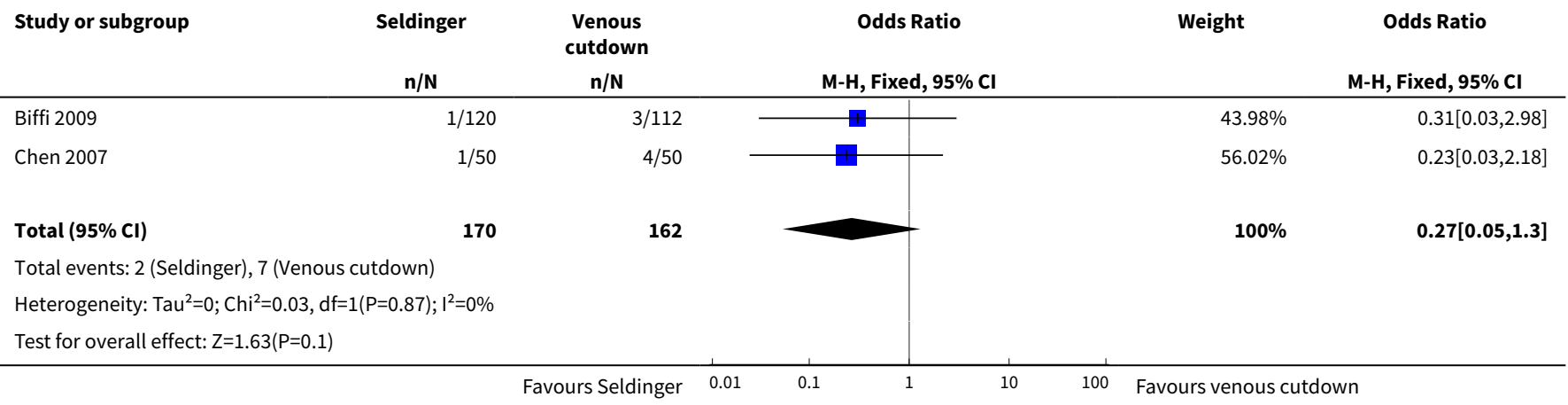


Comparison 5. Catheter/port-related complications

\begin{tabular}{|c|c|c|c|c|}
\hline Outcome or subgroup title & No. of studies & $\begin{array}{l}\text { No. of partici- } \\
\text { pants }\end{array}$ & Statistical method & Effect size \\
\hline $\begin{array}{l}1 \text { Seldinger (subclavian \& IJ) versus venous } \\
\text { cutdown (cephalic vein) ITT }\end{array}$ & 7 & 1006 & $\begin{array}{l}\text { Odds Ratio }(\mathrm{M}-\mathrm{H} \text {, } \\
\text { Fixed, } 95 \% \mathrm{Cl})\end{array}$ & $1.00[0.61,1.64]$ \\
\hline $\begin{array}{l}2 \text { Seldinger (subclavian vein) versus venous } \\
\text { cutdown (cephalic vein) ITT }\end{array}$ & 5 & 672 & $\begin{array}{l}\text { Odds Ratio }(\mathrm{M}-\mathrm{H} \text {, } \\
\text { Fixed, } 95 \% \mathrm{Cl})\end{array}$ & $6.77[2.31,19.79]$ \\
\hline $\begin{array}{l}3 \text { Seldinger (IJ vein) versus venous cutdown } \\
\text { (cephalic vein) ITT }\end{array}$ & 2 & 367 & $\begin{array}{l}\text { Odds Ratio }(\mathrm{M}-\mathrm{H} \text {, } \\
\text { Fixed, } 95 \% \mathrm{Cl})\end{array}$ & $0.81[0.43,1.52]$ \\
\hline $\begin{array}{l}4 \text { Seldinger (subclavian \& IJ) versus venous } \\
\text { cutdown (cephalic vein). On-treatment analy- } \\
\text { sis }\end{array}$ & 7 & 938 & $\begin{array}{l}\text { Odds Ratio }(\mathrm{M}-\mathrm{H} \text {, } \\
\text { Fixed, } 95 \% \mathrm{Cl})\end{array}$ & $0.93[0.57,1.53]$ \\
\hline $\begin{array}{l}5 \text { Seldinger (subclavian vein) versus venous } \\
\text { cutdown (cephalic vein). On-treatment analy- } \\
\text { sis }\end{array}$ & 5 & 618 & $\begin{array}{l}\text { Odds Ratio }(\mathrm{M}-\mathrm{H} \text {, } \\
\text { Fixed, } 95 \% \mathrm{Cl})\end{array}$ & $6.62[2.24,19.58]$ \\
\hline $\begin{array}{l}6 \text { Seldinger (IJ vein) versus venous cutdown } \\
\text { (cephalic vein). On-treatment analysis }\end{array}$ & 2 & 332 & $\begin{array}{l}\text { Odds Ratio }(\mathrm{M}-\mathrm{H} \text {, } \\
\text { Fixed, } 95 \% \mathrm{Cl})\end{array}$ & $0.75[0.40,1.43]$ \\
\hline
\end{tabular}

Analysis 5.1. Comparison 5 Catheter/port-related complications, Outcome 1 Seldinger (subclavian \& IJ) versus venous cutdown (cephalic vein) ITT.

\begin{tabular}{|c|c|c|c|c|c|}
\hline \multirow[t]{2}{*}{ Study or subgroup } & Seldinger & $\begin{array}{l}\text { Venous } \\
\text { cutdown }\end{array}$ & Odds Ratio & Weight & \multirow{2}{*}{$\begin{array}{c}\text { Odds Ratio } \\
\text { M-H, Fixed, } 95 \% \mathrm{Cl}\end{array}$} \\
\hline & $n / N$ & $n / N$ & M-H, Fixed, $95 \% \mathrm{Cl}$ & & \\
\hline Biffi 2009 & $33 / 270$ & $20 / 133$ & & $74.36 \%$ & $0.79[0.43,1.43]$ \\
\hline Boldó 2003 & $1 / 50$ & $0 / 50$ & & $1.53 \%$ & $3.06[0.12,76.95]$ \\
\hline Chen 2007 & $0 / 50$ & $4 / 50$ & - & $14.09 \%$ & $0.1[0.01,1.95]$ \\
\hline D'Angelo 2002 & $0 / 25$ & $0 / 25$ & & & Not estimable \\
\hline Nocito 2009 & $1 / 76$ & $0 / 76$ & & $1.55 \%$ & $3.04[0.12,75.8]$ \\
\hline Riapisarda 2006 & $5 / 49$ & $2 / 50$ & - & $5.62 \%$ & $2.73[0.5,14.78]$ \\
\hline Total $(95 \% \mathrm{Cl})$ & 571 & 435 & & $100 \%$ & $1[0.61,1.64]$ \\
\hline \multicolumn{6}{|c|}{ Total events: 45 (Seldinger), 27 (Venous cutdown) } \\
\hline \multicolumn{6}{|c|}{ Heterogeneity: $\mathrm{Tau}^{2}=0 ; \mathrm{Chi}^{2}=7.5, \mathrm{df}=5(\mathrm{P}=0.19) ; \mathrm{I}^{2}=33.29 \%$} \\
\hline
\end{tabular}


Analysis 5.2. Comparison 5 Catheter/port-related complications, Outcome

2 Seldinger (subclavian vein) versus venous cutdown (cephalic vein) ITT.

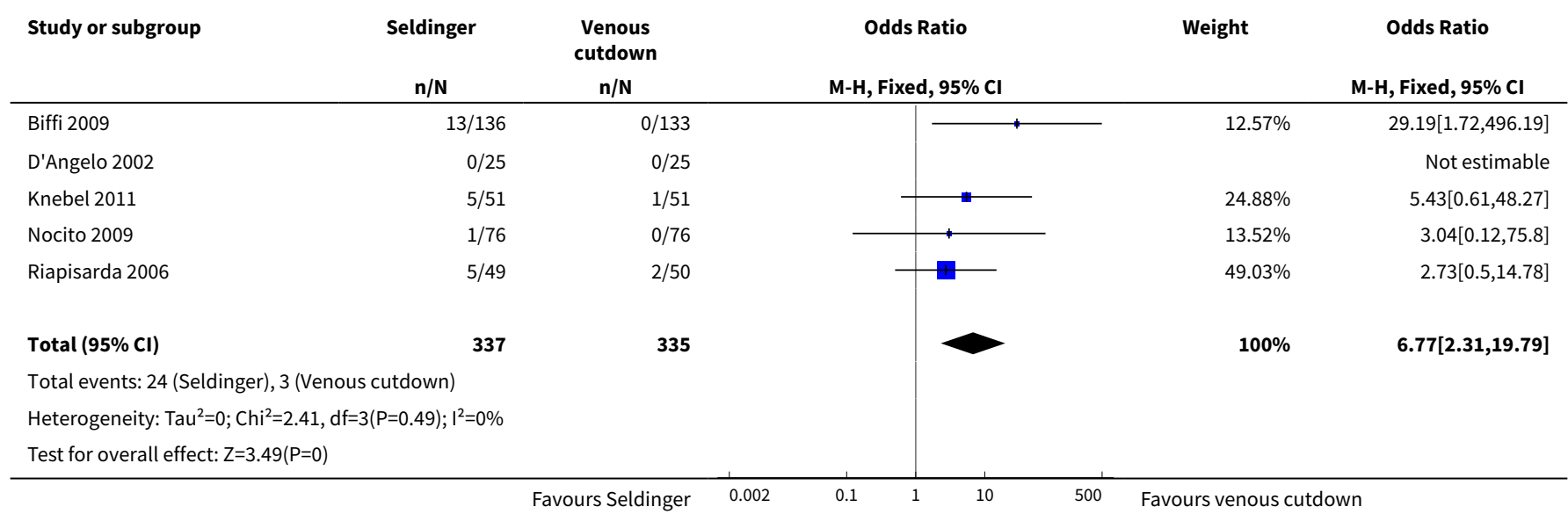

Analysis 5.3. Comparison 5 Catheter/port-related complications, Outcome 3 Seldinger (IJ vein) versus venous cutdown (cephalic vein) ITT.

\begin{tabular}{|c|c|c|c|c|c|}
\hline \multirow[t]{2}{*}{ Study or subgroup } & Seldinger & $\begin{array}{l}\text { Venous } \\
\text { cutdown }\end{array}$ & Odds Ratio & Weight & \multirow{2}{*}{$\begin{array}{c}\text { Odds Ratio } \\
\text { M-H, Fixed, } 95 \% \mathrm{Cl}\end{array}$} \\
\hline & $\mathrm{n} / \mathbf{N}$ & $\mathrm{n} / \mathrm{N}$ & M-H, Fixed, 95\% Cl & & \\
\hline Biffi 2009 & $20 / 134$ & $20 / 133$ & & $79.31 \%$ & $0.99[0.51,1.94]$ \\
\hline Chen 2007 & $0 / 50$ & $4 / 50$ & " & $20.69 \%$ & $0.1[0.01,1.95]$ \\
\hline Total $(95 \% \mathrm{Cl})$ & 184 & 183 & & $100 \%$ & $0.81[0.43,1.52]$ \\
\hline \multicolumn{6}{|c|}{ Heterogeneity: $\mathrm{Tau}^{2}=0 ; \mathrm{Chi}^{2}=2.24, \mathrm{df}=1(\mathrm{P}=0.13) ; \mathrm{I}^{2}=55.42 \%$} \\
\hline Test for overall effect & & & & & \\
\hline
\end{tabular}

Analysis 5.4. Comparison 5 Catheter/port-related complications, Outcome 4 Seldinger (subclavian \& IJ) versus venous cutdown (cephalic vein). On-treatment analysis.

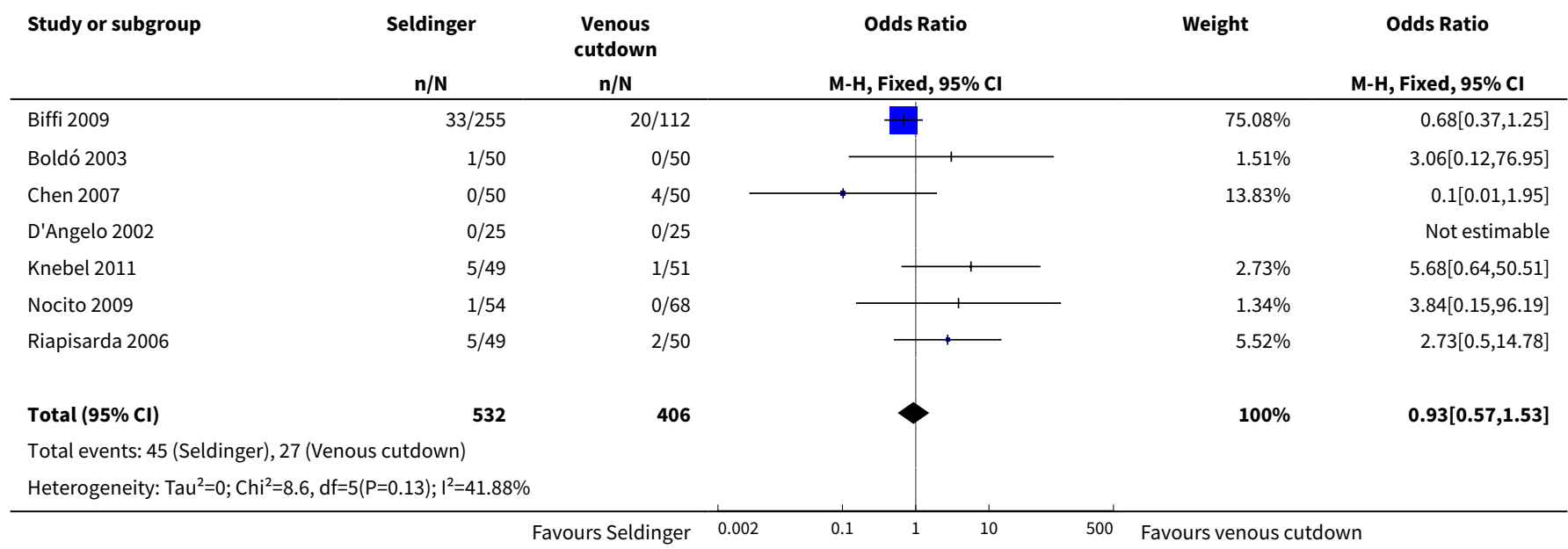




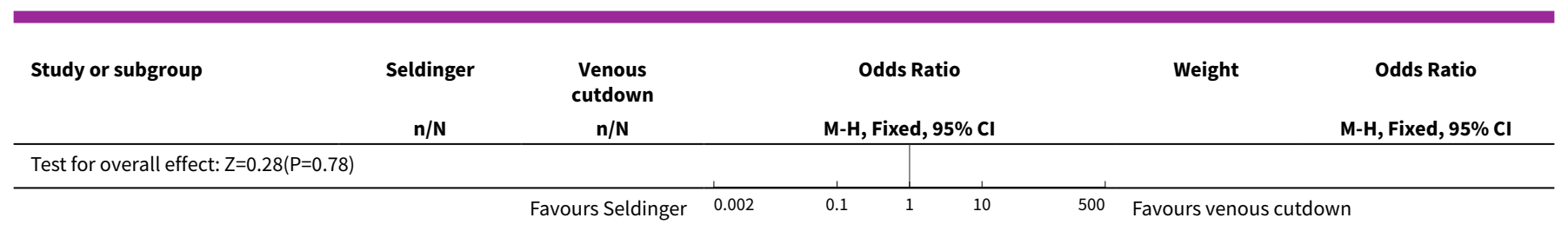

Analysis 5.5. Comparison 5 Catheter/port-related complications, Outcome 5 Seldinger (subclavian vein) versus venous cutdown (cephalic vein). On-treatment analysis.

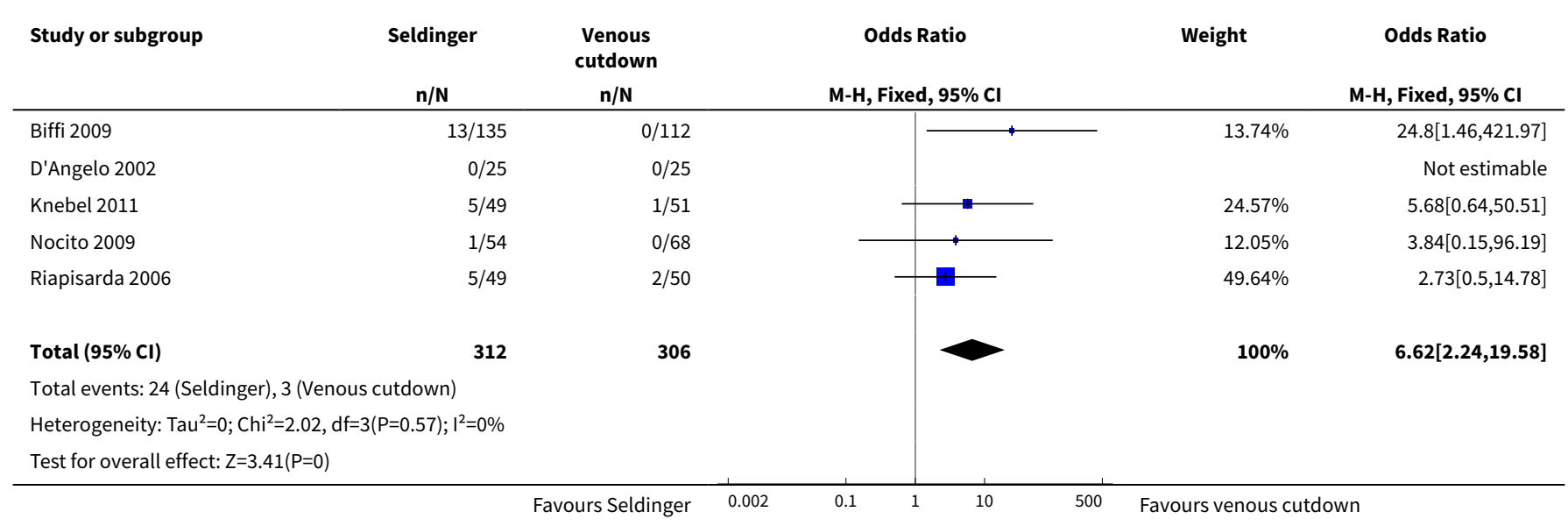

Analysis 5.6. Comparison 5 Catheter/port-related complications, Outcome 6 Seldinger (IJ vein) versus venous cutdown (cephalic vein). On-treatment analysis.

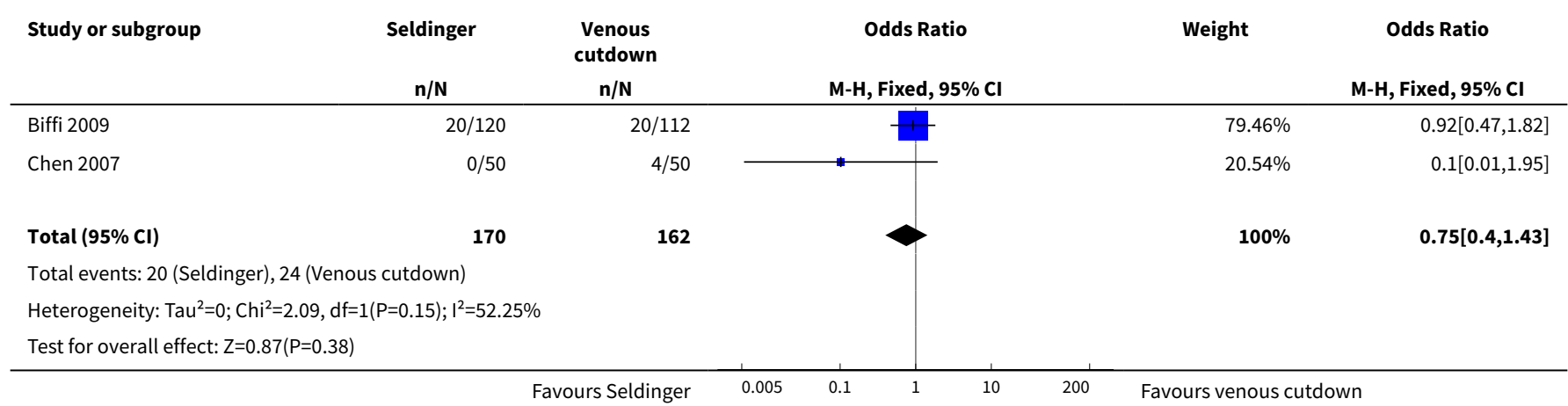

\section{Comparison 6. Other complications}

\begin{tabular}{lllll}
\hline Outcome or subgroup title & No. of studies & $\begin{array}{l}\text { No. of partici- } \\
\text { pants }\end{array}$ & Statistical method & Effect size \\
\hline $\begin{array}{l}1 \text { Seldinger (subclavian \& IJ) versus venous } \\
\text { cutdown (cephalic vein) ITT }\end{array}$ & 7 & 1006 & $\begin{array}{l}\text { Odds Ratio (M-H, } \\
\text { Fixed, 95\% Cl) }\end{array}$ & $0.59[0.18,1.96]$ \\
\hline $\begin{array}{l}\text { 2 Seldinger (subclavian vein) versus venous } \\
\text { cutdown (cephalic vein) ITT }\end{array}$ & 5 & 672 & $\begin{array}{l}\text { Odds Ratio (M-H, } \\
\text { Fixed, 95\% Cl) }\end{array}$ & $0.59[0.18,1.96]$ \\
\hline
\end{tabular}




\begin{tabular}{lllll}
\hline Outcome or subgroup title & No. of studies & $\begin{array}{l}\text { No. of partici- } \\
\text { pants }\end{array}$ & Statistical method & Effect size \\
\hline $\begin{array}{l}\text { 3 Seldinger (IJ vein) versus venous cutdown } \\
\text { (cephalic vein) ITT }\end{array}$ & 2 & 367 & $\begin{array}{l}\text { Odds Ratio (M-H, } \\
\text { Fixed, 95\% Cl) }\end{array}$ & $0.0[0.0,0.0]$ \\
\hline $\begin{array}{l}4 \text { Seldinger (subclavian \& IJ) versus venous } \\
\text { cutdown (cephalic vein). On-treatment analy- } \\
\text { sis }\end{array}$ & 7 & 938 & $\begin{array}{l}\text { Odds Ratio (M-H, } \\
\text { Fixed, 95\% Cl) }\end{array}$ & $0.64[0.19,2.14]$ \\
\hline $\begin{array}{l}5 \text { Seldinger (subclavian vein) versus venous } \\
\text { cutdown (cephalic vein). On-treatment analy- } \\
\text { sis }\end{array}$ & 5 & 618 & Odds Ratio (M-H, & $0.64[0.19,2.14]$ \\
\hline $\begin{array}{l}6 \text { Seldinger (IJ vein) versus venous cutdown } \\
\text { (cephalic vein). On-treatment analysis }\end{array}$ & 2 & Fixed, 95\% Cl) & \\
\hline
\end{tabular}

Analysis 6.1. Comparison 6 Other complications, Outcome 1 Seldinger (subclavian \& IJ) versus venous cutdown (cephalic vein) ITT.

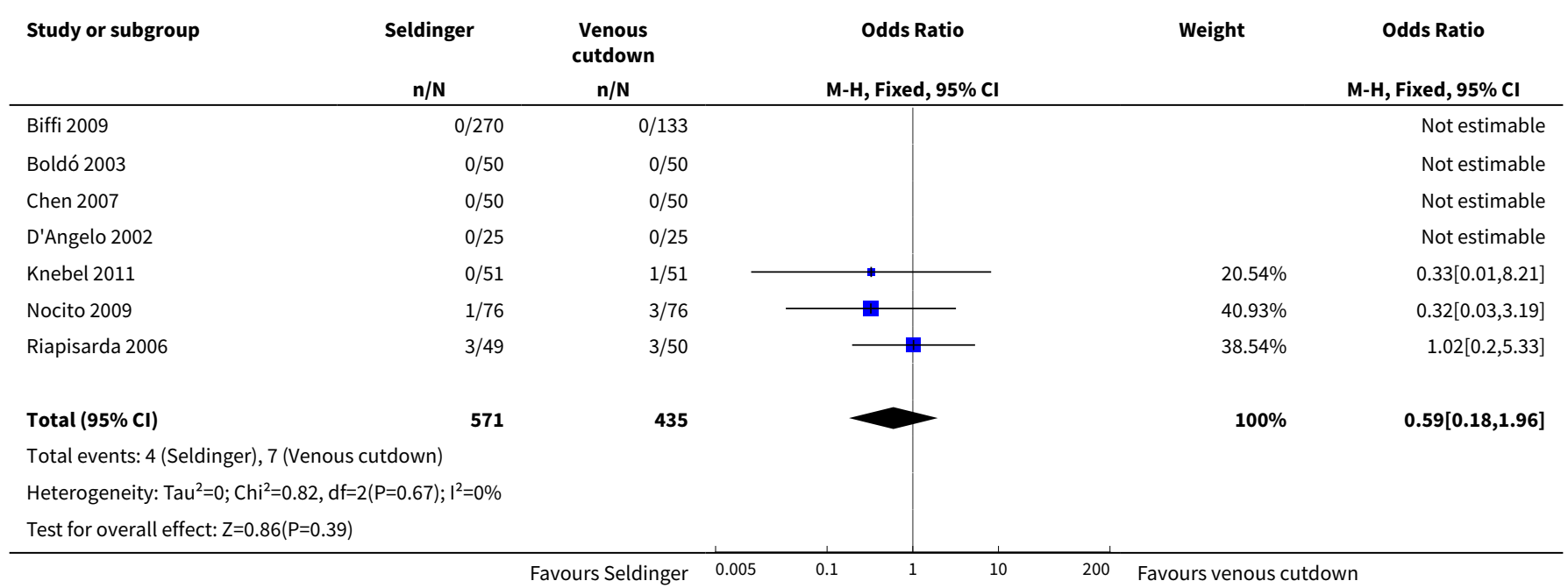

Analysis 6.2. Comparison 6 Other complications, Outcome 2 Seldinger (subclavian vein) versus venous cutdown (cephalic vein) ITT.

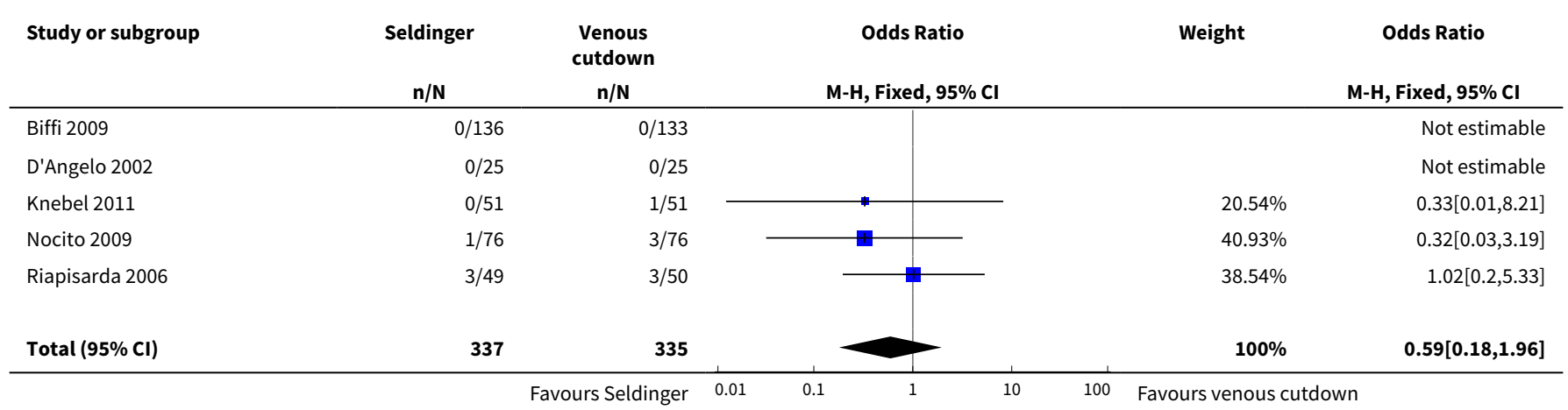




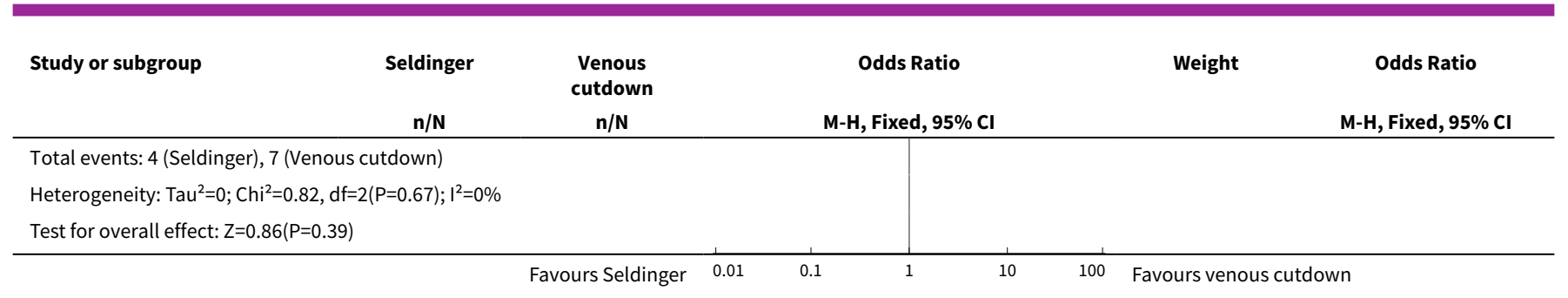

Analysis 6.3. Comparison 6 Other complications, Outcome 3 Seldinger (IJ vein) versus venous cutdown (cephalic vein) ITT.

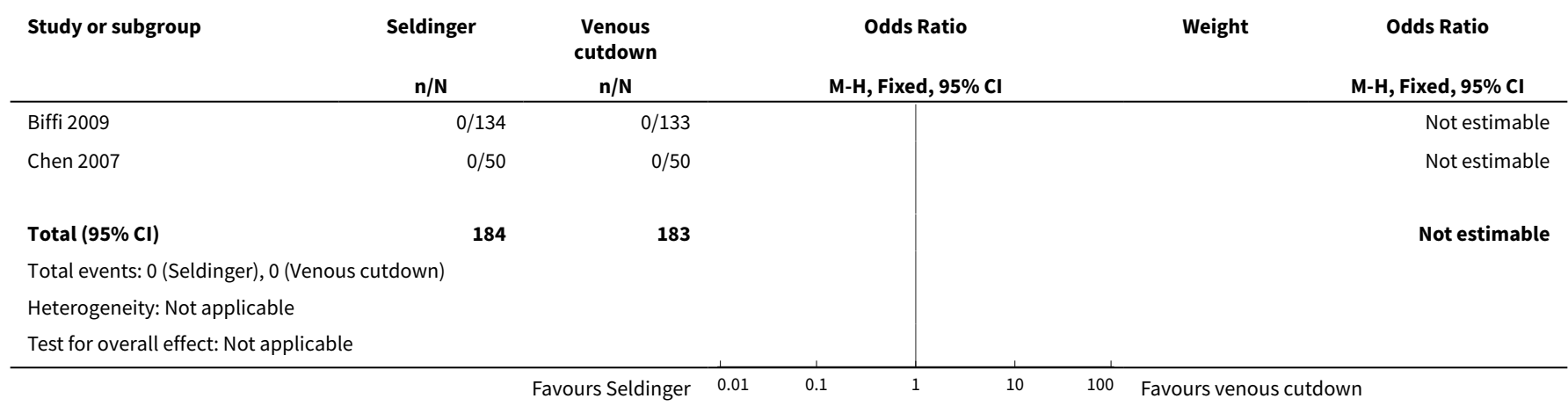

Analysis 6.4. Comparison 6 Other complications, Outcome 4 Seldinger (subclavian \& IJ) versus venous cutdown (cephalic vein). On-treatment analysis.

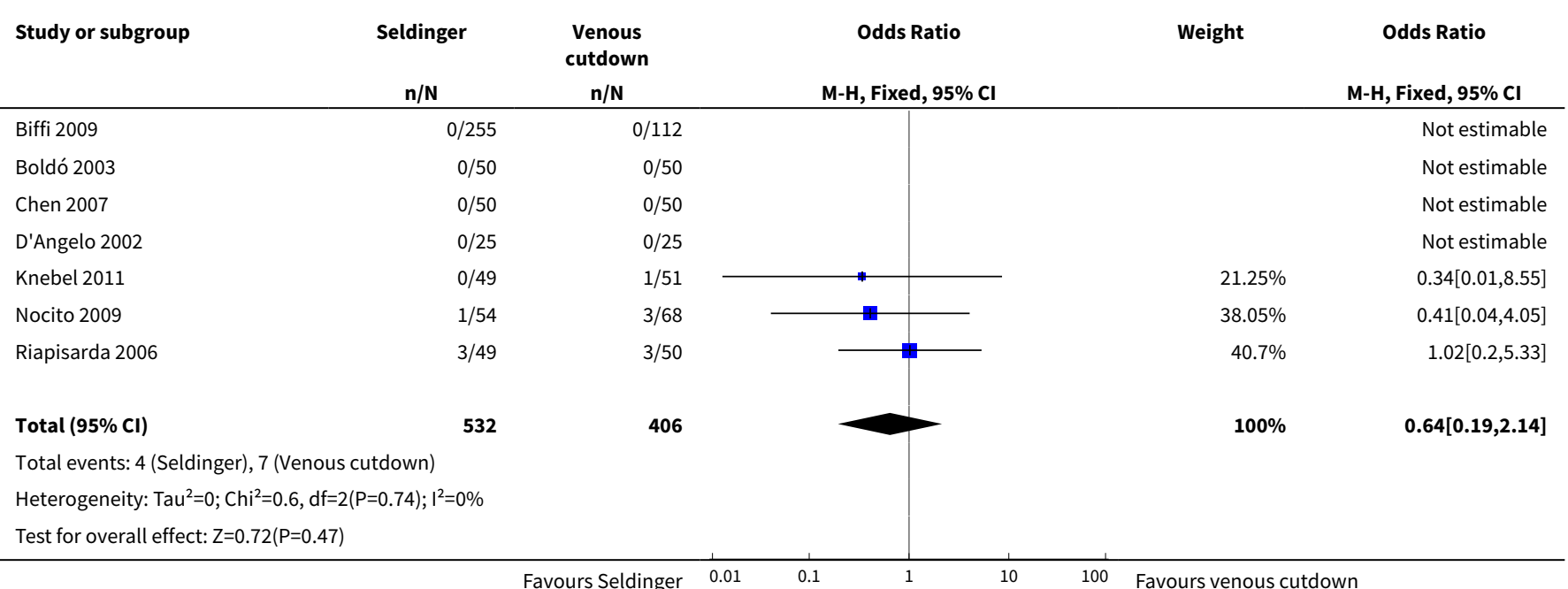


Analysis 6.5. Comparison 6 Other complications, Outcome 5 Seldinger

(subclavian vein) versus venous cutdown (cephalic vein). On-treatment analysis.

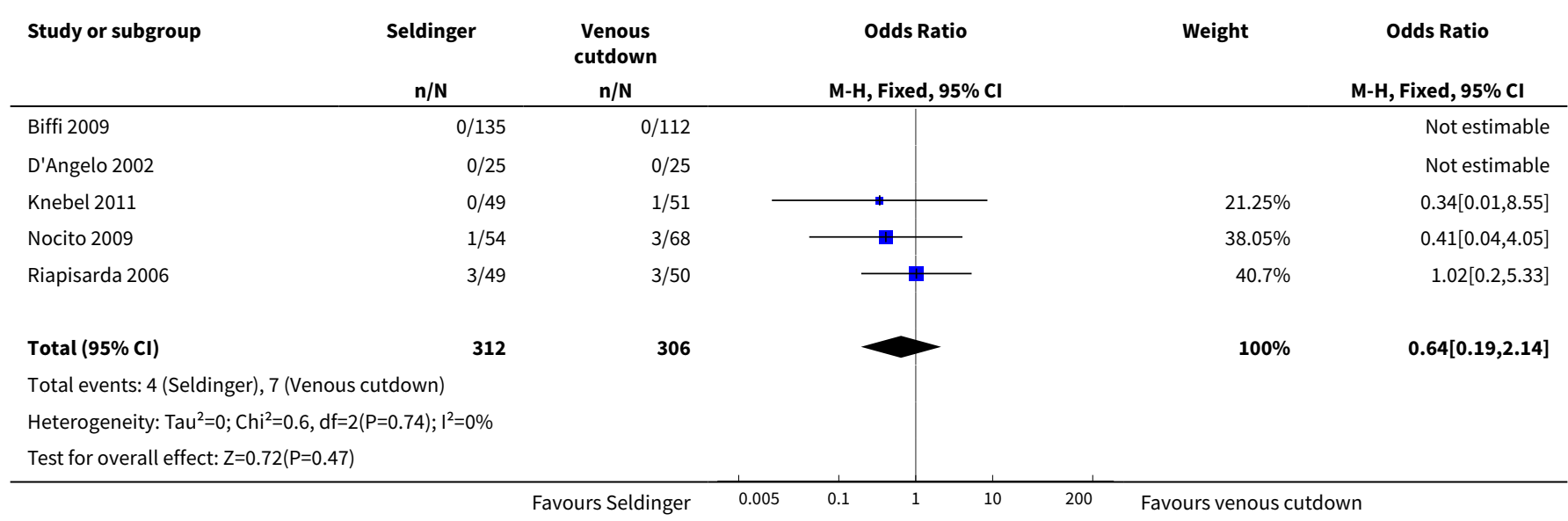

Analysis 6.6. Comparison 6 Other complications, Outcome 6 Seldinger (IJ vein) versus venous cutdown (cephalic vein). On-treatment analysis.

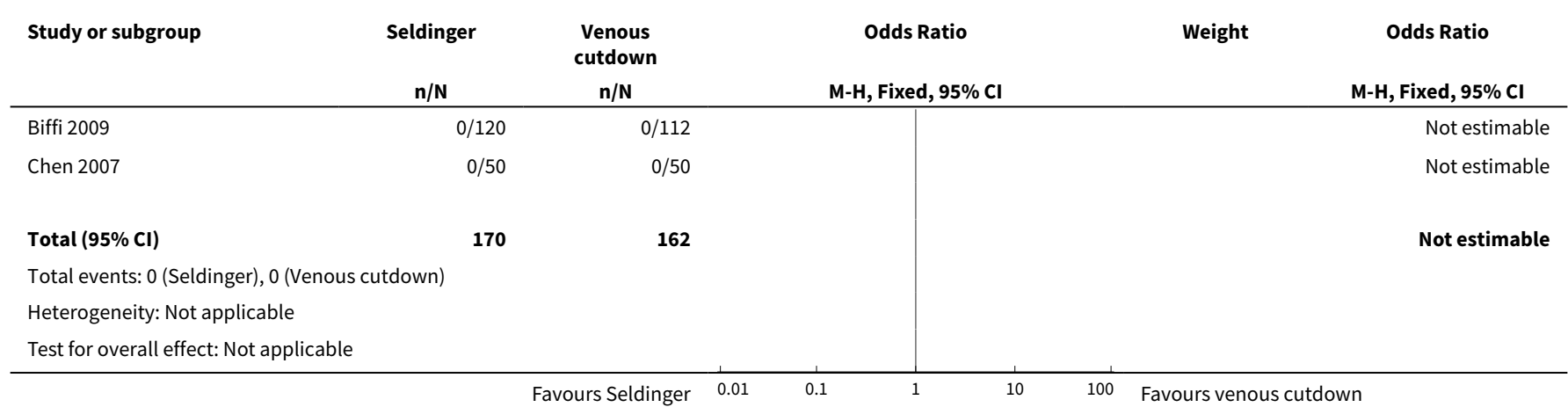

\section{APPENDICES}

\section{Appendix 1. CRS search strategy}

Search run on Tue Aug 252015

\begin{tabular}{llc}
\hline$\# 1$ & MESH DESCRIPTOR Catheterization, Central Venous EXPLODE ALL TREES & 599 \\
\hline$\# 2$ & MESH DESCRIPTOR Catheters, Indwelling EXPLODE ALL TREES & 821 \\
\hline$\# 3$ & MESH DESCRIPTOR Veins EXPLODE ALL TREES WITH QUALIFIERS SU & 659 \\
\hline$\# 4$ & catheter $:$ TI,AB,KY & 14043 \\
\hline
\end{tabular}


(Continued)

\begin{tabular}{|c|c|c|}
\hline \#5 & TIVAD* $^{\star}$ TI,AB,KY & 4 \\
\hline \#6 & TIVAP $^{\star}: T I, A B, K Y$ & 4 \\
\hline$\# 7$ & (Implantable near3 Venous ):TI,AB,KY & 30 \\
\hline \#8 & (venous near3 access ):TI,AB,KY & 300 \\
\hline \#9 & (venous near3 insert ${ }^{\star}$ ):TI,AB,KY & 105 \\
\hline \#10 & port:TI,AB,KY & 898 \\
\hline \#11 & (vascular access):TI,AB,KY & 604 \\
\hline \#12 & \#1 OR \#2 OR \#3 OR \#4 OR \#5 OR \#6 OR \#7 OR \#8 OR \#9 OR \#10 OR \#11 & 16157 \\
\hline \#13 & MESH DESCRIPTOR Veins EXPLODE ALL TREES WITH QUALIFIERS SU & 659 \\
\hline \#14 & MESH DESCRIPTOR Venous Cutdown EXPLODE ALL TREES & 10 \\
\hline \#15 & MESH DESCRIPTOR Cardiovascular Surgical Procedures & 88 \\
\hline \#16 & seldinger:TI,AB,KY & 75 \\
\hline \#17 & cutdown:TI,AB,KY & 28 \\
\hline \#18 & cut-down:TI,AB,KY & 75 \\
\hline \#19 & percutaneous:TI,AB,KY & 8194 \\
\hline \#20 & (closed cannulation):TI,AB,KY & 1 \\
\hline \#21 & \#13 OR \#14 OR \#15 OR \#16 OR \#17 OR \#18 OR \#19 OR \#20 & 9009 \\
\hline \#22 & \#12 AND \#21 & 1906 \\
\hline
\end{tabular}

\section{CONTRIBUTIONS OFAUTHORS}

The review was performed by Charlie Chia-Tsong Hsu (CC-TH), Gigi Nga Chi Kwan (GNCK), Hannah Evans-Barns (HEB), John A Rophael (JAR) and Mieke L van Driel (MLvD). CC-TH and MLvD conducted the 'Risk of bias' assessment and the data extraction. CC-TH drafted the review, and all review authors contributed to the final version of this review.

\section{DECLARATIONS OF INTEREST}

CC-TH: none known

GNCK: none known

HEB: none known

JAR: none known

MLVD: none known

\section{SOURCES OF SUPPORT}

\section{Internal sources}

- No sources of support supplied 


\section{External sources}

- Chief Scientist Office, Scottish Government Health Directorates, The Scottish Government, UK.

The Cochrane Vascular editorial base is supported by the Chief Scientist Office.

\section{DIFFERENCES BETWEEN PROTOCOLANDREVIEW}

We removed secondary success rate, previously defined as the correct placement of a functional TIVAP after conversion to an alternative technique, as an outcome measure by review author consensus. After failure of the initial designated procedure, the majority of identified trials failed to mention participant conversion to an alternate procedure or the success rate of such conversion. In addition, we re-organised the secondary outcomes to reflect the overall and specific types of peri- and postoperative complications. Due to a lack of available information, we were unable to perform all planned subgroup analyses. Instead of subgroup analyses we performed separate analyses for the potential percutaneous puncture sites.

\section{INDEX TERMS}

\section{Medical Subject Headings (MeSH)}

*Jugular Veins [diagnostic imaging]; *Subclavian Vein [diagnostic imaging]; *Vascular Access Devices [adverse effects]; Arm [*blood supply]; Catheter-Related Infections; Catheterization, Central Venous [adverse effects] [ ${ }^{\star}$ methods]; Intention to Treat Analysis; Pneumothorax [etiology]; Randomized Controlled Trials as Topic; Ultrasonography, Interventional [methods]; Veins [diagnostic imaging]; Venous Cutdown [adverse effects] [*methods]

\section{MeSH check words}

Humans 